\title{
Improved reproductive health and STD services for women presenting to family planning services in North Jakarta. Final report of activities
}

Meiwita B. Iskandar

Catherine Vickers

Subadra Indrawati

Siti Nurul Qomariyah

Follow this and additional works at: https://knowledgecommons.popcouncil.org/departments_sbsr-rh

Part of the Health Services Research Commons, International Public Health Commons, and the Women's Health Commons

How does access to this work benefit you? Let us know!

\section{Recommended Citation}

Iskandar, Meiwita B., Catherine Vickers, Subadra Indrawati, and Siti Nurul Qomariyah. 1997. "Improved reproductive health and STD services for women presenting to family planning services in North Jakarta. Final report of activities," Asia and Near East OR/TA Project Final Report. Jakarta: Population Council. 


\section{Final Report of Activities for "Improved Reproductive Health and STD Services for Women Presenting to Family Planning Services in North Jakarta"}

FCO Number: 51434

Date of Submission

Reporting Period

Submitted to

Project Monitor

Technical Advisor

Submitted by

Project Manager
June 30, 1997

October 1996 - June 1997

Jane Wilson, BA Hons, Dip. Ed, MAPS Chief of Party, HAPP/AIDSCAP

John S. Moran, MD, MPH STD Advisor, HAPP/AIDSCAP

Dr. Meiwita B. Iskandar, Ph.D

Resident Advisor, Population Council Jakarta

Catherine Vickers, RN BSN CNP

Consultant, Population Council Jakarta

Subadra Indrawati, MPH

OR Fellow, Population Council Jakarta

Dr. Siti Nurul Qomariyah

Project Officer

The Population Council - Jakarta and the Indonesian Ministry of Health HIV/AIDS Prevention Project under USAID Funding Coordinated by Family Health International/AIDSCAP in collaboration with the U.S. Centers for Disease Control 


\section{Contents}

List of Table

Page

List of Abbreviation iv

Acknowledgement

Abstract vi vi

Executive Summary vii

I. Introduction and Literature Review 1

I.A. Introduction 1

I.B. Literature Review 1

I.B.1 RTI/STD in Low Risk Populations and Women 1

I.B.2 RTI/STD/HIV/AIDS in Indonesia 2

I.B.3 Family Planning and STDs 4

I.B.4 Costs of FP and STD Integration 5

I.B.5 Feasibility, Sustainability and Risks 5

$\begin{array}{ll}\text { I.C. Project Summary } & 6\end{array}$

II. Description of Subproject $\quad 7$

$\begin{array}{lll}\text { II.A. } & \text { Background } & 7\end{array}$

$\begin{array}{ll}\text { II.B. Scope of Work } & 10\end{array}$

$\begin{array}{lll}\text { II.B.1 Objectives } & 10\end{array}$

II.B.2 Study Design 11

II.B.3 Eligibility Criteria of Study Participants 11

$\begin{array}{lll}\text { II.B.4 Diagnostic Model } & 12\end{array}$

II.B.5 Physical Examination and Specimen Collection 12

II.B.6 Sample Size 14

II.B.7 Data Collection Methods and Patient Management Policy 14

II.B.8 Data Procesing and Analysis 15

II.B.9 Major Activities 16

$\begin{array}{lll}\text { II.B.10 Key Collaborators } & 16\end{array}$

III. Subproject Implementation 17

$\begin{array}{ll}\text { III.A. Management } & 17\end{array}$

$\begin{array}{ll}\text { III.B. Accomplishments } & 18\end{array}$

III.B.1 Pre-Intervention Needs Assessment: Health Facilities Observations $\quad 18$

III.B.2 Pre-Intervention Needs Assessment: HCPs KAP 19

III.B.3 Standardized Clinical Evaluation 24

III.B.4 Clinical Practice Protocols 25

III.B.5 Training Programs 25

III.B.6 Advisory Board 28

III.B.7 RTI/STD Treatment Formulary 29

III.B.8 Treatment Cost Implications 31

III.B.9 IEC Development 31 
$\begin{array}{ll}\text { III.C. Constraints } & 31\end{array}$

III.D. Findings and Results 35

III.D.1 Prevalence of RTIs and Associated Factors 37

III.D.2 Parameters Related to Confirmed RTIs 41

III.D.3 Validation of Diagnostic Approaches for RTIs 42

III.D.4 Observations of HCP/Client Interactions 49

III.D.5. $\quad$ Existing RTI/STD Reporting and Recording Practices 56

IV. Conclusion and Recommendations 58

$\begin{array}{ll}\text { References } & 64\end{array}$

Appendices
A. Clinic Evaluation
B. Logframe of Activities
C. Directorate Binkesga
D. Protocols
E. Workshops Reports
F. RTI/STD Clinical Evaluation Guide
G. HCP/Client Interaction
H. STD Rx Guideline Comparisons
I . RTI/STD Treatment Cost Implication
$\mathrm{J}$. IEC Cartoons
K. Informed Consent
L. RTI/STD Case Management Manual
M. Maps of the Subproject Site
N. Questionnaires

\section{List of Tables}

Table 1: Contraceptive Choices in Two Subdistricts

Table 2: $\quad$ Rates of Reported STDs by Cases and Total Percentage of Clinic Visits Diagnosed in Out-Patient Health Care Facilities in 1995 in North Jakarta

Table 3 : $\quad$ Training Activities Summary, January-April 1997

Table 4 : $\quad$ RTI/STD Treatments 
Table 5: Contraceptive Method Use Reported by Clients 36

Table 6: Prevalences of Confirmed RTIs in the Two FP Clinics 37

Table 7: $\quad$ Frequency of Positive Risk Findings Obtained During the History Taking

Table 8: Positive Physical Examination Finding in Two Clients 40

Table 9: Client Characteristics, Risk Factors, Reported Symptoms and Clinical Findings and Measures of Association with Infections Status

Table 10: $\quad$ Trends and Overall Rates of 1. Prevalence of Any RTI/STD Diagnosis, and 2. Concurrence Between Initial Clinical Diagnoses and Final Laboratory Diagnoses

Table 11: Comparative Analysis of Syndromic with Etiologic Diagnoses

Table 12: $\quad$ Sensitivity and Specificity of Clinic Site Gram Stains in Detecting Bacterial Vaginosis

Table 13: Sensitivity and Specificity of Clinic Site Gram Stains in Detecting Candidiasis

Table 14: Cervical Leukocytosis and Final Laboratory Findings for RTI/STDs

Table 15: $\quad$ Number Prescription Written at Initial Clinical Evaluations for Clients with Final Negative Laboratory Diagnoses

Table 16: Observed Frequency of HCP/Client Interaction Behaviors 51

Table 17: Status of Client Treatment for Non-Sexually Transmitted RTIs 52

Table 18: Status of Client and Partner Treatments for RTIs that are Sexually 55 Transmitted (STDs)

\section{Figures}

Figure 1: Excluded Study Participants 35

Figure 2: Client Reasons for Refusing Participation in the Study 35

\section{List of Abbreviations}

AWA

Binkesga

$\mathrm{CDC}$

CMT

FHI

FP

GNID

HAPP/AIDSCAP
: American Women Association

: $\quad$ Bina Kesehatan Keluarga (Directorate Family Health)

: Centers for Disease Control

: Cervical Motion Tenderness

: Family Health International

: Family Planning

: Gram Negative Intracelluler Diplococci

: HIV/AIDS Prevention Project/AIDS control and Prevention 


$\begin{array}{lll}\text { HCP } & : & \text { Health Care Provider } \\ \text { HSV } & : & \text { Herpes Simplex Virus } \\ \text { HPV } & : & \text { Human Papilloma Virus } \\ \text { IRB } & : & \text { Institutional Review Board } \\ \text { KAP } & : & \text { Knowledge, Attitude, Practice } \\ \text { KOH } & : & \text { Potassium Hydroxide } \\ \text { MCH } & : & \text { Maternal and Child Health } \\ \text { mg } & : & \text { milli gram } \\ \text { MOH } & : & \text { Ministry of Health } \\ \text { Obgyn } & : & \text { Obstetrics and Gynecology } \\ \text { OR } & : & \text { Operation Research } \\ \text { PHC } & : & \text { Primary Health International } \\ \text { PMNs } & : & \text { Polimorphonuclears } \\ \text { POGI } & : & \text { Persatuan Obstetri Ginekologi Indonesia (the Indonesian } \\ & & \text { ObGyn Association) } \\ \text { PUS } & : & \text { Pasangan usia subur (Reproductive age couple) } \\ \text { Puskesmas } & : & \text { Pusat Kesehatan Masyarakat (Primary Health Center) } \\ \text { RA } & : & \text { Research Assistant } \\ \text { RPR } & : & \text { Rapid Plasma Reagin } \\ \text { RSUD } & : & \text { Rumah Sakit Umum Daerah (District general Hospital) } \\ \text { RTI } & : & \text { Reproductive Tract Infection } \\ \text { STD } & : & \text { Sexually Transmitted Diseases } \\ \text { TPHA } & : & \text { Treponema pallidum Hemagglutination Assay } \\ \text { WHO } & : & \text { World Health Organization }\end{array}$




\section{Acknowledgment}

This study was conducted by The Population Council Jakarta with support from the Indonesian Ministry of Health HIV/AIDS Prevention Project (HAPP) under USAID funding coordinated by Family Health International/AIDSCAP in collaboration with the U.S. Centers for Disease Control.

We would like to express our gratitude to Dr. Umar Wahid, director of Koja Hospital, and Dr. Sri Wahyudiyati, head of Cilincing Health Center, whose cooperation made it possible to conduct this study. We would also like to thank Dr. Basuki Mulyono, DSOG, head of Koja Hospital ObGyn Unit, and Dr. Melina Henratna, DSPK, head of Koja Hospital Laboratory Unit, and all medical staff in the family planning and laboratory units at Koja Hospital and Cilincing Health Center who have been willing collaborators in this study.

We are grateful to Dr. Sjaiful Fahmi Daili, DSKK, Dr. Wresti Indriatmi B. Makes, DSKK, Dr. Farida Zubier, DSKK, and Dr. Jubianto Judanarso, DSKK, from the Indonesian Sexually Transmitted Diseases Study Group, for their guidance in protocol development and training. Special thanks goes to Maemunah for her hard work at Cipto Mangunkusomo Dermatovenereology Laboratory Unit.

We are indebted to the following MOH officials: Dr. Ardi Kaptiningsih, MPH, Dr. Hariadi Wibisono, MPH, Dr. Sigit Priohutomo, MPH, and Dr. Frans Sumampouw, DAJ, MPH, for their encouragement and advice. Without direct involved in the preparatory stage, this study would not have been possible. We wish to thank Dr. Djajadilaga, DSOG, and Midwife Coos Leiwakabessy at the National Resource Center (NRC) Jakarta for their significant contribution during the intervention stage of this study. We certainly appreciate the support from Dr. Enud Jayasunarya, DSOG (Head of Makmal Integrated Immuno-endocrinology Unit, Faculty of Medicine- University of Indonesia), and Dr. Subianto, DSOG (Head of the Melati Infertility Unit at Harapan Kita Hospital) for providing access to their invaluable clinical data.

Special acknowledgment is due to Dr. John S. Moran, MPH, STD consultant for the U.S. Centers for Disease Control, for carefully reading the report and for making excellent technical suggestions on the data analyses and presentation. We also received great administrative support from Jane Wilson, BA Hons, Dip.Ed, MAPS, Nancy Jamieson, RN MS, MPH, Dra. Ancilla Murdyastuti, M.Ed, and Drs. E. Slamet of the HAPP/AIDSCAP project management.

The following research team members have contributed directly to the implementation of this study: Dr. Siti Nurul Qomariyah as project officer, Lila Amaliah, SKM, Zakianis, SKM, Eti Sulaeha, SKM, and Milla Herdayati, SKM. Finally, the authors wish to thank Djoko Hartono, Ph.D, for assisting with data processing and analyses, Jane Patten, MPH, for her careful editing of the final draft, and also Dr. Lugiyanti, Dr. Emiliana Tjitra, Msc, and Susy K. Sunarjo, MPH, for their help in the early Bahasa Indonesia draft of our clinical protocol. Special thanks are due to the American Women Association (AWA) Jakarta, for their additional funding to purchase medications and also to the Indonesian ObGyn Association (POGI) Jakarta Chapter for facilitating the drug treatment supply.

Authors

Meiwita B. Iskandar

Catherine Vickers

Subadra Indrawati 


\begin{abstract}
The overall goal of this study was to develop an integrated program of RTI/STD clinical services within two family planning clinics in urban-harbor, lowincome neighborhoods. Multiple training programs to introduce a standardized clinical evaluation for the detection, treatment and management of RTI/STDs were conducted. Prior and subsequent to training, observations of health care provider (HCP) and client interactions were conducted to evaluate the behavior changes of the HCP. Each consenting client received a standardized reproductive health history, pelvic exam, and provided specimens for laboratory testing to detect the RTIs of: Candida albicans, Bacterial Vaginosis, Trichomonas vaginalis, Chlamydia trachomatis, Neisseria gonorrhoeae, and Treponema pallidum. On site laboratories performed microscopic evaluations of combined Gram stains and wet mounts. The Gram stains were validated by a referral lab at the national infectious disease hospital. Endocervical \& serology specimens were sent to the referral lab for final confirmation. Of the 478 clients who presented to one of two family planning clinics within the 12 weeks, $89 \%$ (425) were willing to become study participant. A total of 53 clients refused to participate due to fear of the exam and not enough time, and 113 clients were excluded from participation due to current menstruation or antibiotics use. The final study sample was 312. Findings indicate that through universal screening of the participants by an STD referral laboratory, 24.7\% ( $n=77)$ of the participants were confirmed to have one or more RTI while $13.8 \%$ had one or more STD (9 women had two diagnoses). The following disease prevalences were found: chlamydia cervicitis $10.3 \%$; candidiasis $6.7 \%$; trichomoniasis $5.4 \%$; bacterial vaginosis $5.1 \%$; and gonococcal cervicitis $0.3 \%$. No positive blood tests for syphilis were detected. HCPs were observed by trained research assistants who recorded an itemized evaluation of HCP behavioral components. The results of this 70 item observation tool showed a preference for performing physical examination tasks, and a reluctance to perform history taking, education, partner treatment plans and prevention counseling skills.
\end{abstract}




\section{Executive Summary}

With support from HAPP/AIDSCAP and the Population Council, an eight month program funded by USAID to improve reproductive health services for "ordinary housewives" was undertaken. This program included the incorporation of RTI/STD clinical services into the menu of routine services offered in two family planning (FP) clinics in North Jakarta. The two study settings included FP clinics at a 202 bed district hospital, and at a community level primary health center (PHC or Puskesmas). The primary target group of this study were the health care providers (HCP) who received the intervention. Five HCPs participated fully in all components of the study three doctors from the hospital and two midwives from the PHC. The clientele of these two FP clinics formed the secondary target group of the study. The clientele were in general married, multiparous, low income women whose primary risk of acquiring a sexually transmitted infection was via sexual intercourse with their spouses. The majority of these women, despite being long time consumers of contraceptive services, had never previously received pelvic examination or been tested for the presence of RTI/STDs.

Baseline data from the study area of North Jakarta were gathered by use of multiple interviews with local providers, a retrospective medical record review, and extensive observations of health care facilities and $\mathrm{HCP} / \mathrm{client}$ interactions to determine the feasibility of incorporating RTI/STD clinical services into the family planning clinical setting. Despite evidence of an acceptable level of resources and facilities to begin RTI/STD care at the two study settings, there was very minimal prior experience among the staff in diagnosing or treating specific RTI/STDs.

The existence of an adequate infrastructure combined with the absence of RTI/STD case recognition pointed to the HCPs as the target group for intervention activities of this project. The primary intervention was a series of educational activities for the HCPs on RTI/STD diagnosis and case management. The main study objective was to assess the feasibility and acceptability of improving FP provider skills in provision of STD services in the two selected FP clinics. An advisory board of national experts and leaders from the fields of public health, dermatovenereology, obstetrics and gynecology, served as editors for the clinical protocols, instructors during the training, and role models for the HCPs. The basic study design was a quasi-experimental evaluation comparing the ability of HCPs to recognize and appropriately respond to RTI/STDs within their population of FP clients before and after the training intervention. A broad range of data were collected during the course of this evaluation.

The baseline assessment data and initial educational workshops were valuable inputs for the development of a standardized clinical evaluation flowsheet and clinical protocols for use in PHC family planning settings. The standardized procedures on the flowsheet included obtaining an RTI/STD risk assessment history, performing a pelvic examination, obtaining laboratory specimens to screen for the presence of six selected treatable RTI/STDs, selecting a nationally approved 
treatment for identified infections, and providing client education with partner treatment for future disease prevention.

Each presenting FP client during the twelve week post intervention observation period was individually advised of the main purpose of the study and given a complete description of the clinical evaluation procedure by a trained research assistant (RA). Their consent was then requested with an assurance of voluntary participation and an option to withdraw from the study at anytime without compromising family planning benefits. All prospective participants were informed that the examination, laboratory testing and any necessary treatment would not require any additional charge. Additional project funding for the express purpose of purchasing medications to treat identified infections was obtained from the Jakarta chapter of the American Women's Association (AWA). An additional donation procured through the Indonesia ObGyn Association (POGI) Jakarta chapter consisted of 75 single dose anti-fungal treatments for non-pregnant women. No other incentives to participate were given. The content of this client disclosure was recorded on an informed consent form. This informed consent form also doubled as a record of the client's requested follow-up notification procedure in the case that final laboratory results indicated the need for additional treatment for either herself or her partner(s).

Of the majority of clients, $89 \%$ of 478 who presented to the two FP clinics during the twelve week observation, were willing and eager to participate. The requirement of a full pelvic examination did not discourage the level of participation. On the contrary, the clients' desire to learn about their reproductive health status might have been influenced by the desire to receive "free" medical care and treatment. The 53 clients who refused to participate cited fear of the exam and not enough time as the most common reasons, and another 113 clients were excluded from participation due to current menstruation or antibiotic use. The final number of study participants was 312. Day-to-day direct post-intervention observations were conducted in both sites for a twelve week period between February 17 and May 9, 1997. During that period, the 312 client evaluations were observed and a supervisory medical checklist was used to record progress and behavioral changes among the five HCPs. Biological samples from the vagina, endocervix, and blood were obtained to determine the prevalence of six treatable RTI/STDs. Three sociodemographic variables were gathered for all participating clients: age, current contraceptive use and marital status. Eleven additional potential risk factors for RTI/STD infection were also explored with each participant. Among those clients with a confirmed RTI, no risk factor was found to occur at a significantly higher rate than among uninfected clients, and none of the risk factors had predictive value. 
Through universal screening of the participants by an STD referral laboratory, $24.7 \%(n=77)$ of the participants were confirmed to have one or more RTI and $13.8 \%$ (43) had one or more STD ( 9 women had two diagnoses). The following disease prevalences were found: chlamydia cervicitis $10.3 \%$; candidiasis $6.7 \%$; trichomoniasis 5.4\%; bacterial vaginosis 5.1\%; gonococcal cervicitis $0.3 \%$. No positive blood tests for syphilis were detected. HCPs were asked to evaluate and record on the flowsheet the presence or absence of seventeen separate clinical signs of infection. Presence of cervical mucopus and cervical inflammation occurred at higher rates among women who were eventually confirmed to have an RTI but the difference was not statistically significant. As with the risk factors, no clinicals signs were found to be predictive of final diagnosis.

Through the standardized history taking/risk assessment and physical examination procedures, HCPs were encouraged by the trainers to attempt an accurate clinical/syndromic diagnosis for each client. Doctors were much more likely to attempt an initial client diagnosis (including negative) than the midwives (98\%.vs 68.5\%), and were much more likely to be accurate (41\% vs. $35 \%$ ). 56 women (18\%) did not receive an initial diagnosis. Of those 256 women who did receive a syndromic diagnosis, $7 \%$ of women received correct initial positive diagnoses and $31 \%$ received correct negative diagnoses. Thus a total of 98 (38\%) women received a correct initial diagnosis, ie. concurrent with the final diagnosis. The most common initial diagnosis was a false negative (44\%). Concurrence between initial and final diagnoses improved at the hospital but not at the PHC. By the end of the observation period (May 9, 1997), 73\% of clients with non sexually transmitted RTIs had received appropriate treatment for their confirmed infections, and $73.5 \%$ (36) of clients with STDs had received appropriate treatment. The remaining women were not treated as they did not return to the clinic. No one was treated with inappropiate medication due to pre-packaging and labeling of medications for the study. Furthermore, only 55\% (27) of the sexual partners of STD positive participants received treatment for infections, potentially exposing 9 of the treated STD clients to the risk of reinfection.

This low partner treatment rate reflects the level of HCP interpersonal communication skills found overall. It was found that $62 \%$ of the time, the midwives "smiled and greeted the client respectfully", while doctors did so only $3.5 \%$ of the time. Only with one client did one HCP (a midwife) review the health effects of RTI/STDs and make a connection to birth control. Eight clients received information about the diagnosis and only two clients received any mention of condoms. Only 26 of 63 clients receiving prescriptions were warned of possible side effects ( 24 of them by a midwife). Client counseling was generally neglected and risk assessment was largely delegated to the research assistants which indicated that it was undervalued by the HCPs who were mostly unwilling to take the time or to ask such personal questions. 
Findings on infection control varied. In only 2 out of 312 examinations did the HCP not use visibly clean instruments, and for $79 \%$ of pelvic examinations, a new/disinfected glove was used. However, rates of hand washing before and after the exam were low, about $20 \%$ each over the (post-intervention) observation period.

A six month retrospective medical record review (July 1 to December 31, 1996) showed that essentially it is a non-existent practice to categorize gynecological problems with a disease specific diagnosis. At Koja Hospital, more than 100 diagnosis each of vaginitis and cervicitis were made, but no further diagnoses or records of counseling were made. Also there was no evidence of a standardized prescriptive regimen. At Cilincing, a monthly disease report revealed a total of three RTI/STD diagnoses, all for gonorrhea. These could not be linked to medical records to assess treatment or interventions as no client identifiers were included.

The main findings revealed that the provision of medical care by the HCPs and return rate of laboratory results from the referral lab were the greatest constraints to service integration. Both doctors and midwives were willing to perform standardized clinical physical examinations with the collection of laboratory specimens from the vagina and endocervix. However, they were not as consistent in performing education and partner treatment plans for RTI/STD positive clients. The referral laboratory could not provide a consistent rate of turn around time for final lab reports. The actual length of time between initial evaluation and final lab reports varied from one to four weeks. Future studies of RTI/STDs should strive to improve diagnostic microscopy skills that have a more rapid final report rate which do not need to be sent to a referral laboratory.

Another side-product of this study is a RTI/STD treatment formulary, which was selected after reviewing the costs and benefits associated with each treatment regimen included in the recently published national STD Treatment Guidelines (Daili, et al., 1996). Medications were purchased and individually prepackaged for the six treatable infections that all clients were screened for.

Future efforts to improve reproductive health and STD services for clients of family planning clinics must also investigate strategies to strengthen or supplement the skills of the HCP in conducting risk assessment and providing counseling and partner treatment for clients discovered to be STD positive. The widely held HCP belief that factually informing a client of the discovery of an RTI/STD would cause emotional distress was not validated during a single encounter with a client, according to the RAs. Additional exploration of the client's and affected partner's perceptions of participating in such a program would be invaluable in developing future strategies to overcome the reluctance of HCPs to see the truth, and speak the truth about RTI/STDs in the real lives of ordinary housewives. 


\section{Introduction and Literature Review}

\section{I.A. Introduction}

In the national workshop on Reproductive Health (RH) last May 1996, representatives from the Indonesian Ministry of Health (MOH or DepKes), the National Family Planning Coordinating Board (NFPCB or $B K K B N$ ), other public sector programs, NGOs, professional organizations, and donor agencies, agreed on four services which will become the main components of the new Essential Reproductive Health Care (ERHC) Package at the primary health care (PHC) level. These components are: a) Safe Motherhood; b) Family Planning; c) Management of Reproductive Tract Infections/Sexually Transmitted Diseases (RTI/STD); and d) Adolescent Reproductive Health.

This ERHC initiative is a major step towards the implementation of the International Conference on Population and Development (Cairo, 1994). The ICPD platform recommended that family planning (FP) services be expanded to include the prevention and treatment of sexually transmitted diseases (STDs), including HIV/AIDS, in a reproductive health context, aimed largely at reducing reproductive morbidity from RTIs in women (Jain, 1995; Zizic, 1994). The HIV epidemic has made the prevention and treatment of RTI/STDs a high priority on the world's reproductive health agenda.

Unfortunately, despite the formulation of the ERHC package one year ago, Indonesia's $\mathrm{MOH}$ currently has no reproductive health program. The maternal and child health $(\mathrm{MCH}) / \mathrm{FP}$ programs and STD control programs deliver their services independently, with the latter targeted primarily at men and high risk groups. This vertical structure poses potential obstacles to service integration, although conceptually it seems to be a natural union (Fox, Williamson, Cates and Dalabetta, 1996). The high disease burden of STDs, both in terms of morbidity and mortality, demand that family planning and infectious disease control programs work together.

\section{I.B. Literature Review}

\section{I.B.1 RTI/STD in Low Risk Populations and Women}

RTIs include: (1) STDs, such as chlamydia, gonorrhea, trichomoniasis, syphilis, chancroid, genital herpes, genital warts, and HIV infection; (2) endogenous infections caused by overgrowth of organisms in the genital tract of healthy women, such as bacterial vaginosis and vulvovaginal candidiasis; and (3) iatrogenic infections, which are brought about by medical procedures (Wasserheit and Holmes, 1992:7). All these infections are preventable or treatable, but current health and FP programs give them low priority.

Women are more often asymptomatic and thus more difficult to diagnose than men, but their health is also more seriously threatened by STDs than men. STDs 
can cause pelvic inflammatory disease (PID) and tubal infertility, and several STDs can be passed perinatally to infants (Fortney, 1995:6). Women are also more vulnerable to STD transmission from men than vice versa (Fox et al., 1996). In addition, women suffer more social stigma associated with sexual morbidity (Fortney, 1995:8). Thus, special attention is needed to alert women to RTI/STDs, encourage them to seek treatment, use more effective barrier methods that they can control, and notify their sexual partners so that they too can be treated and prevent reinfection of the woman.

Worldwide, the most common STDs are trichomoniasis, genital chlamydia, human papilloma virus, gonorrhea, and genital herpes (Fox, et al., 1996). Estimates from selected studies of low-risk populations (FP/prenatal clients and adults in population-based studies) show that among these women, risk of STD/HIV is largely determined by the behavior of their male partners (Fox et al., 1996:131). Studies in developing countries indicate that among prenatal clinic attendees, gonorrhea rates are 10 to 15 times higher, chlamydia rates 2 to 3 times higher, and syphilis rates 10 to 100 times higher than among comparable women in developed countries. Risk assessment surveys in FP clinics found that $25 \%$ of clients report behaviors that put them at increased risk for STDs (Cates and Stone, 1992:125).

\section{I.B.2 RTI/STD/HIV/AIDS in Indonesia}

The magnitude of the HIV/AIDS epidemic in Indonesia is still unknown because of the lack of a well-monitored surveillance system. Based on a passive recording and reporting system, $413 \mathrm{HIV}(+)$ cases including 132 AIDS cases were recorded in 21 out of the 27 provinces of Indonesia, as of May, 1997 (Yayasan Pelita Ilmu, 1997). Over one-third (31.4\%) of these cases were residents of Jakarta. The first HIV+ baby was announced on October 5, 1996 (the Jakarta Post, October 5, 1996).

In Indonesia, there is precious little data on STDs in non-high risk populations. In 1994, the Kusuma Buana Foundation ( $Y K B$, an NGO working in the FP and HIV fields) announced a disturbing finding of nearly 29\% STD prevalence among 6,666 women aged 25-45 years who came for Pap-tests at six clinics in Jakarta and were also tested for STDs (cited in Daili, Nuning and Asri, 1994:4-5). Another study among 695 women presenting for menstrual regulation (abortion) in 1987 and 1988 at an urban clinic in Bali, found that $53 \%$ had one or more RTI/STD, including $16.3 \%$ bacterial vaginosis, $15.5 \%$ candidiasis, $7.3 \%$ trichomoniasis and $5.2 \%$ chlamydia, among others (Susanti, 1993). While 67\% of these women were unmarried, they did not fall into any high-risk group category. A review of studies and articles on STDs in Indonesia

published between 1988 and 1994 found that the two most frequently mentioned were gonorrhea (16\% to 58\%) and non-gonorrheal urethritis (24\% to 54\%) (Daili, 
Masjkuri and Adisasmita, 1994:2-6). The reviewers suspected that these data were limited by the availability of diagnostic facilities (ibid).

Although anyone may be infected, RTI/STDs tend to be diseases of poverty. Conditions of economic deprivation, social disenfranchisement, and gender inequality, have a detrimental impact on women's reproductive health from a very young age (see Sadli, et al., 1994:6). In general in Indonesia, women seeking care at a primary health center, or Puskesmas, tend to be of lower socio economis status. They are not informed or asked about STD/RTI risks when they present themselves for FP services, and do not receive appropriate information or referrals even if presenting with potential RTI symptoms. A survey needs assessment on reproductive health among 318 women (96\% married) in rural Bali found that $53.5 \%$ of the women had ever experienced an adverse symptom, including discolored discharge (36\%), odorous discharge (17\%), itchiness (34\%), genital sores $(4 \%)$, dysuria $(9.5 \%)$ and lower abdominal pain with fever $(13.5 \%)$. Women were more likely to have experienced symptoms if they were pill or IUD users or if their husband's work required him to travel frequently or live elsewhere. $70 \%$ of the afflicted women sought health care for the problems, 55\% of them at a puskesmas. However 53\% of the participants expressed some form of dissatisfaction with the available services and only $35 \%$ had ever received any form of information on STDs (Susanti and Patten, 1996). There is a great need to address prevailing undiagnosed RTI/STD problems among poor or rural women.

Clearly Indonesian women are vulnerable to RTIs including STDs and HIV/AIDS, infertility, and reproductive tract cancers. There is an unmet demand and need for services and information. A study on women's perspectives of RTI's quoted a Jakarta woman's complaint, "if we go to the doctor and ask whether this [vaginal discharge] is serious or not, the doctor always answers 'no problem"' (Hull, Widyantoro and Fetters, 1996).

Why, then, has the primary health care system in Indonesia been incapable of addressing RTI/STDs? There are four possible answers: (1) women are generally unaware of RTI/STDs symptoms and do not seek care; (2) only STD clinics offer STD diagnosis and treatment, and women do not go to STD clinics, thus they are not approachable; (3) health care providers at the FP clinic (or $\mathrm{MCH}$ ) fail to recognize RTI/STD symptoms; and (4) health care providers who recognize RTI/STD do not inform the client, record the case, nor report it in the monthly statistics. 


\section{I.B.3 Family planning and STDs}

Clearly there are differences in clientele and training orientation between FP and STD services. Unlike STD clinic clientele, FP clients are typically women seeking contraceptive services who are generally unaware of STDs. FP providers are more physiologically oriented than microbiologically, and are trained to offer a choice of options (not a strict treatment regimen). Furthermore, the most common FP methods have no value for STD prevention, and FP providers are not trained to ask personal questions about sexual behavior.

In Indonesia, at the hospital and subdistrict health center (Puskesmas) level, there are very few records of STD diagnoses among FP clients. This is not only due to a lack of medical and laboratory facilities, but also because FP providers prefer not to take on uncomfortable topics, such as STDs and extramarital transmission. Providers avoid confronting the reality of STDs and the need for partner notification and treatment in their efforts to help patients "save face".

At the PHC level, there is little evidence of counseling on effectiveness, advantages and disadvantages of available FP methods, or careful screening of potential IUD users by history and pelvic examination. All in all, there is a broad lack of the communication skills (e.g., risk assessment, education, counseling) and clinical examination skills that are necessary in providing both FP and STD/RTI care.

Professional re-training is needed because the FP and other primary health care providers are not uniformly aware of STD diagnosis, tests and treatment regimens. Currently, even in areas with high STD and HIV prevalence rates, many FP workers are not aware of or equipped to address the risk behaviors of their clients. On the other hand, the existing STD interventions are not targeted at women in general, but at high risk groups. FP providers can be trained to make a diagnosis based on a standardized clinical evaluation, or at the very least, to do a risk assessment, provide education and make a referral for care.

Risk assessment tools for use with all FP clients can be developed to include STD risk issues for little additional cost (Fox et al., 1995:131), thus opening the door for discussion of prevention and counseling. Even just a commitment to offer simple advice from the FP provider on condom and spermicide use can provide protection against STDs (Cates and Stone, 1992:122), and is a step up from STD services available from many FP clinics. 


\section{I.B.4 Costs of FP and STD integration}

The costs of adding STD services are always a concern to FP programs. A recent cost study on RTI management services in India used a production process analysis model to analyze inputs, processes and outputs, looking at both fixed and variable costs. It was found that costs vary widely by level of utilization, level of infection and existing capability of health centers in terms of facilities and staff. Laboratory testing and treatment costs were found to be high, pointing to an emphasis on prevention a vital cost-saving strategy in the long term. The authors of this study recommend that program managers need "to examine both initial and continuing costs to examine the quality and sustainability of RTI case management" in the context of the entire reproductive health package (RamaRao, Townsend and Khan, 1996).

\section{I.B.5 Feasibility, Sustainability and Risks}

If women in the general population are to get STD services, public and private $\mathrm{FP} / \mathrm{MCH}$ programs are the most logical place to provide them, as they are women's primary contact with the health care system. Ideally, FP providers should be able to understand client needs and be capable of advising clients on methods for prevention of both pregnancy and STD transmission when needed. So far, FP clients in Indonesia have not been receiving such information. The decision to expand FP programs to include STD/HIV prevention or treatment services in accordance with the ERHC package, involves studying client needs, assessing program capacity and potential resources, estimating costs and also determining the availability and acceptability of alternative STD services.

Sustainable integration of FP and STD services also requires that providers of the two types of services support the integration initiative. There may be resistance due to the possibility that FP activities may be weakened and human resources may be spread thin. Training of FP providers in the basics of STDs and counseling techniques may not automatically bring changes in attitude or practice, especially if they feel overburdened with new responsibilities or lengthy procedures. This resistance must be acknowledged and addressed by discussion of the common service goals and potential for significant and much needed improvement in the lives of Indonesian women. 


\section{I.C. Project Summary}

In the interests of working towards integrating STD/RTI services into FP services in Indonesia, as outlined in the MOH's 'Essential Reproductive Health Care Package', the Population Council attempted to run a pilot-test in a real primary health care environment. The study aimed at identifying and attempting to address barriers to the integration of STD services into FP services in two selected pilot FP clinics. The intervention involved initial and on-going training of five Health Care Providers (HCPs) and a follow-up twelve week observation of their attitude and behavior changes in the delivery of RTI/STD services to 312 consenting client participants. 


\section{Description of Subproject}

\section{II.A. Background}

This study is part of the Indonesian Ministry of Health HIV/AIDS prevention project (HAPP) coordinated by Family Health International/AIDSCAP in collaboration with U.S. Centers for Disease Control (CDC) and the Government of Indonesia. The overall goal for year 1 of the HAPP project was to facilitate the development and implementation of national policies supportive of HIV/AIDS control and surveillance. This study, by the Population Council Jakarta, as a subcontracted executive agency has conducted a study focusing on integrating clinical services for reproductive tract infection and sexually transmitted disease (RTI/STD) into two different family planning (FP) clinics, one at the primary health center and one at a public hospital. As the entry point to primary health care for the majority of women seeking reproductive health services. The FP setting was seen as the ideal place to prevent and control RTI/STDs.

The two study sites in the target area of North Jakarta include (1) the outpatient FP clinic of the Koja District Public Hospital (Rumah Sakit Umum Daerah Koja or RSUD Koja), and (2) the Primary Health Center (PHC or Puskesmas) at Sub-District (kecamatan) Cilincing. Koja $\left(11.3 \mathrm{Km}^{2}\right)$ and Cilincing $\left(42.6 \mathrm{Km}^{2}\right)$ are two of the seven sub-districts in North Jakarta. These two sites are in Jakarta's harbor area on the Java sea which is the main port for the commercial shipping and fishing industries of a metropolitan area of more than 12 million people. Like most major urban ports, the surrounding neighborhoods are primarily low income. The predominant occupations in both Koja and Cilincing are sailors, laborers, ship loaders, fishermen and vendors. In this densely populated area, the average level of education is middle school level, with only $15 \%$ of residents finishing high school and 3\% going on to higher education (North Jakarta Health Office, 1995). The average number of family members per household is 13.8 in Koja, and 6.7 in Cilincing (North Jakarta Health Office, App. Table 2). Only 44\% of Koja households have piped water, and even fewer in Cilincing 25\% (ibid, App. Table 9 A). The highest rates of STDs are generally found in urban men and women in their most sexually active years, ages 15 to 35 (Over and Piot, 1996).

There were two separate target groups in this study. The primary target group was the health care providers (HCPs) in the two FP clinics who provided the clinical services. The secondary target group was women who presented as their clients for FP services. They were selected because the majority of FP/MCH health care clients are of reproductive age and sexually active. Coincidentally, most of these women are married, and monogamous sexual behavior for married women is the cultural norm. This target group was also deliberately chosen as women who were not necessarily perceived as being at high risk for STD infection. The target group and the area in North Jakarta make an optimum environment to study the integration RTI/STD services into the existing venue of FP clinics for reproductive health care. 
According to data from the 1990 census, the total population of the North Jakarta district was almost 1.6 million, with 341,786 people living in the sub-district of Koja, and 262,677 people living in Cilincing. The estimated total number of women of reproductive age between 15 and 44 years was 97,458 in Koja and 74,900 in Cilincing (North Jakarta Health Office, 1995:Table IA). According to the annual report for 1995 from the North Jakarta Health Office, the total couples of reproductive age (PUS) seeking family planning clinical services in Koja was 24,068 and in Cilincing 24,364 people (ibid, Table 21A). Koja Hospital received 21 clients per week, and Cilincing Health Center 19 clients per week, during the observation. A breakdown of the types of contraception given to these clients reveal that very few of these sexually active women use a method that is a barrier to the acquisition of STDs (see Table 1).

Table 1: Contraceptive Choices in the Two Subdistricts

\begin{tabular}{|l|c|c|}
\hline Contraceptive Method & Koja & Cilincing \\
\hline Injectable Hormones & $36 \%$ & $42 \%$ \\
\hline Pills & $34 \%$ & $33 \%$ \\
\hline Intrauterine Device (IUD) & $21 \%$ & $14 \%$ \\
\hline Sterilization & $5 \%$ & $5 \%$ \\
\hline Norplant & $2 \%$ & $4 \%$ \\
\hline Condoms & $2 \%$ & $2 \%$ \\
\hline
\end{tabular}

Source : North Jakarta Health Office. Health Profile for the District of North Jakarta. 1995: App. Table 21A

The surveillance of reported STDs by the local District Health Office for the studied area only includes diagnoses of Neisseria gonorrhoeae and syphilis. As a baseline of reported STDs, Table 2 presents annual cases of STDs recorded by all the Puskesmas and Hospitals in North Jakarta. However, clearly, this represents an inadequate recognition of actual disease and incidence rates. 
Table 2: $\quad$ Rates of Reported STDs by Cases and Total Percentage of Clinic Visits Diagnosed in Out-Patient Health Care Facilities in 1995 in North Jakarta.

\begin{tabular}{|c|c|c|c|}
\hline $\begin{array}{l}\text { Out-Patient } \\
\text { Clinic at: }\end{array}$ & STD Diagnoses & \# of Cases & $\%$ of Total Visits \\
\hline \multirow{2}{*}{$\begin{array}{l}\text { District Health } \\
\text { Center }\end{array}$} & gonorrhea & $63 / 417,819$ & 0.015 \\
\hline & syphilis & $20 / 417,819$ & 0.005 \\
\hline \multirow{2}{*}{$\begin{array}{l}\text { District } \\
\text { Hospitals }\end{array}$} & gonorrhea & 299/16,322 & 1.83 \\
\hline & syphilis & $15 / 16,322$ & 0.092 \\
\hline
\end{tabular}

Source : North Jakarta Health Office. Health Profile for the District of North Jakarta. 1995: Table 10A and 10B

A recent RTI/STD prevalence study among a similar target group of women, conducted during 1994-1995 in four Puskesmas in urban Jakarta and rural west Java, performed a total of 1,136 laboratory examinations using wet mount microscopy and Gram stains to detect bacterial vaginosis, candidiasis, trichomoniasis, gonorrhea, and Non-specific genital infections (leukocytosis). Based on the results of this study, the authors cite a combined RTI/STD prevalence rate of 40-45\% (Pratomo, Kodim, et al., 1995: 66-67). Since microscopy is a subjective analysis infections for gonorrhea and chlamydia, the actual STD prevalence rates may differ from the findings of this study.

In an attempt to gather additional data illuminating the local consequences of untreated RTI/STDs, such as ectopic pregnancies and tubal infertility, secondary data from the infertility clinic of Harapan Kita private hospital was requested. The percentage of infertility due to tubal factors was $38.5 \%$ for 725 women who sought in-vitro fertility (IVF) treatment between 1991 and 1995. Diagnoses were based on hydrosalphingography and laparoscopy procedures.

Additional data was also gathered from the WHO Laboratory for Matched Reagent Program in Immunoendocrinology of the Faculty of Medicine, University of Indonesia (Makmal Terpadu Immunoendokrinologi, FKUI ). These data recorded serological markers for past infections with a variety of pathogens that could be related to auto-immune induced spontaneous abortions (SABs). The prevalence rate of serological markers for Herpes Simplex Virus (HSV) was 68.9\% among 3,475 serological samples and for Chlamydia, $67.7 \%$ among 3,821 specimens, all from women who sought care for SABs between 1994-1996. 
Primary data collection at the pre-intervention stage covered the following four areas:

1. Study site facility (logistic) observations

2. HCP knowledge, attitudes and acceptance of integrated RTI/STDs into FP services

3. The level of recorded RTI/STD from FP services in a six month retrospective medical record review

4. Observations of the content of actual HCP and client clinical interactions.

In summary, the findings from the above four areas of inquiry revealed that the two selected sites were adequate to support RTI/STD program integration, and, at the same time revealed specific HCP clinical and record keeping practices that overlook the possibility of RTI/STD in FP clients. These identified deficiencies served to guide and direct the development of standardized protocols and training curricula for use as the study intervention. Results of overall needs assessment directed attention to problematic health practices that had not been anticipated, such as infection control and the client education process, and this led to future adjustments in the original work plan.

\section{II.B Scope of Work}

\section{II.B.1 Objectives}

The overall goal of this study was to strengthen the skills of FP providers in appropriate and feasible methods of RTI/STD clinical practices that would lead to an effective identification and treatment of women who were infected with certain RTI/STDs in the family planning clinic setting at the PHC and hospital levels. During the needs assessment phase, the study design evolved to include the following specific objectives:

1. To determine the prevalence of specific RTI/STDs: candidiasis, bacterial vaginosis, trichomoniasis, gonococcal cervicitis, chlamydia cervicitis, and syphilis, among women presenting for routine FP services in two FP clinics in North Jakarta who gave informed consent to participate in this study;

2. To study possible associations between the presence of infection and the women's socio-demographic characteristics, and sexual and obstetric/ gynecological history;

3. To study the practice of infection control in daily family planning services;

4. To assess the clinical and laboratory skills of doctors and midwives in the diagnosis of RTI/STDs in female clients levels; 
5. To assess the compliance of doctors' and midwives' RTI/STD prescriptive recommendations with the national STD treatment guidelines;

6. To assess the interpersonal communication skills of doctors and midwives for effective RTI/STD risk assessment and client counseling;

7. To study the quality of the existing RTI/STDs recording and reporting system.

\section{II.B.2 Study Design}

A quasi-experimental design using a single pre-intervention observation and repeated measurement of post-intervention observations in 12 weeks was employed.

$$
\begin{array}{llllll}
\mathrm{O}_{1} & \mathrm{X} & \mathrm{O}_{2} & \mathrm{O}_{3} & \mathrm{O}_{4}
\end{array}
$$

O $\quad$ was the pre-intervention observation of the study measures, which were conducted between December 1996 - January 1997;

$\mathbf{X}$ was the intervention consisting of various workshops for FP HCPs on:

a) diagnostic clinical and laboratory skills;

b) RTI/STD treatment regimens;

c) interpersonal communication skills;

d) recording and reporting; and

e) infection control practices.

$\mathbf{O}_{2-4} \quad$ were repeated post-intervention observations for twelve weeks between February 17 and May 9, 1997.

\section{II.B.3 Eligibility Criteria of Study Participants}

All clients who attended the FP clinic in either Koja Hospital or Puskesmas Cilincing during the twelve week period of study were advised that a study to improve the detection and treatment of RTI/STDs was seeking interested volunteers. The FP staff, doctors at Koja hospital and midwives at the Puskesmas Cilincing, presented an introductory discussion of contraceptive options and their link to RTI/STDs. Those clients choosing to participate received standardized information for informed consent and then were briefly interviewed by the HCP to determine their eligibility. All consenting FP clients were considered eligible to participate unless: 
- they were menstruating at the time of the exam (in which case they were invited to return to the clinic two weeks later for evaluation);

- they had taken antibiotics in the past 14 days.

It was anticipated that a population of both symptomatic and asymptomatic clients would be gained by including all presenting FP clients as potential participants. There was no extra compensation for the clients to participate.

\section{II.B.4 Diagnostic Model}

The syndromic STD case management algorithms from the World Health Organization (WHO) require an evaluation that is dependent on the primary symptom of vaginal discharge to start the diagnostic process (WHO, 1993). Previous investigations using a hierarchical syndromic algorithm to evaluate RTIs in asymptomatic populations have not found such algorithms to be highly sensitive specific for the detection of RTI's, and in particular, the cervical infections of gonorrhea and chlamydia (Vuylsteke, 1993; Behets, 1995; Thomas, 1996). Therefore, all participants were evaluated by risk assessment, physical examination and laboratory testing.

\section{II.B.5 Physical Examination and Specimen Collection}

The physical examination included 17 separate steps and the collection of five separate lab specimens, all of which were sequentially recorded on the clinical evaluation form (Appendix A). The examination of the abdomen and skin included visual inspection for rashes that might be related to secondary syphilis infections. The abdomen and inguinal area were palpated for organomegally and lymphadenopathy, respectively.

Examination of the vulva and vagina noted the presence or absence of inflammation (erythema), ulceration or abnormal lesions of the vulvovaginal mucosa. Recording a written description of abnormal findings was encouraged. The following three lab-diagnostic tests were conducted on vaginal discharge:

(1) Gram stain for the presence of an elevation (above 30) of polymorphonuclear leukocytes (PMNs), suggestive of inflammation, hyphae and/or pseudo hyphae (candidiasis), and clue cells (bacterial vaginosis);

(2) Wet mount microscopy with normal saline for the detection of motile trichomonads;

(3) A positive amine odor when combined with $10 \%$ potassium hydroxide $(\mathrm{KOH})$.

After removing cervical discharge with a cotton swab, the cervix was visually inspected for signs of ectopy, erythema, mucopus and friability. Another 
three lab-diagnostic procedures were applied to the endocervical specimen :

(1) inoculating a modified Thayer-Martin medium plate with immediate placement in a candle extinction jar prior to transport to the referral lab where each plate was then incubated at 37 degrees Celsius for 24 to 48 hours;

(2) heat fixed Gram stain for the detection of gram negative intracellular diplococci (GNID);

(3) chlamydia ELISA screen, by using a sterile dacron swab in the endocervix for a minimum of 10 seconds and rotating the swab in the endocervix three times before placing in a chlamydial transport medium.

Isolates for $N$. gonorrhoeae were identified by the referral laboratory on the basis of typical colonial morphology and oxidase reaction. $C$. trachomatis was tested from endocervical specimens by enzyme-linked immunoassay or ELISA (IDEIA ${ }^{\circledR}$ from DAKO Diagnostic Ltd, UK).

All consenting participants also had a $5 \mathrm{ml}$ sample of blood (aseptically) drawn for syphilis serology using the non-treponema RPR as a screen. In the event that an RPR tested positive, the same sample of blood would have been re-tested for confirmation by TPHA. The Gram stains, cultures, and ELISAs and serology samples were transported daily at noon to the referral laboratory at a medical teaching hospital, Rumah Sakit Cipto Mangunkusumo (RSCM). This referral lab is in the Department of Dermatovenerology, which is the primary STD clinical training program in Jakarta. The department head also acted as a member of the advisory committee for this study. He also chairs the National STD working group who recently published the first National Treatment Guidelines for RTI/STDs (Daili et al, 1996). The referral laboratory at RSCM hospital re-screened the Gram stains for verification of initial microscopy diagnoses, and also performed the reading and reporting of culture, ELISA and serology results.

To complete the physical examination, a bimanual examination was performed to assess for cervical motion tenderness (CMT), and to rule out uterine enlargement or adnexal mass. The results of all clinical examination findings were documented on the study's standardized clinical evaluation form (see example in Appendix A).

\section{II.B.6 Sample Size}

Five HCPs participated in this study as our primary target group for intervention. These five participated in all phases, from the pre-intervention needs assessment interviews, to the intervention trainings and follow-up evaluative observation of client interactions by research assistants. These five HCPs consisted of three out of the four doctors in the FP clinic at Koja Hospital, plus two of the three 
midwives at the FP clinic at Cilincing PHC. The midwives were both female, but of the three doctors, two were male. The other doctor and midwife also participated in the training, but not the other study components. This is also true of the one doctor at Cilincing PHC (the head of Puskesmas), three doctors at Koja Hospital ( two clinical pathologist and one ObGyn, head of ObGyn unit), and two lab technicians at each site. Therefore, 19 people received training, but only five were targeted for full participation; two midwives at Cilincing, and three doctors at Koja.

The secondary target group were the FP client. A total of 312 women were participated in the study between February 17 and May 9, 1997; 144 women at Koja Hospital, and 168 women at Puskesmas Cilincing (see section III. D. Findings and Results for exclusions, etc).

\section{II.B.7 Data Collection Methods and Patient Management Policy}

Every health care interaction between provider and client was observed by a trained research assistant using a coded observation checklist (see Appendix G). The checklist involved noting the presence or absence of the following HCP behaviors:

- exhibited positive communication skills

- obtained a standardized gynecological and sexual history

- maintained infection control practices

- performed a standardized physical examination

- provided diagnostic laboratory specimens

- provided client education and follow-up for client and partner(s) if an RTI/STD was diagnosed

- wrote a correct prescription for infections that were clinically diagnosed in accordance with National STD Guidelines

Analysis of laboratory specimens used a separate documentation tool. Clinical assessments were compared with on-site laboratory diagnoses of Gram stains and partial wet mounts. Subsequently, on-site Gram stain laboratory reports were reevaluated by

the RSCM reference laboratory to confirm the diagnosis of the on-site laboratory staff. This same report served to report the results of testing for gonorrhea, chlamydia and syphilis, which were performed at the referral laboratory.

The clinical evaluation, which included history, exam and lab findings as well as the HCPs teaching and client recommendations, along with the observations of the $\mathrm{HCP} / \mathrm{client}$ interaction were all recorded and checked for completeness on a daily basis by the project officer before the data was entered into the computer. 
Standard double entry procedures and consistency checks were used to ensure that the data set was clean prior to analysis. Client records used new assigned ID code numbers, so that individual identifiers were minimized in the data files.

\section{II.B.8 Data Processing and Analysis}

The data used here are taken from observations of 1) client provider interactions; 2) client background, including behavior, medical histories, and examination; and 3) results of laboratory tests. The software used to enter these data allowed for both numeric and character responses. It also included automatic checking for invalid and inconsistent responses. The data was organized in such a way that each client has a complete set of the three types of data mentioned above.

Preliminary analyses included univariate descriptive statistics to obtain a simple data description of all variables under study. This established how the cases were distributed across the various categories of each variable, the number of missing values per variable, and the shapes of the distributions of key variables.

Bivariate analyses using two variables for sub group comparisons were used for a descriptive presentation of some preliminary findings. They were also used for the preliminary analysis of the association between dependent variables (STD disease status -with or without gonorrhea, syphilis, and chlamydia) and selected disease markers as independent variables. Cross tabulations described the distribution of key variables of interest, such as disease status across various client's backgrounds behavioral characteristics, medical histories and results of physical examinations. An unadjusted odds ratio was calculated to assess the individual or gross effect of selected markers on the dependent variables.

A two way contingency table was employed to test the validity of some disease markers for predicting an STD infection. In this case, the results of RSCM's laboratory works were used as the standard.

\section{II.B.9 Major Activities}

A multitude of activities took place to accomplish the various objectives of this study. This project was not a singular intervention to study disease prevalence, but also a broader plan to study the feasibility of sustainably incorporating RTI/STD clinical services into the existing family planning services. The actual implementation of these activities closely followed the plan established in the original HAPP FHI/AIDSCAP Logframe of Activities (see Appendix B). The sequence of project activities started with pre-intervention data collection and needs assessment. These pre-intervention baseline findings contributed to the development of clinical protocols and HCP training curricula, followed by the clinical observation of each client and HCP interaction. During the study there was on-going coaching and 
refinement of HCP skills, as observations and program monitoring revealed the need for additional and continuous strengthening of HCP skills.

\section{II.B.10 Key Collaborators}

The key collaborators and members of the advisory committee were recruited early on in the preparatory stage as experts who also initially served as facilitators for training activities (intervention). These collaborators were selected for their positions of leadership, not only for training skills and also for their ability to supervise the HCPs and laboratory personnel who would be trained to perform clinical care. This cadre of leaders were also able to serve as mascots for ensuring that HCPs and laboratory staff would attend and participate fully in training activities. The list of policy makers/program managers selected at the central level is as follows:

- Head, Subdirectorate of ObGyn - Family Health, Ministry of Health $(\mathrm{MOH})$

- Section Head, Subdirectorate of STDs and Yaws - Centers for Disease Control (CDC), $\mathrm{MOH}$

- Chairman, The Indonesian ObGyn Association (POGI) - Jakarta Chapter

- Chairman, The Indonesian STD Working Group \& Department. of Dermatovenerology, Faculty of Medicine, University of Indonesia.

- Member, The Indonesian STD Study Group

- Head, Subdirectorate Surveillance, Directorate Epidemiology at PHC $\mathrm{CDC}, \mathrm{MOH}$

- Head, Subdirectorate of Mental Preventive Health - Family Health, $\mathrm{MOH}$ 


\section{Subproject Implementation}

\section{III.A Management}

With the exception of the position of the Project Officer during the first quarter, all staff positions were filled in the beginning of the project and continued through the entire period of study. The final project staff included:

$\begin{array}{lcl}\text { Project Manager } & : & \text { Dr. Meiwita B. Iskandar, Ph.D } \\ \text { OR Fellow } & : & \text { Subadra Indrawati, MPH } \\ \text { Project Officer } & : & \text { Dr. Siti Nurul Qomariyah } \\ \text { Data Analyst } & : & \text { Djoko Hartono, Ph.D } \\ \text { Health Consultant } & : & \text { Cathy Vickers, RN, BSN, CNP } \\ \text { Research Assistant } & : & \text { Lila Amaliah, SKM } \\ & & \text { Zakianis, SKM } \\ & & \text { Eti Sulaeha, SKM } \\ & \text { Milla Herdayati, SKM }\end{array}$

The selection of advisory board members reflected diplomatic negotiations for the operational integration of two traditionally distinct programs (FP and STD management) to establish the desired outcome of a more comprehensive reproductive health care delivery system. To support this goal, leaders from divergent programs were approached. Many of them have been used to working in strictly vertical and well defined $\mathrm{MCH}$ programs. The concepts of teamwork and collaboration, although unfamiliar to some, were critical element of the board functions. As a consequence, there were times when an individual member had very strong opinions about the composition of the advisory committee, or the group of trainers. This collaboration required many compromises in implementing the final protocols and delivery of actual training programs.

A strong consensus among project staff, advisory board members, and clinic site HCPs was that women with treatable infections detected during the course of the study should be provided with medications for themselves and their partner(s). Due to the budgetary prohibition of medication purchases, it was necessary to seek funding from an additional source for the procurement of these medications. A proposal for funds to purchase medications was submitted to the American Women's Association (AWA) of Jakarta. This organization awarded a grant of 5 million Rupiah to the Population Council for the acquisition of RTI/STD treatments. An additional donation procured through the Indonesian ObGyn Association (POGI) Jakarta chapter consisted of 75 single dose anti-fungal treatments for non-pregnant women. 


\section{III.B. Accomplishments}

A series of operations research (OR) products and findings emerged from the activities and may be of future help for efforts to improve reproductive health for women in Indonesia. An unanticipated accomplishment was that the $\mathrm{MOH}$ Directorate of Family Health recognized this study as a "model development project". This led to the invitation of the program manager to present the results of the field work to the Ministry of Health on April 5, 1997 in a seminar devoted to recommendations for the future integration of STD program planning into $\mathrm{PHC}$ at the national scale. This national meeting was attended by $\mathrm{MOH}$ representatives from multiple provinces. Of greatest interest to the $\mathrm{MOH}$ advisory board members was the fact that the protocols for STD case management were comprehensive, yet concise and manageable for the FP clinicians. The program manager was informed by the Head of the Subdirectorate of ObGyn-Family Health at this April 5th presentation, that the $\mathrm{MOH}$ intended to incorporate some parts of the Population Council's protocols into future $\mathrm{MOH}$ planning guidelines to integrate RTI/STD clinical services into broader FP/MCH programs in Indonesia (see Appendix $\mathbf{C}$ for a report of this $\mathrm{MOH}$ meeting). An $\mathrm{MOH}$ pilot test is going to be implemented in two health centers in Bali, under AusAID funding.

\section{III.B.1 Pre-Intervention Needs Assessments: Health Facility Observations}

Observation at the two clinical sites, Koja Hospital and Puskesmas Cilincing, revealed an adequate existing infrastructure for the provision of RTI/STD detection services without the need for significant additional equipment. Observations also revealed the need for enhanced written instructions, particularly in the protocols of infection control and education and counseling.

The most significant difference in clinic resources between the hospital and the PHC was the absence of an autoclave for sterilization of speculums at Puskesmas Cilincing. The method of disinfection used in this facility was to wash with water, then dry them, and place them in a container with formalin tablets. This toxic and potentially dangerous practice was immediately addressed with a recommendation to use safer disinfectants. This procedural problem was addressed in the second training program which placed a greater emphasis on infection control procedures. Supplies for hand washing and instrument disinfection were purchased and distributed as needed. The Puskesmas staff did not use disposable gloves for pelvic examination, therefore, disposable gloves were also purchased for the health center.

Koja District Hospital is presently a class "C" hospital, but expects to be promoted a class "B" facility this fiscal year. Koja hospital is a 202-bed hospital covering 18,000 square meters of land. Within the hospital, there are 13 specialty clinics, run by 55 doctors, 4 dentists, 10 midwives, 142 nurses and 14 nursemidwives. The PHC at Cilincing is a coordinating subdistrict (kecamatan) health 
center (Puskesmas), with 9 subsidiary village (kelurahan) health centers. The four story building covers 1,500 square meters and was established in 1994. Cilincing employs a physician as medical director and 3 midwives for $\mathrm{MCH} / \mathrm{FP}$ clinical services. Besides FP/MCH, the Puskesmas offers multiple medical services including inpatient deliveries, general medical, dental and optometry services.

\section{III.B.2 Pre-Intervention Needs Assessment: Health Care Provider (HCP) Knowledge Attitudes and Practices (KAP)}

Five in-depth interviews were conducted prior to the training intervention to obtain a baseline assessment of HCP experience, knowledge, and acceptance about the provision of RTI/STD services within the FP clinic. Three doctors were interviewed at Koja hospital and two midwives were interviewed at Puskesmas Cilincing, using a verbally administered structured questionnaire. Doctors were interviewed by the project officer (a physician), and midwives were interviewed by the research assistants. All of the interviewers attempted to employ a non-threatening manner. They conveyed a sense of informality in their verbal interviews to limit the appearance of scrutiny. Interviews were conducted after the clients had all been seen for the morning clinics. Unfortunately, both of these study sites are also used for another RTI/STD study sponsored by HAPP. This created a crowd of researchers obtaining baseline data through observations and interviews of clinical staff in the same time period. Consequently there was frustration among the clinical staff about repetitive questions from different interviewers. Fortunately for this study, our research assistants were the first to access the Puskemas and were able to interview fresh staff.

The length of employment for doctors in the hospital ranged from 10 to 23 years, with an average of 15 years of employment in the FP clinic. The two midwives had a much shorter duration of employment in their clinics, ranging from one month to two years. None of the five HCPs were able to give an estimate of the average number of FP clients seen in one month. 
All of the five HCPs reported that they had not diagnosed a single STD in the last six months. Two of the doctors had referred an FP client to the STD clinic in the past six months. One described the number of clients referred to the STD unit as "just a few". The other referring physician reported referring three clients to the STD clinic in the last six months.

The comparatively new midwives were unable to estimate or rank the most common RTI/STDs encountered in their clinical practices. All three of the doctors chose candidiasis and trichomoniasis as frequently encountered infections, with two choosing bacterial vaginosis and gonorrhea as the next most common infections seen in the FP clinic.

Two distinctly different perceptions of the main barriers to RTI/STD identification emerged from the midwives in contrast to the doctors. The midwives felt that FP clients were uneducated about signs of infection as well as being embarrassed to provide an accurate sexual history. Both midwives also felt that the lack of laboratory diagnostic procedures was a barrier to disease recognition. The three doctors did not attribute lack of disease identification to inherent qualities of the clients. One physician, despite a self-reported track record of not diagnosing any RTI/STDs in the last six months, believed that there were no existing barriers to disease recognition. This doctor believed that a disease recognition system producing an accurate rate of infection already existed in the clinic. A second doctor believed that there was not enough time in the busy daily schedule of FP services to include the additional work involved in STD detection. One reason cited was the difficulty in locating clients for follow-up since culture or serological results were not available until after the clients had left the clinic. Another perception of barriers to disease identification was that most FP clients could not afford to pay for additional laboratory diagnostic tests for diagnosis of RTI/STDs. The third physician felt that relatively rare use of laboratory tests was sufficient to support routine clinical recognition of RTI/STDs.

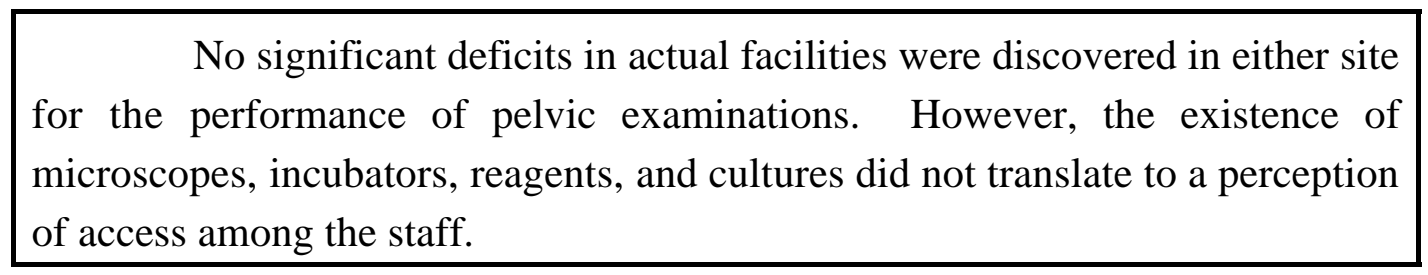

For a hypothetical female client complaining of genital discharge, no consistent pattern of ordering or performing wet mount microscopy to determine the causative organism for the vaginitis was evident from interviews. Only 1 of 5 HCPs acknowledged wet mount microscopy as a rapid diagnostic practice available and appropriate for such a clinical presentation. This HCP felt that the determining factor in whether or not this simple, inexpensive laboratory test was performed, was the economic status of the client. 
Doctors, in particular, embraced the conviction that their experience, and superior education superseded the need to include an etiological investigation of pathogens that caused vulvovaginitis. Actual patient interactions with these same doctors revealed that they never recognized more than one pathogen from an approach that only included listening to the client's description of the discharge, or less frequently, an investigation of the history and a visual examination of the vaginal environment.

In a related, but not directly measured indicator of reproductive health in this study, the HCPs were asked under what clinical circumstances they would order a Pap smear. A comparison of their responses follows:

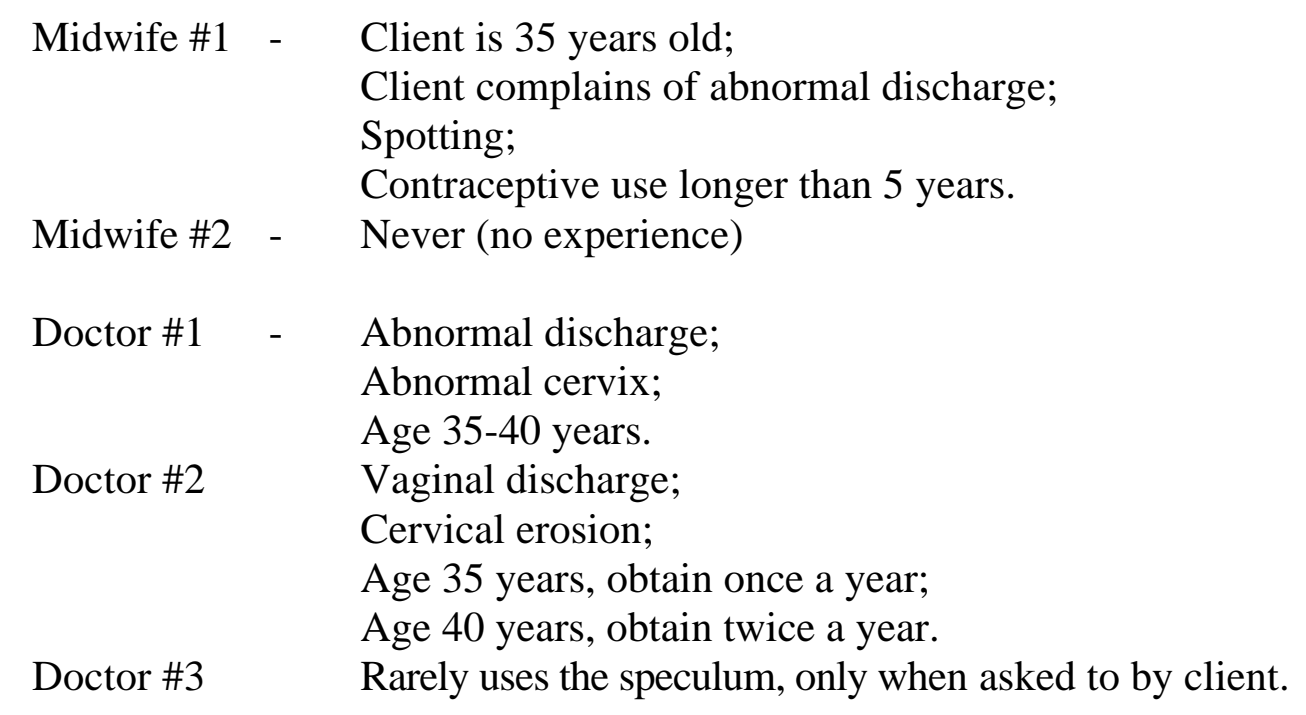

The above pattern of using a Pap smear for clinical presentations of vaginal discharge, indicates a misunderstanding of the purpose of cytological screening and would also increase the probability of false positive cytological results from inflammatory atypia.

The frequency of recommending that a cervical culture be obtained for the detection of gonorrhea was very low. Only one doctor recommended obtaining a culture if a client presented with vaginal discharge and also admitted any risk behavior in the history taking. This same doctor used these two indicators for recommending that serology be obtained for the detection of syphilis. Another doctor reported never using serology for syphilis in Koja hospital, but in other facilities he would do so if there was evidence of genital ulcers. The third doctor honestly admitted a lapse of memory on how to diagnose syphilis. Both of the midwives reported never recommending a test for syphilis. All 5 HCPs were unanimous in never having recommended that a client be tested for HIV infection. 
An analysis of medication prescription practices for candidiasis, gonorrhea, and chlamydia yielded vague responses reflecting a lack of knowledge among family planning HCPs. HCPs were asked to describe the drug of choice and the recommended dosage, frequency and duration of use for each regimen. The majority of the responses only included a name of the drug and not a precise measure for how much, when, and how long it should be taken for. The drugs mentioned were often not appropriate for the suspected organism.

Only 2 of the 3 doctors were able to refer to a specific antifungal medicine by name. One of these doctors also included a traditional regimen of "sirih" leaf water for some of the clients with candidiasis. One of the midwives was unable to cite a drug for the treatment of a yeast infection. The other midwife used a dual regimen of Metronidazole, which is not effective for eliminating candidiasis, along with a local cream "Albothyl", which is a condensation of metacresol sulfonic acid and methanal. In its undiluted state, Albothyl is a caustic agent that can debride wounds.

When the drug selections did have therapeutic efficacy for a targeted organism (such as Thiamphenicol for gonorrhea), were lacked knowledge of a standardized dosage and administration schedule. In reference to the practice of automatically providing additional treatment for chlamydia when a diagnosis of gonorrhea is made, none of the HCPs reported this to be a standard practice. One doctor consistently relied on the "economic status" of a client as a determinant for whether or not a prescription was offered. One of the midwives was unaware of the correct regimen for gonorrhea, and the other midwife mentioned the outdated and ineffective regimen of Ampicillin.

A frequent and resonating theme mentioned by both doctors and midwives was the difficulty of educating clients about reproductive tract infection, especially sexually transmitted infections. An investigation of the HCPs perceptions on the utility of educational resources such as flip charts, brochures, posters, etc. did not reveal a consensus on the utility of materials. The midwives who perceived their client's level of awareness as an important diagnostic determinant, were more inclined to think that all resources could be helpful for educating clients. Only one of the three doctors felt that brochures and pamphlets would be helpful. Two doctors specifically felt that written information was not helpful, and felt that direct communication was the best method of client education with regard to STD prevention. Although these two HCPs valued direct communication, they both felt that client education was a difficult and time consuming clinical practice.

HCPs were asked if they provided condoms with instructions to clients who were diagnosed with STDs. Two of the doctors responded that they never did this. One doctor responded that "occasionally" condoms were given. One midwife did not provide condoms, the other reported that she always provided condoms if the 
husband had a history of dysuria. A general feeling expressed by all HCPs was that it was unrealistic to expect an "ordinary housewife" to convince her spouse to use condoms. Both midwives also agreed that condoms promote immoral sexual behavior. Only one of the HCPs reported being "comfortable" discussing STDs with clients. All the other providers admitted that it was very difficult to be open about RTIs with their FP clients. One of the doctors felt that condoms were not efficacious in STD prevention, because they were uncomfortable and interfered with men's sexual pleasure. Two other doctors felt that good qualities condoms were helpful if used correctly. Another doctor expressed a strong belief that "condoms don't prevent STDs as effectively as abstinence".

This same physician who felt condoms were not effective againts STDs expressed many other opinions about STD management. He was candid about his habit of never telling a female FP client that she had an STD because it would make her feel uncomfortable and cause problems with her spouse. He also felt very confident making an etiological diagnosis based only on a history and visual exam. He felt that any pruritic vaginal discharge was a fungal infection, and any milky discharge with a bad odor and dysuria was Trichomonas vaginalis. He agreed that trichomoniasis was sexually transmitted, and would prescribe Metronidazole for both the client and her spouse. He would tell the women to give her husband the pills with the explanation that they would increase his sexual potency and performance. This same physician articulated the perception that RTI/STD case management was not connected to FP clinical care.

With the general level of discomfort among HCPs in discussing STDs with their clients, it was not surprising to learn that these same providers were not well informed about which STDs required concurrent treatment of the sexual partner. Both midwives in the Puskesmas reported that they did not know which infections should also include partner treatment. Since their job experience did not include the detection of STDs, they did not hesitate to say that they did not know.

Each HCP was specifically asked which of the 10 infections (candidiasis, trichomoniasis, bacterial vaginosis, gonorrhea, chlamydia, chancroid, syphilis, HSV, HPV and HIV) require partner treatment. One of the doctors responded that all clients with any signs of infection should have their partner evaluated at a clinic. Another doctor only identified trichomoniasis as an infection requiring partner treatment. The third doctor correctly identified trichomoniasis and gonorrhea as infections requiring partner treatment along with an incorrect identification of candidiasis and bacterial vaginosis in the same category. 


\section{III.B.3 Standardized Clinical Evaluation}

Based on the results of pre-intervention assessment, the development of a comprehensive, but pragmatic clinical evaluation procedures was necessary to standardize the intervention. This also served as a template for HCPs to absorb minimal quality of care behaviors integral to the performance of a pelvic examination for the detection of RTI/STDs. However it was necessary to minimize changes in HCP practice, limiting changes to those that are essential for both RTI/STD case management and contraceptive care. According to the World Health Organization guidelines (WHO, 1994:2), comprehensive STD case management should include:

- $\quad$ correct diagnosis

- $\quad$ effective treatment

- $\quad$ education on risk reduction and treatment

- $\quad$ promotion and provision of condoms

- $\quad$ clinical follow-up where appropriate.

These five components of STD case management were included in the standardized clinical evaluation. Two comparable clinical evaluations were studied during the course of this instrument development. The final clinical evaluation was a one page format that included essential RTI/STD evaluation elements (see Appendix A), although a four page evaluation was drafted. This four page draft provided more socio-demographic data and a thorough contraceptive history investigation. It was decided to use the abbreviated one page tool for HCP acceptability.

Unlike common RTI/STD prevalence studies where the history and risk assessment is obtained by field research staff, this study attempted to sharpen the skills of the HCP in obtaining an accurate history. Thus, in order to limit the demands on the busy HCP, who was also often culturally and professionally predisposed to avoiding candid sexual histories, an abridged sexual history form was used.

This study employed a non-hierarchical inventory of risk factors, clinical symptoms and signs, accompanied by serology and vaginal and endocervical specimen collection. This diagnostic investigation was etiological and not syndromic. It allowed for the determination of prevalence rates since all consenting clients were universally screened. It further allowed for comparison of sensitivity, specificity and positive predictive values among the various assessments that all clients were screened with (i.e., clinical assessment versus lab tests). 


\section{III.B.4 Clinical Practice Protocols}

Nine separate clinical protocols were developed to merge RTI/STD case management into the context of the family planning clinic setting (see Appendix D). These protocols served as the framework for training activities to help the HCPs develop the ability to introduce the subject of RTI/STDs to the FP client, and then proceed with examination, diagnosis, treatment and interventions. These protocols address the following contents areas:

\begin{tabular}{|c|c|}
\hline$\underline{\text { Protocol }}$ & $\underline{\text { Title }}$ \\
\hline I & Contraceptive Education \\
\hline II & Diseases of Women's Reproductive Organs \\
\hline III & Taking an Effective Reproductive Health History \\
\hline IV & Providing a Reproductive Health Physical Exam \\
\hline V & Laboratory Tests \\
\hline VI & Diagnosis and Case Management \\
\hline VII & RTI/STD Treatment Guidelines \\
\hline VIII & Client Education and Counseling \\
\hline IX & Infection Control \\
\hline
\end{tabular}

\section{III.B.5 Training Programs}

Training family planning HCPs to expand their awareness and normal clinical routine to include a vigilant consideration of RTI/STDs in every single client demanded large scale professional consciousness-raising.

This demand could not be met by a single training event, but rather required close project monitoring and post-training supervisory trouble-shooting activities.

HCPs were induced to participate in training activities by multiple incentives, including:

- attendance of department head and institution management at major training activities;

- attendance of outside professional "mascots" which were also project advisory board members at training programs;

- financial reimbursement for "missed opportunity costs" due to attendance;

- the chance to improve professional expertise by gaining applied knowledge for enhancing private practice. 
The following summary of the training process shows the scope and diversity of training efforts. The pre-intervention collection of baseline data on HCPs knowledge, attitudes and practices (KAP) revealed a strong aversion among the specialists/ physicians to the concept of training and the amount of time it would require. This aversion was not expressed by the midwives. To accommodate the perception that training was not needed by "expert/experienced HCPs", and should not last as long as originally proposed, a new semantical and temporal approach was pursued. Instead of offering training on the clinical aspects of RTI/STD case management, a "Round-Table Discussion" was conducted as the initial training activity. Instead of the original five day presentation, the curriculum was presented in multiple half-day doses. The published time schedule of a total of four hours per day, transformed in reality to a six-hour day of "discussion" to include all the learning objectives targeted in the original plan (see Table 3) and Appendix E : Workshop Reports, includes a greater description of these training activities. 
Table 3: $\quad$ Training Activities Summary, January-April 1997

\begin{tabular}{|c|c|c|c|c|c|}
\hline Date & $\begin{array}{l}\text { Workshop } \\
\text { Topics }\end{array}$ & Length & Trainers & Site & $\begin{array}{l}\text { Personnel } \\
\text { Trained }\end{array}$ \\
\hline $\begin{array}{l}\text { Jan } \\
24-25\end{array}$ & $\begin{array}{l}\text { Round Table } \\
\text { Discussion }\end{array}$ & 2 days & $\begin{array}{l}\text { Combined Advisory } \\
\text { Board }\end{array}$ & $\begin{array}{l}\text { Koja Hospital } \\
\text { Conference } \\
\text { Room }\end{array}$ & $\begin{array}{l}\text { Combined FP } \\
\text { staff from Koja } \\
\text { Hospital \& } \\
\text { Cilincing PHC } \\
\text { (Doctors, } \\
\text { midwives, \& lab) }\end{array}$ \\
\hline $\begin{array}{l}\text { Jan } \\
28-29\end{array}$ & $\begin{array}{l}\text { Clinical } \\
\text { specimen } \\
\text { collection \& lab } \\
\text { analysis }\end{array}$ & $\begin{array}{l}2 \text { half } \\
\text { days }\end{array}$ & $\begin{array}{l}\text { RSCM STD clinic staff, } \\
\text { led by } \\
\text { Dr. Sjaiful F. Daili, } \\
\text { DSKK }\end{array}$ & Cilincing PHC & $\begin{array}{l}\text { Cilincing PHC } \\
\text { midwives \& lab }\end{array}$ \\
\hline Jan 31 & $\begin{array}{l}\text { Lab testing } \\
\text { procedures }\end{array}$ & half day & RSCM STD clinic staff & Cilincing PHC & $\begin{array}{l}\text { Cilincing PHC } \\
\text { lab }\end{array}$ \\
\hline Feb 5 & $\begin{array}{l}\text { Refreshing HCP } \\
\text { clinical skills } \\
\text { on counseling } \\
\text { and infection } \\
\text { control }\end{array}$ & half day & $\begin{array}{l}\text { Dr. F. Sumampouw, DAJ, } \\
\text { MPH \& } \\
\text { Dr. Djajadilaga, DSOG }\end{array}$ & $\begin{array}{l}\text { Koja Hospital } \\
\text { dormitory } \\
\text { classroom }\end{array}$ & $\begin{array}{l}\text { Combined from } \\
\text { Doctors, } \\
\text { midwives Koja } \\
\text { \& Cilincing }\end{array}$ \\
\hline Feb 5 & $\begin{array}{l}\text { Clinical } \\
\text { specimen } \\
\text { collection \& } \\
\text { preparation }\end{array}$ & half day & RSCM STD clinic staff & $\begin{array}{l}\text { Koja Hospital } \\
\text { FP clinic }\end{array}$ & $\begin{array}{l}\text { Koja Hospital } \\
\text { medical staff }\end{array}$ \\
\hline Feb 7 & $\begin{array}{l}\text { Lab testing } \\
\text { procedures }\end{array}$ & half day & RSCM STD lab staff & $\begin{array}{l}\text { Koja Hospital } \\
\text { lab }\end{array}$ & $\begin{array}{l}\text { Koja Hospital } \\
\text { lab staff }\end{array}$ \\
\hline $\begin{array}{l}\text { March } \\
21\end{array}$ & $\begin{array}{l}\text { RTI/STD case } \\
\text { management } \\
\text { update }\end{array}$ & $\begin{array}{l}\text { quarter } \\
\text { day }\end{array}$ & $\begin{array}{l}\text { Dr. Iskandar \& } \\
\text { C. Vickers }\end{array}$ & Cilincing PHC & $\begin{array}{l}\text { Cilincing PHC } \\
\text { midwives and } \\
\text { lab staff }\end{array}$ \\
\hline $\begin{array}{l}\text { March } \\
25\end{array}$ & $\begin{array}{l}\text { RTI/STDcase } \\
\text { management } \\
\text { update }\end{array}$ & $\begin{array}{l}\text { quarter } \\
\text { day }\end{array}$ & $\begin{array}{l}\text { Dr. Iskandar \& } \\
\text { C. Vickers }\end{array}$ & Koja Hospital & $\begin{array}{l}\text { Koja Hospital } \\
\text { medical \& lab } \\
\text { staff }\end{array}$ \\
\hline $\begin{array}{l}\text { April } \\
21\end{array}$ & $\begin{array}{l}\text { Communication } \\
\& \text { infection } \\
\text { control skills }\end{array}$ & $\begin{array}{l}\text { quarter } \\
\text { day }\end{array}$ & $\begin{array}{l}\text { Dr. F. Sumampouw, DAJ, } \\
\text { MPH \& Senior Midwife } \\
\text { Coos Leiwakabessy }\end{array}$ & Cilincing PHC & $\begin{array}{l}\text { Cilincing PHC } \\
\text { midwives, lab \& } \\
\text { nursing staff }\end{array}$ \\
\hline
\end{tabular}

RSCM = referral laboratory at Cipto Mangunkusumo Hospital

The initial "Round-Table Discussion" conducted in two parts on Friday, January 24th and Saturday, January 25th at Koja Hospital initiated the series of training activities. This was the longest and most formal training program of the project. The hospital contributed a large conference room with audiovisual equipment, tables, chairs, and microphones. It also provided valuable feedback from the HCP participants about their reactions to the protocols and the expectations of the research. This process of collaboration and feedback was important to instill a sense of ownership among HCP and the project Advisory Board.

Providing small-dose training sessions over a long period meant that trainers and investigators periodically visited the sites and could observe problems 
and successes with the implementation of the new protocols. This allowed for remedial instruction in subsequent training, as well as refinement of the protocols prior to data collection on clients. The process of utilizing members of the advisory board as trainers allowed for supervisory visits as envisioned in the original work plan. However, rather than doing a checklist style of supervision, the supervisor used the RAs records on $\mathrm{HCP} /$ client interaction to guide discussions. The checklist inventory was given to each HCP as a tool to assess their own progress in integrating the written protocols and formal instruction with actual client care (see Appendix F for the itemized HCP skills inventory that was utilized throughout the supervisory visits).

An evaluation of the impact of the training activities on actual HCP behavior change was designed through the daily observations of each $\mathrm{HCP} / \mathrm{client}$ interaction (see Appendix G). An additional gauge of the impact of the training is the comparison of pre-training rates of RTI/STD disease recognition (determined through the retrospective six month medical record review), and the rates of confirmed positive findings obtained during the course of the study. The results of these analyses are discussed in section III.D. Findings and Results.

\section{III.B.6 Advisory Board}

The creation of the advisory board as described earlier in section III.A (Management), was simultaneously an accomplishment and a constraint. It was anticipated in the design of this study that the feasibility of integrating additional work and services into an already well-established and busy FP program would require broad support from leaders in influential positions. It was also a carefully considered choice to utilize persons with leadership and solid clinical expertise in the practice of reproductive health in Indonesia as training instructors. As a result, these advisory board members brought credibility and expertise in family medicine, obstetrics \& gynecology, public health, mental health and dermatovenereology to the training program. This diverse constituency of successful practitioners set a new standard and simultaneously lent a "reality-check" to the tone of the training sessions.

A frequently expressed concern by more than one member of the $\mathrm{HCP}$ trainee group during the first workshop was the inherent difficulty in discussing the need for partner treatment for STDs. The advisory board of instructors possessed the professional authority and experience to acknowledge the difficulty while emphasizing the primacy of not neglecting realistic partner treatment plans for every client diagnosed with an STD. 


\section{III.B.7 RTI/STD Treatment Formulary}

Three sources were used to compare and contrast RTI/STD treatment guidelines; (1) the national guidelines, as recently published by the $\mathrm{MOH}$ for the Republic of Indonesia (RI), (2) the 1993 STD Treatment Guidelines as published by the Centers for Disease Control in Atlanta Georgia (MMWR, 1993), and (3) the guidelines recommended by the World Health Organization (WHO, 1994). The final treatment guidelines used by this project were the guidelines from the $\mathrm{MOH}$ for the RI (Daili, et al., 1996) (see Appendix H for a summary of the contrasted regimens from the $\mathrm{MOH}, \mathrm{CDC}$, and $\mathrm{WHO}$ ). Pharmaceutical supplies were purchased and pre-packaged for individual distribution as indicated either by the initial clinical diagnosis or the final laboratory diagnosis. Table 4 displays the final RTI/STD formulary used in this project. 


\begin{tabular}{|c|c|c|c|}
\hline Drug & Infection & Dose/per person & Pregnancy \\
\hline Metronidazole & $\begin{array}{l}\text { Trichomoniasis } \\
* \text { \& Bacterial } \\
\text { Vaginosis }\end{array}$ & $\begin{array}{l}2 \text { grams- oral single } \\
\text { dose- (tablets) }\end{array}$ & $\begin{array}{l}\text { Contraindicated } \\
\text { in 1st Trimester }\end{array}$ \\
\hline $\begin{array}{l}\text { Clotrimazole } \\
(\text { Canesten } \\
\left.\mathrm{SD}^{\circledR}\right)\end{array}$ & Candidiasis & $\begin{array}{l}500 \text { mg. per day } \\
\text { single dose } \\
\text { (vaginal suppositories) }\end{array}$ & $\begin{array}{l}\text { Not a } \\
\text { contraindication }\end{array}$ \\
\hline $\begin{array}{l}\text { Fluconazole } \\
\left(\text { Diflucan }^{\circledR}\right)\end{array}$ & Candidiasis & $\begin{array}{l}150 \mathrm{mg} \text { oral single dose } \\
\text { (tablet) contraindicated } \\
\text { in liver disease }\end{array}$ & $\begin{array}{l}\text { Contraindicated } \\
\text { in pregnancy \& } \\
\text { lactation }\end{array}$ \\
\hline Ciprofloxacin & Gonorrhea* & $\begin{array}{l}500 \mathrm{mg} \text { oral single dose } \\
\text { (tablets) }\end{array}$ & $\begin{array}{l}\text { Contraindicated } \\
\text { in pregnancy } \\
\text { use } \\
\text { Spectinomycin }\end{array}$ \\
\hline $\begin{array}{l}\text { Spectinomycin } \\
\left(\text { Trobicin }^{\circledR}\right)\end{array}$ & $\begin{array}{l}\text { Gonorrhea* } \\
\text { for pregnant } \\
\text { women }\end{array}$ & $\begin{array}{l}2 \text { grams IM single dose } \\
\text { (Injection-divide dose in } \\
\text { half for each buttock } \\
\text { must use } 2 \text { needles \& } \\
\text { syringes) }\end{array}$ & $\begin{array}{l}\text { Not a } \\
\text { contraindication }\end{array}$ \\
\hline $\begin{array}{l}\text { Doxycycline } \\
\left(\text { Vibramycin }^{\circledR}\right)\end{array}$ & Chlamydia* & $\begin{array}{l}100 \mathrm{mg} \text { oral twice a day, } \\
\text { for } 7 \text { days (tablets) }\end{array}$ & $\begin{array}{l}\text { Contraindicated } \\
\text { in pregnancy } \\
\text { Use } \\
\text { Erythromycin }\end{array}$ \\
\hline Erythromycin & $\begin{array}{l}\text { Chlamydia* } \\
\text { for pregnant } \\
\text { women, and } \\
\text { Chancroid* }\end{array}$ & $\begin{array}{l}500 \mathrm{mg} \text {.- oral four times } \\
\text { a day, for } 7 \text { days } \\
\text { (tablets) }\end{array}$ & $\begin{array}{l}\text { Not a } \\
\text { contraindication }\end{array}$ \\
\hline $\begin{array}{l}\text { Benzathine } \\
\text { penicillin } G\end{array}$ & $\begin{array}{l}\text { Syphilis* } \\
\text { (Must do } \\
\text { follow-up } \\
\text { exams \& titered } \\
\text { serologies to } \\
\text { test Rx } 3 \text { \& } 6 \\
\text { months after } \\
\text { Rx) }\end{array}$ & $\begin{array}{l}2.4 \text { million Units IM, } \\
\text { single dose if confirmed } \\
\text { primary case, or } \\
3 \text { weekly doses if } \\
\text { duration is longer than } 2 \\
\text { years, or of } \\
\text { undetermined duration. } \\
\text { (Injection) }\end{array}$ & $\begin{array}{l}\text { Not a } \\
\text { contraindication }\end{array}$ \\
\hline
\end{tabular}

* These RTI/STDs MUST include treatment for the client \& her partner(s). A specific note was given to HCPs stating the following warnings: "If you do not provide a treatment for the partner(s), your client will become reinfected. Remember to always check the medical history for a possibility of allergies, pregnancy, or other medical conditions before choosing a treatment". 


\section{III.B.8 Treatment Cost Implications}

A market survey of current prices for individual treatments for each treatment regimen was conducted. This was not a full cost analysis, but just a quick survey to determine the actual cost of one complete treatment for all of the recommended RTI/STD regimens included in the National Treatment Guidelines from Indonesia. The results of this market survey are included in Appendix I.

\section{III.B.9 IEC Development}

Although the original proposal did not include the development of IEC materials, the need to use a quick "Ice Breaking" visual symbol to introduce the topic of RTI/STDs to clients, became apparent. A local laboratory technician, who is also an artist sketched two cartoons. The content was culturally recognizable to Indonesian people. He transferred his knowledge of microbiology to blend with well-known colloquialisms to represent individual STDs. This cartoon also served as a teaching aids to describe possible symptom a women might experience if she were infected. The cartoons were laminated into a one page tool for the HCP to introduce this study to clients. The cartoons are shown in Appendix $\mathbf{J}$.

\section{III.C Constraints}

The role of the advisory board of subject matter experts expanded from advisor to a more intimate involvement as protocol editors and workshop instructors mascots. This increased programmatic involvement contributed to an increase of opinions on how to implement RTI/STD into FP services. This team of strong professionals included members from different professional disciplines, and some members were strongly opposed to giving equal status as instructors and advisors to other members. Fortunately, the majority of advisors shared a dedication to the overall goal of the project and were flexible enough to accommodate less flexible members. As described in a paper from Family Health International (Hardee \&Yount, 1995) on the subject of integrating previously separate services: "Fear of takeover and loss of status or career prospects create barriers to effective collaboration" (see also Laing, 1981).

The different medical disciplines to be integrated (STDs and family planning) have a different view and set of priorities when looking at the same client, even when they examine the same organ system. The dermatovenereologist may be keenly interested in the cervix, and neglect the rest of the uterus in performing a pelvic exam, because it has diminished diagnostic yield for the detection of STDs. The family planning specialist on the other hand, performs a bimanual examination routinely, but may neglect a speculum for visual assessment of the cervix.

The revised plan of performing universal screening for all six selected RTIs on all consenting clients created an additional ethical requirement of submitting 
the proposal to the Institutional Review Board (IRB) of the Population Council. This required the inclusion of a formal informed consent procedure. HCPs in the study sites felt that this was a barrier to gaining maximum client participation in the study. It did

create another demand on the part of the field staff to do more recording and reporting. A copy of the individualized consent form, which was also used to determine a plan for follow-up care is included in Appendix $\mathbf{K}$.

A philosophical constraint was evident among HCPs about the relative importance of some of the individualized tasks that accompanied the research process and the detection of RTI/STDs.

It was apparent that the technological update to using a speculum to perform a bimanual examination and obtaining specimens for microscopy, culture and serological analysis were easily accepted by all HCPs. The doctors were very willing to participate in the scientific evaluation process by performing physical tasks, even though they had not been a part of their prior routine. It was not anticipated that the greatest HCP resistance would be in the area of provider/client communication. Specifically, the doctors did not perceive performing client education as a scientific or medical task.

While the doctors and midwives were very willing to learn and perform the high-tech evaluative practices, they were also eager to delegate the tasks of obtaining informed consent, and the standardized thirteen question history to the neutral research assistants (RAs). Recording and reporting the results of the clinical evaluation were also perceived as undesirable tasks which these HCPs were eager to delegate to the RAs or other staff. This resistance shows a devaluation of some clinical evaluation components. A medical model emerged with two distinct sets of practices which HCPs were either willing or unwilling to perform depending on the perceived clinical technology associated with them. This can be summarized as follows:

\begin{tabular}{|c|c|c|c|}
\hline & & \multicolumn{2}{|c|}{ HCP Willingness to Perform } \\
\hline & & High & Low \\
\hline \multirow{2}{*}{$\begin{array}{l}\text { Clinical } \\
\text { Technology } \\
\text { Perceived }\end{array}$} & High & $\begin{array}{ll}\text { - } & \text { Physical examinations } \\
\text { - } & \text { Lab specimen collect } \\
& \text { Prescription of medicine }\end{array}$ & - \\
\hline & Low & - & $\begin{array}{ll}\text { - } & \text { Interpersonal } \\
\text { - } & \text { communication } \\
\text { - } & \text { Client edacating } \\
\text { - } & \text { Reporting and recording }\end{array}$ \\
\hline
\end{tabular}

Clearly the HCPs placed a greater value on the high-tech evaluative practices. The challenge of trying to work with this constraint prompted two workshops in which the less valued areas of practice were discussed. A connection 
between not performing them and a client's likely reinfection (i.e., a reversal of all their high-tech work of examining, testing and treating) was attempted.

A cultural concern not to cause any loss of face to a client by honestly disclosing a diagnosis of STD, and the need for partner treatment, far outweighed any logistical constraints of finances, facilities and supplies. There seemed to be a professional blindness to the necessity of treating a sexual partner in order to prevent a reinfection of the index client.

The most illustrative example of this phenomena occurred during one of the on site clinical training sessions. At the Puskesmas one client who was having her first pelvic exam, and coincidentally was also four months pregnant, was discovered to have mucopurulent cervicitis with a Gram stain showing more than 30 polymorphonuclear leukocytes (PMNs) per high power field. The STD specialist physician who was training the midwives to correctly obtain vaginal and cervical specimens told this woman she had an infection that required treatment. The doctor prescribed 500 milligrams (mg) of Erythromycin four times a day for seven days.

The doctor was able to stress the importance of completing the prescription for the health of the client and her unborn baby. However, the potential need for treatment of the spouse/sexual partner was not mentioned. When interviewed by the research staff about not mentioning treatment for both partners, the reply was: "it is very difficult for us (Indonesians) to talk about partner treatment".

Later, the doctor express a high index of suspicion that the cause of this pregnant woman's mucopurulent cervicitis was infection with chlamydia trachomatis. This suspicion motivated the recommendation of the prescription of Erythromycin. Most experienced STD specialists would agree that a diagnosis of an STD would be premature at this stage, even though a purely syndromic model of care would justify such a diagnosis and treatment plan. However, at a minimum, an ethical need to inform the pregnant client of actions she can take to prevent herself from possible reinfection via sexual intercourse with a potentially infected partner, prior to receiving the final laboratory results, seemed called for. The dissonance between client treatment based on a syndromic diagnosis and a final etiological diagnosis will be discussed later in section III.D. Findings and Results. 
Even for infections with positive STD lab tests, there was a distinct trend to provide a prescription for the index client, while not disclosing the need for concurrent partners therapy. This reluctance was not only evidenced by HCPs reglecting of document to a treatment plan on the clinical evaluation flow sheet, but was frequently in evidence during the $\mathrm{HCP} /$ client observations audited by the research assistants.

A logistical constraint prevented getting the laboratory reports back to the clinic and client in a timely manner, slowing the rate at which a final diagnosis could be reached. The Koja hospital laboratory would hold the Gram stains until they had accrued a sufficient "batch" to do group staining and reading. This resulted in Gram stain reports taking an average of 2-4 hours after the completion of the clinical evaluation. Since saline wet mount microscopy did not require staining and did require a quicker interpretation, the only RTI that was ever reported in the hospital prior to the client departing the site was Trichomonas vaginalis. Wet mount microscopy reports were returned in ten minutes in the hospital. Although the Puskesmas did not hold Gram stains for batching, they had a larger number of clients at each clinic, and could not turn around a laboratory report before the client left the clinic.

A further constraint in receiving timely laboratory reports was also encountered from the referral laboratory. During the 12 weeks of observation there were insufficient chlamydia test kits and gonorrhea culture plates to provide testing for each study participant. Another constraint at the referral lab was the excessive demands on the laboratory technician to read all the Gram stains and endocervical tests for gonorrhea and chlamydia. The head of the STD department required the technician to submit slides to him for concurrence in the case of a positive judgement of infection. Thus, whenever the department head was unavailable or out of town, final reports were delayed until his return. This practice resulted in a turn around time of one to four weeks for final laboratory reports. The referral laboratory also pooled chlamydia tests until they had batches of five specimens which added to the delay in some cases.

In the process of specimen collection, another problem observed was the high frequency of improper swab placement and insufficient absorption time, especially in week 1-4. Specifically for gonorrhea, cross-streaking the swab over the surface of the agar in 3 directions might have been done poorly in the first weeks. 


\section{III.D Findings and Results}

Of the 478 clients who presented to one of the two FP clinics in the 12 weeks, $89 \%$ (425) were willing to become study participants. Figure 1 shows the reasons for the exclusion of a further 113 clients and figure 2 shows the reasons why 53 of the original clients chose not to participate. The final study sample was 312 .

Figure 1. Exclusion of Study Participants

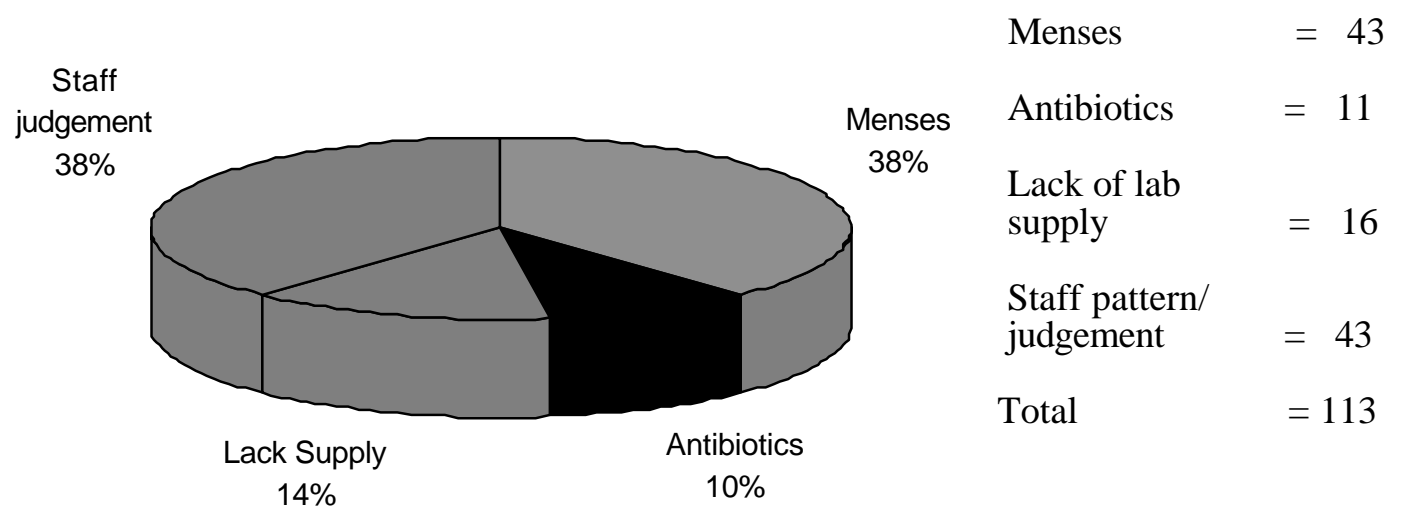

Figure 2. Clients Reasons for Refusing Participation in the Study

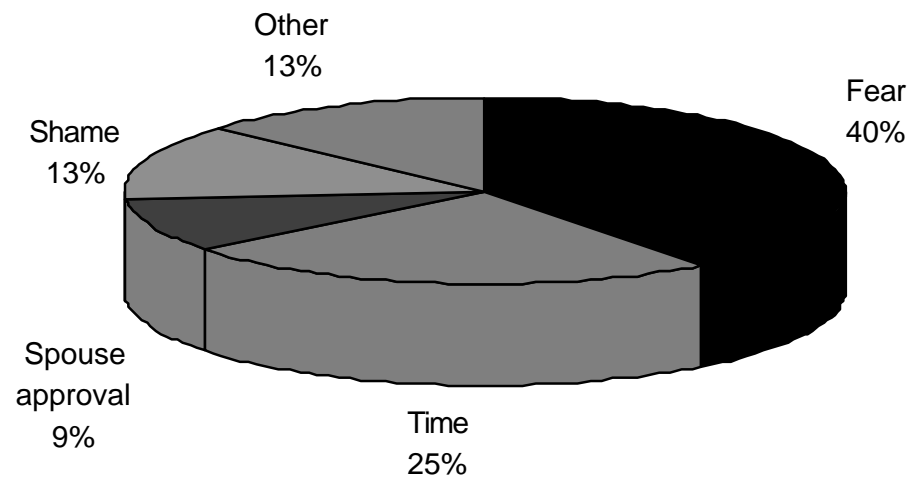

$\begin{array}{ll}\text { Fear of exam } & =21 \\ \begin{array}{l}\text { Evaluation too } \\ \text { time consuming }\end{array} & =13 \\ \begin{array}{l}\text { Wanted spouse } \\ \text { approval }\end{array} & =5 \\ \begin{array}{l}\text { Pelvic exam too } \\ \text { shame full }\end{array} & 7 \\ \text { Other } & =7\end{array}$

Total $=53$

By the fourth week of the study period, the RAs observed that additional new FP clients were presenting to the clinic specifically to obtain the RTI evaluation. They had heard of the "free" study from their female friends who had already been evaluated, and expressed a desire to also be examined. Certainly, the provision of "free"medicine had the effect of drawing more study participants, possibly introducing self-selection bias into the study. 
Only one women was widowed/divorced. The remainings 311 were all married. The most common contraceptive method employed by the FP clients in both clinic study site in North Jakarta was hormonal injection. Table 5 illustrates the breakdown of contraceptive methods reported by study participants.

Table 5: $\quad$ Contraceptive Method Use Reported by Clients

\begin{tabular}{|c|c|c|c|c|}
\hline \multirow[t]{2}{*}{ Contraceptive Method } & $\begin{array}{c}\text { Koja } \\
\text { Hospital } \\
\text { N=144 }\end{array}$ & $\begin{array}{c}\text { Puskesmas } \\
\text { Cilincing } \\
\mathrm{N}=168\end{array}$ & \multicolumn{2}{|c|}{$\begin{array}{c}\text { Combined } \\
\text { Clinics } \\
\mathrm{N}=\mathbf{3 1 2}\end{array}$} \\
\hline & n $\quad(\%)$ & n $\quad(\%)$ & & $(\%)$ \\
\hline Injectable Hormones & $62 \quad(43.0)$ & $\begin{array}{l}53 \\
(31.5)\end{array}$ & 115 & $(36.9)$ \\
\hline Intrauterine Device (IUD) & $47 \quad(32.6)$ & $\begin{array}{l}34 \\
(20.2)\end{array}$ & 81 & $(26.0)$ \\
\hline Pills & $20 \quad(13.9)$ & $\begin{array}{l}52 \\
(31.0)\end{array}$ & 72 & $(23.0)$ \\
\hline Sterilization & $(6.3)$ & $(0.0)$ & 9 & $(2.9)$ \\
\hline Norplant & $(2.1)$ & $(1.2)$ & 5 & $(1.6)$ \\
\hline Condoms & $(2.1)$ & $(3.0)$ & 8 & $(2.6)$ \\
\hline Other & $0 \quad(0.0)$ & $(0.6)$ & 1 & $(0.3)$ \\
\hline Not using contraceptive & $(0.0)$ & $\begin{array}{l}20 \\
(11.9) \\
\end{array}$ & 20 & $(6.4)$ \\
\hline Not reported & $0 \quad(0.0)$ & $(0.6)$ & 1 & $(0.3)$ \\
\hline
\end{tabular}

To simplify the history taking procedure and to direct the HCP to consider history variables that are strongly associated with a risk for STD infection, the client's age was coded as being either younger than 25, or 25 and over (see Table 7). For 312 participants, the actual ages ranged between 19 and 52 years, with a mean age of 32.6 (36 missing values). 


\section{III.D.1 Prevalence Rates of RTI/STDs and Associated Factors}

The prevalence level of the six tested RTIs is shown in Table 6. A total of 86 separate RTIs diagnoses in 77 individual clients were confirmed by the referral laboratory. Nine clients tested positive for more than one RTI. Although a total of 312 women were examined, the full range of specimens was not obtained for some clients, either due to a lack of test supplies furnished by the referral laboratory, or due to the client's refusal to submit a blood sample. Following are the actual counts of each specimen type: 301 for chlamydia, 309 for gonorrhea cultures and 302 serology samples for the Rapid Plasma Reagin (RPR) test. Chlamydia trachomatis was the most prevalent RTI found in $10.3 \%$ of the tested participants. Only one client tested positive for N. Gonorrhoeae, and none of 302 RPR tests were positive for syphilis. Following is a full list of lab tests performed:

\begin{tabular}{|lrrr|}
\hline & Koja & Cilincing & Combined \\
Gram stains & 144 & 168 & 312 \\
Wet Mounts & 144 & 167 & 311 \\
Chlamydia tests & 143 & 158 & 301 \\
Gonorrhea cultures & 143 & 166 & 309 \\
RPR & 139 & 163 & 302 \\
\hline
\end{tabular}

Table 6:

Prevalences of Confirmed RTIs in the Two FP Clinics

\begin{tabular}{|l|cc|cc|cr|}
\hline \multirow{2}{*}{$\begin{array}{c}\text { Reproductive Tract } \\
\text { Infections }\end{array}$} & \multicolumn{2}{|c|}{$\begin{array}{c}\text { Koja Hospital } \\
\text { N=144* }\end{array}$} & \multicolumn{2}{|c|}{$\begin{array}{c}\text { Puskesmas } \\
\text { Cilincing } \\
\text { N=168* }\end{array}$} & \multicolumn{2}{|c|}{$\begin{array}{c}\text { Combined } \\
\text { Clinics } \\
\text { N=312* }\end{array}$} \\
\cline { 2 - 8 } & $\mathbf{n}$ & $(\boldsymbol{\%})^{*}$ & $\mathbf{n}$ & $(\boldsymbol{\%}) *$ & $\mathbf{n}$ & $(\%)^{*}$ \\
\hline Candidiasis & 11 & $(7.6)$ & 10 & $(5.9)$ & 21 & $(6.7)$ \\
\hline Bacterial Vaginosis & 8 & $(5.5)$ & 8 & $(4.8)$ & 16 & $(5.1)$ \\
\hline Trichomoniasis & 13 & $(9.0)$ & 4 & $(2.4)$ & 17 & $(5.4)$ \\
\hline Gonorrhea & 1 & $(0.7)$ & 0 & $(0.0)$ & 1 & $(0.3)$ \\
\hline Chlamydia & 18 & $(12.6)$ & 13 & $(8.3)$ & 31 & $(10.3)$ \\
\hline Syphilis & 0 & $(0.0)$ & 0 & $(0.0)$ & 0 & $(0.0)$ \\
\hline Any RTI & & & & & 77 & $(24.7)$ \\
\hline & & & & & 43 & $(13.8)$ \\
\hline
\end{tabular}

* There were 86 RTI/STDs diagnosed in 77 clients. Multiple infections were confirmed in 9 clients. Percentages were calculated on the actual number of tests performed for each infection, at the reference laboratory, RSCM. 
The following diagnostic criteria were used to confirm these RTIs:

1. Bacterial Vaginosis: Confirmed presence of clue cells visible in the Gram stain. $\mathrm{pH}$ was not measured. Amine odor $(\mathrm{KOH})$ was recorded but not directive of a diagnosis.

2. Candidiasis: Confirmed presence of hyphae and or budding yeast visible in the Gram stain.

3. Trichomoniasis: Evidence of motile trichomonads seen by clinic site laboratory staff on normal saline wet mount.

4. Chlamydia: Confirmed by positive antigen response with ELISA commercial kit.

5. Gonorrhea: Confirmed presence of gram negative intracellular diplococci visualized with Gram stain, and positive growth of colonies on culture.

6. Syphilis: By use of RPR test, with TPHA re-test for positive findings.

In addition to the three socio-demographic characteristic of marital status, contraceptive use and age, eleven potential risk factors for RTI/STD were also recorded for each study participant during history taking. Table 7 presents the frequency of positives for each risk factor, including age less than 25 as an additional risk factor ( $15 \%$ of the sample). Since all but one of the women were currently married and since contraceptive use is not a risk factor per se, these two characteristic are not included in Table 7. 
Table 7: $\quad$ Frequency of Positive Risk Findings Obtained During

\section{the History Taking}

\begin{tabular}{|c|c|c|c|c|c|c|}
\hline \multirow[t]{2}{*}{ Positive Risk Findings } & \multicolumn{2}{|c|}{$\begin{array}{c}\text { Koja Hospital } \\
\quad \mathrm{N}=\mathbf{1 4 4}\end{array}$} & \multicolumn{2}{|c|}{$\begin{array}{c}\text { Puskesmas } \\
\text { Cilincing } \\
\text { N=168 }\end{array}$} & \multicolumn{2}{|c|}{$\begin{array}{c}\text { Combined } \\
\text { Clinics } \\
\mathrm{N}=312\end{array}$} \\
\hline & $\mathbf{n}$ & & $\mathbf{n}$ & $(\%)$ & $\mathbf{n}$ & $(\%)$ \\
\hline 1. Age younger than 25 years & 22 & $(15.3)$ & 26 & $(15.5)$ & 48 & (15.4) \\
\hline 2. Past history of STD ever & 0 & $(0.0)$ & 5 & $(3.0)$ & 5 & (1.6) \\
\hline $\begin{array}{l}\text { 3. More than } 1 \text { sex partner in past } \\
3 \text { months }\end{array}$ & 0 & $(0.0)$ & 2 & $(1.2)$ & 2 & (0.6) \\
\hline $\begin{array}{l}\text { 4. Sexual intercourse without } \\
\text { condoms }\end{array}$ & 136 & (94.9) & 153 & $(91.1)$ & 289 & (92.6) \\
\hline $\begin{array}{l}\text { 5. Unusual vaginal discharge (bad } \\
\text { odor/color) }\end{array}$ & 78 & $(54.2)$ & 106 & $(63.1)$ & 184 & $(59.0)$ \\
\hline 6. Pain with urination & 25 & (17.4) & 26 & $(15.5)$ & 51 & $(16.3)$ \\
\hline 7. Lower abdominal pain & 59 & $(41.0)$ & 69 & $(41.1)$ & 128 & $(41.0)$ \\
\hline 8. Bleeding after intercourse & 14 & $(9.7)$ & 16 & $(9.5)$ & 30 & (9.6) \\
\hline 9. Genital sores or lumps & 14 & $(9.7)$ & 13 & (7.7) & 27 & (8.6) \\
\hline $\begin{array}{l}\text { 10. Sex partner with unusual } \\
\text { discharge from penis }\end{array}$ & 4 & $(2.8)$ & 2 & $(1.2)$ & 6 & (1.9) \\
\hline $\begin{array}{l}\text { 11. Sex partner with sores or lumps } \\
\text { on penis }\end{array}$ & 2 & (1.4) & 2 & $(1.2)$ & 4 & (1.3) \\
\hline 12. Sex partner not monogamous & 6 & $(4.2)$ & 2 & $(1.2)$ & 8 & (2.6) \\
\hline
\end{tabular}

Note: All refer to the past three months before the interview, except \#1 and \#2

It was noticed that clients had great deficits of information about common STD symptoms. There was a high level of uncertainty among study participants about the implication of penis discharge, lesions and monogamy, for their partners' potential STD status. However, during this study, FP clients did not receive any systematic educational intervention. It was hoped that HCPs would be prompted by the training to follow the flow chart and provide some counseling and education if indicated. However, as discussed earlier, this interaction was undervalued and generally reglected by the HCPs. There remains a great unmet need for information among this target population (FP clients). 
Turning to the physical examination, the HCPs were asked to record the presence or absence of 17 separate symptoms and signs. Table 8 presents these findings.

Table 8: $\quad$ Positive Physical Examination Findings in Two FP Clinics

\begin{tabular}{|c|c|c|c|c|c|c|}
\hline \multirow[t]{2}{*}{ Positive Physical Examination Findings } & \multicolumn{2}{|c|}{$\begin{array}{c}\text { Koja } \\
\text { Hospital } \\
\text { N=144 }\end{array}$} & \multicolumn{2}{|c|}{$\begin{array}{c}\text { Puskesmas } \\
\text { Cilincing } \\
\text { N=168 }\end{array}$} & \multicolumn{2}{|c|}{$\begin{array}{c}\text { Combined } \\
\text { Clinics } \\
\text { N=312 }\end{array}$} \\
\hline & n & $(\%)$ & $\mathbf{n}$ & $(\%)$ & $\mathbf{n}$ & $(\%)$ \\
\hline $\begin{array}{l}\text { 1. Skin rashes (includes trunk, palms, soles } \\
\text { of feet) }\end{array}$ & 1 & $(0.7)$ & 0 & $(0.0)$ & 1 & $(0.3)$ \\
\hline $\begin{array}{l}\text { 2. Abdominal masses, organomegally, } \\
\text { tenderness }\end{array}$ & 1 & $(0.7)$ & 1 & $(0.6)$ & 2 & $(0.6)$ \\
\hline 3. Inguinal lymphadenopathy & 2 & (1.4) & 0 & $(0.0)$ & 2 & (0.6) \\
\hline 4. External vulvar erythema/ inflammation & 11 & (7.6) & 2 & $(1.2)$ & 13 & $(4.2)$ \\
\hline 5. Urethral discharge & 0 & $(0.0)$ & 0 & $(0.0)$ & 0 & $(0.0)$ \\
\hline 6. External genital ulcers & 0 & $(0.0)$ & 0 & $(0.0)$ & 0 & $(0.0)$ \\
\hline 7. External genital lesions (wart, etc) & 0 & $(0.0)$ & 4 & $(2.4)$ & 4 & (1.3) \\
\hline 8. Vaginal inflammation (speculum) & 20 & (13.9) & 36 & (21.4) & 56 & $(17.9)$ \\
\hline 9. Abnormal vaginal discharge (speculum) & 14 & $(9.7)$ & 90 & (53.6) & 104 & $(33.3$ \\
\hline 10. Vaginal lesion/ulcers (speculum) & 1 & $(0.7)$ & 5 & $(3.0)$ & 6 & (1.9) \\
\hline 11. Cervical ectopy (speculum) & 1 & $(0.7)$ & 0 & $(0.0)$ & 1 & $(0.3)$ \\
\hline $\begin{array}{l}\text { 12. Cervical erythema/inflammation } \\
\text { (speculum) }\end{array}$ & & (31.9) & 55 & (32.7) & 101 & (32.4) \\
\hline 13. Cervical mucopus (speculum) & 63 & $(43.8)$ & 54 & $(32.1)$ & 117 & $(37.5)$ \\
\hline 14. Cervical friability (speculum) & 11 & $(7.6)$ & 8 & $(4.8)$ & 19 & $(6.15)$ \\
\hline 15. Cervical motion tenderness & 8 & $(5.6)$ & 2 & $(1.2)$ & 10 & (3.2) \\
\hline 16. Abnormal uterine size and/or shape & 2 & (1.4) & 1 & $(0.65)$ & 3 & (1.0) \\
\hline 17. Adnexal mass & 0 & $(0.0)$ & 0 & $(0.0)$ & 0 & $(0.0)$ \\
\hline
\end{tabular}

Note : Data were collected between February 17 and May 9, 1997

Approximately one third of women had signs of abnormal discharge, cervical erythema and cervical mucopus, however, the proportion with abnormal discharge was far higher at the hospital. Four women had genital lesions/warts and six had vaginal lesions/ulcers but none had external genital ulcers. 


\section{III.D.2 Parameters Related to Confirmed RTIs}

The associations between confirmed RTI diagnoses and client risk factors, symptoms and clinical signs (as measured by Odds Ratio and p-value) are, shown in Table 9. The only statistically significant $(p=0.02)$ association was for vaginal lesions/ulcers. However, the value of this statistic is limited by the small numbers of women experiencing this symptom.

Table 9: $\quad$ Client Characteristic, Risk Factors, Reported Symptom and Clinical Findings and Measures of Association with Infection Status

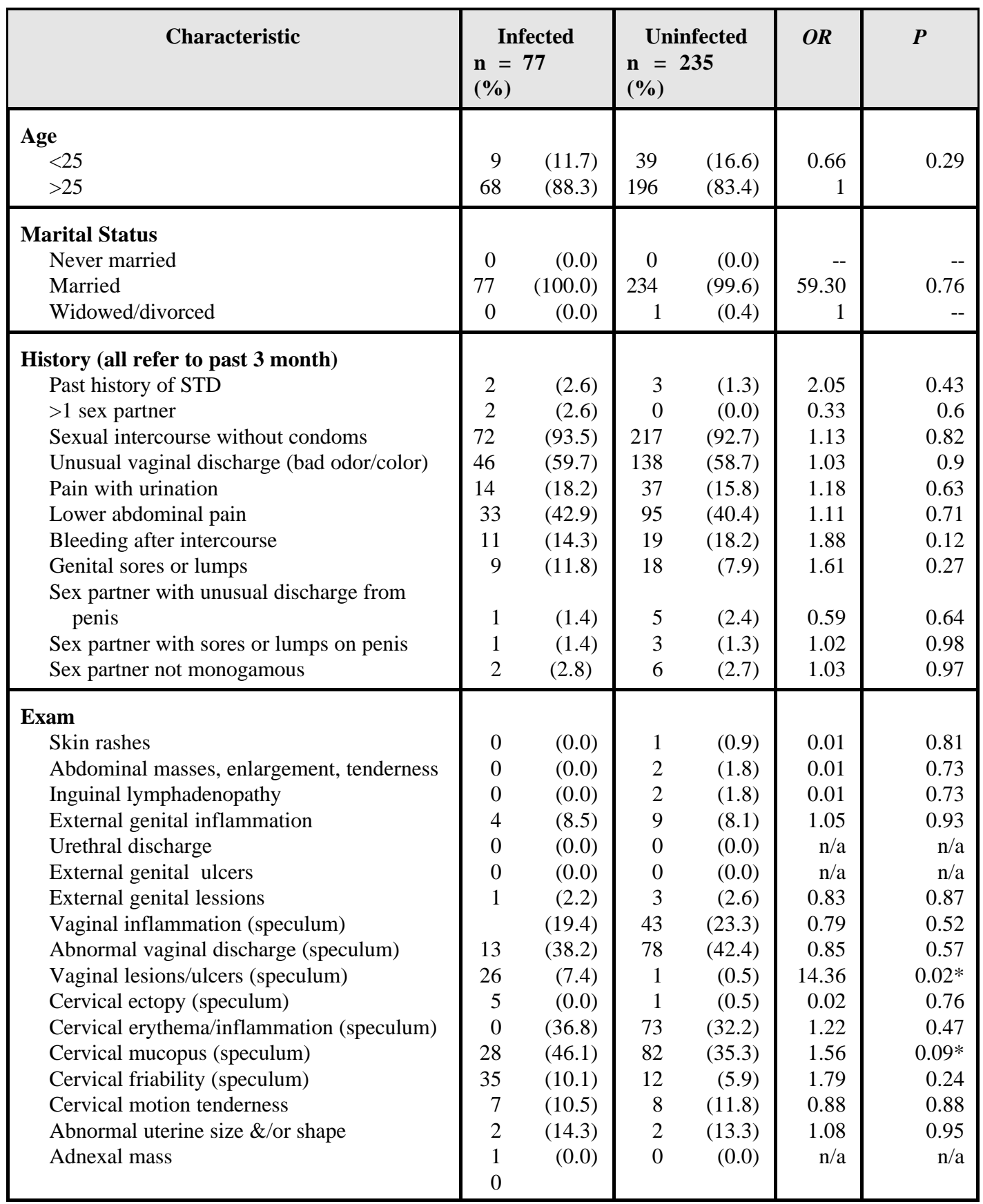

*Statistically significant $(<0.05)$ or boderline significant $(<0.1)$

Note : $\mathrm{n} / \mathrm{a}=$ measures of association were not calculated (not applicable) if there were zero values or very low numbers.

OR = Odds Ratio 


\section{III.D.3 Validation of Diagnostic Approaches for RTIs}

Although, of course, no laboratory test is infallible in determining the presence of each and every RTI, for the purposes of data analysis, the final laboratory results were used as an indicator of actual presence or absence of an RTI. This study provided the opportunity to compare initial clinical (or syndromic) diagnoses, made at the time of the clinical evaluation, with the results of the final confirmatory laboratory reports, of etiologic diagnosis. The results in Table 10 show a $42.6 \%$ of concurrence. The disparity represents both over- and under- diagnosing at both clinic sites. The doctors in the FP clinic at Koja Hospital achieved a higher rate of correct initial diagnoses (47.5\%) than the midwives at Puskesmas Cilincing (36.5\%). However in practice it should be noted that the final laboratory results were not used to override the independent judgment of the HCP if there was strong clinical evidence (multiple signs and risk factors) of infection after the history and examination had been completed. Table 10 illustrates the trends observed over the 12 weeks in the prevalence of infection and the level of concurrence between initial and final diagnoses in each FP clinic. This shows that while confirmed prevalence remained steady overall at about $25 \%$, the concurrence rates improved at the hospital but not at the Puskesmas. 
TABLE 10: Trends and Overall Rates of 1. Prevalence of Any RTI/STD

Diagnosis, and 2. Concurrence Between Initial Clinical

Diagnoses and Final Laboratory Diagnoses

\begin{tabular}{|c|c|c|c|c|c|}
\hline $\begin{array}{l}\text { Actual STD } \\
\text { Status }\end{array}$ & $\begin{array}{l}1 \text { st quarter } \\
\text { (weeks 1-3) }\end{array}$ & $\begin{array}{l}\text { 2nd quarter } \\
\text { (weeks 4-6) }\end{array}$ & $\begin{array}{l}\text { 3rd quarter } \\
\text { (weeks 7-9) }\end{array}$ & $\begin{array}{c}\text { 4th quarter } \\
\text { (weeks 10-12) }\end{array}$ & TOTAL \\
\hline $\begin{array}{l}\text { 1. Prevalence } \\
\text { of any } \\
\text { RTI/STD: } \\
\text { Koja Hospital } \\
\text { Cilincing PHC } \\
\text { Combined Sites }\end{array}$ & $\begin{array}{c}11 / 38 \quad(8.9 \%) \\
(21.2 \%)^{7 / 33} \\
18 / 71 \\
(25.4 \%)^{2}\end{array}$ & $\begin{array}{l}11 / 34(32.4 \%) \\
6 / 37(16.2 \%) \\
17 / 71 \quad(3.9 \%)\end{array}$ & $\begin{array}{r}14 / 38(36.8 \%) \\
9 / 46(19.6 \%) \\
23 / 8(27.4 \%)\end{array}$ & $\begin{array}{r}9 / 34(26.5 \%) \\
10 / 52 \\
(19.2 \%) \\
\\
19 / 86 \\
(22.1 \%)\end{array}$ & $\begin{array}{r}45 / 144 \\
(31.3 \%) \\
32 / 168(19.0 \%) \\
\\
77 / 312 \\
(24.7 \%)\end{array}$ \\
\hline $\begin{array}{l}\text { 2. Concurrence } \\
\text { between clinical } \\
\text { \& Lab } \\
\text { Diagnoses:* }\end{array}$ & & & & & \\
\hline Koja Hospital & $10 / 36(27.7 \%)$ & $15 / 34(44.1 \%)$ & $13 / 38(34.2 \%)$ & $20 / 33(60.6 \%)$ & $58 / 141(41.1 \%)$ \\
\hline Cilincing PHC & $7 / 10(70.0 \%)$ & $5 / 7(71.4 \%)$ & $15 / 47(31.0 \%)$ & $13 / 51(29.4 \%)$ & $40 / 115(34.8 \%)$ \\
\hline Combined Sites & $17 / 46(36.9 \%)$ & $20 / 4(48.8 \%)$ & $28 / 85(32.9 \%)$ & $33 / 84(39.3 \%)$ & $98 / 256(38.3 \%)$ \\
\hline
\end{tabular}

* 56 out of the 312 women (17.9\%) did not receive any clinical diagnosis (3 at Koja Hospital and 53 at Cilincing PHC), therefore concurrence can only be assessed in 256 of the cases.

Notes:

Actual Prevalence of RTI/STD was determined by any RTI/STD diagnoses made at the referral laboratory at RSCM between February 17 and May 9, 1997 (i.e. positive for bacterial vaginosis, candidiasis, trichomoniasis, gonorrhea and/or chlamydia)

Clinical Diagnoses in general, were based only on history risk assessment and physical examinations.

Concurrence includes (1) matches between positive clinical RTI/STD diagnoses and positive final RTI/STD diagnoses (note: only if the diagnosis was correct, eg. an initial diagnosis of bacterial vaginosis for a final diagnosis of candidiasis was not considered correct, but an initial diagnosis of cervicitis and a final of chlamydia was considered correct); and (2) matches between two negative diagnoses (note: initial recorded diagnoses which had no relation to potential RTI/STD, such as ammenhorrea or a problem with an IUD, were also considered negative diagnoses for our purposes here.)

As previously described, universal etiologic testing for six treatable RTIs was attempted on each client, which allowed the opportunity to compare the initial clinical diagnosis (or syndromic diagnosis) with the final laboratory confirmed diagnosis (or etiologic diagnosis). 
Further analyzing the concurrence and discordance of syndormic and etiologic diagnoses, Table 11 charts the false and correct negatives and positives, using the etiological diagnoses as the "true" diagnoses.

Table 11: Comparative Analysis of Syndromic with Etiologic Diagnoses

\begin{tabular}{|c|c|c|c|c|c|c|}
\hline \multirow{2}{*}{$\begin{array}{l}\text { Accuracy of initial clinical } \\
\text { (syndromic) diagnoses } \\
\text { compared with final } \\
\text { confirmed laboratory } \\
\text { (etiologic) diagnoses }\end{array}$} & \multicolumn{2}{|c|}{ Koja Hospital } & \multicolumn{2}{|c|}{$\begin{array}{c}\text { Puskesmas } \\
\text { Cilincing } \\
\text { N=115 }\end{array}$} & \multicolumn{2}{|c|}{$\begin{array}{c}\text { Combined } \\
\text { Clinics } \\
\mathrm{N}=256\end{array}$} \\
\hline & & $(\%)$ & $\mathbf{n}$ & $(\%)$ & $\mathbf{n}$ & $(\%)$ \\
\hline Correct positive diagnoses & 14 & $(9.9)$ & 5 & $(4.3)$ & 19 & $(7.4)$ \\
\hline False negative diagnoses & 54 & $(38.3)$ & 59 & $(51.3)$ & 113 & $(44.1)$ \\
\hline Correct negative diagnoses & 44 & $(31.2)$ & 35 & $(30.4)$ & 79 & $(30.9)$ \\
\hline False positive diagnoses & 29 & $(20.6)$ & 16 & $(14.0)$ & 45 & $(17.6)$ \\
\hline
\end{tabular}

*Note:

56 out of the 312 women $(17.9 \%$ ) did not receive any clinical diagnosis (3 at Koja Hospital and 53 at Puskesmas Cilincing ), therefore concurrence can only be assessed in 256 of the cases.

Correct positive $=$ syndromic and etiologic diagnoses agreed - both were positive

False negative = syndromic diagnosis was negative but the correct (etiologic) diagnosis was positive Correct negative $=$ syndromic and etiologic diagnoses agreed - both were negative

False positive = syndromic diagnosis was positive but the correct (etiologic) diagnosis was negative

A total of 19 clients from both clinic sites (14 from Koja and 5 from Cilincing), had correct initial positive diagnoses. A total of 79 clients from both clinic sites had correct "Normal" (negative) diagnoses. This combined diagnostic accuracy rate yielded a total of 98 clients $(38.3 \%)$ who were correctly diagnosed at the time of the initial clinical evaluation.

A higher number of clients received false syndromic diagnoses $(113+45=158)$ than received correct syndromic diagnoses $(19+79=98)$. The most likely diagnosis was a false negative $(44.1 \%)$. 
During the first quarter of the study, there was a high degree of reluctance by the midwives to render a clinical diagnosis without laboratory confirmation. The midwives had a much higher rate of making no initial diagnosis (53/168 or $31.5 \%$ of cases) compared to their physician counterparts at the hospital clinic (3/144 or $2.1 \%$ of cases). Compared to the doctors, the midwives also had a lower rate of achieving a correct clinical diagnosis $(41.1 \%$ vs $34.8 \%)$ when it was attempted. Overall, 56 women (17.9\%) did not receive an initial diagnosis.

After this trend of non-diagnosis by the midwives was observed during the first two weeks, various training and coaching activities ensued to encourage the midwives to make an initial clinical diagnosis. As a group, the midwives started the study with less diagnostic experience. This lack of experience, along with all HCPs struggle to make an accurate initial diagnosis, motivated the development of an RTI/STD Case Management Manual (see Appendix L). This training manual utilized the exact case management protocol (see Protocol VI, Appendix D) previously distributed during the initial "Round Table Discussion" but each RTI protocol was accompanied with photographs to provide a visual example for future reference. The photographs were reproduced from slides previously used during an additional training on "RTI/STD case management" held March 21st for the staff of Puskesmas and 25 March for hospital staff.

Same day accurate clinical diagnosis could be facilitated by prompt and accurate microscopy results. Comparisons of the sensitivity and specificity of on-site lab results with final diagnoses are presented in Table 12 and 13, for bacterial vaginosis and candidiasis, respectively.

Table 12. Sensitivity and Specificity of Clinic Site Gram Stains in Detecting Bacterial Vaginosis

\begin{tabular}{|c|c|c|c|}
\hline \multirow{2}{*}{ On-site Lab Tests } & \multicolumn{2}{|c|}{ Confirmation Lab Results } & \multirow{2}{*}{ Total } \\
\cline { 2 - 3 } & + & - & \\
\hline+ & 9 & 29 & 38 \\
\hline- & 7 & 267 & 274 \\
\hline Total & 16 & 296 & 312 \\
\hline
\end{tabular}

The prevalence of Bacterial vaginosis in this population : 16/312 $=5.13 \%$

Reliability of local clinical labs for detecting Bacterial vaginosis :

Sensitivity $: 9 / 16=56.2 \%$

Specificity : 267/296 $=90.2 \%$

Positive Predictive Value (PPV): 9/38 = 23.7\%

Negative Predictive Value (NPV): 267/274 = 97.5\% 
Table 13. Sensitivity and Specificity of Clinic Site Gram Stain in Detecting Candidiasis

\begin{tabular}{|c|c|c|c|}
\hline \multirow{2}{*}{ On-site Lab Tests } & \multicolumn{2}{|c|}{ Confirmation Lab Results } & \multirow{2}{*}{ Total } \\
\cline { 2 - 3 } & + & - & \\
\hline+ & 9 & 15 & 24 \\
\hline- & 12 & 276 & 288 \\
\hline Total & 21 & 291 & 312 \\
\hline
\end{tabular}

The prevalence of candidiasis in this population : $21 / 312=6.7 \%$

Reliability of local clinical labs for detecting candidiasis :

Sensitivity : $9 / 21=42.8 \%$

Specificity : $276 / 291=94.8 \%$

PPV : $9 / 24=37.5 \%$

NPV : $276 / 288=95.8 \%$

Sensitivity and specificity were calculated comparing the clinic site gram stain microscopy results with the results from the same gram stain read by referral laboratory at RSCM. Comparison could not be performed for wet mounts to screen trichomonads, since these had to be performed on site only (before the trichomonads died). Also the comparison was not made for chlamydia or gonorrhea, as these were only tested for at the referral lab. We can see that sensitivity and positive predictive values of these initial on-site diagnoses were limited for both bacterial vaginosis and candidiasis.

A customary practice of the referral laboratory, independent of this study, was to include "Non-Specific Genital Infection" (or NSGI) as a laboratory diagnosis, based on leukocytosis as indicated by more than 30 polymorphonuclear leucocytes (PMNs) per HPF, both on vaginal and cervical Gram stains. Previous RTI/STD screening conducted by some of the national working group have used an elevation of PMNs as a prevalence marker in RTI/STD studies without performing cervical cultures for $N$. gonorrhoeae or specific testing for C. trachomatis (Pratomo, Nasrin, et. al., 1995). However, a study in Zaire stated that the presence of leukocytosis $>10$ PMN/hpf was not a good predictor of actual STD diagnosis (Vuylsteke, Laga, Alary, et.al., 1993). Following the universal literature on RTI/STDs, the presence of cervical leukocytosis was not assigned a diagnostic significance in this study. The presence of increased PMNs on the cervix was also not interpreted as diagnostic of an RTI or STD in this study, since universal screening for both gonorrhea and chlamydia was performed. Since the data on elevated PMNs are available, however, they are presented in Table 14 in comparison with the lab diagnoses. In brief, Table 14 shows that $36.2 \%$ (113) of clients were identified as having cervical leukocytosis, but $70.8 \%$ of them $(80 / 113)$ had negative final lab results. 
Table 14: Cervical Leukocytosis and Final Laboratory Findings for RTI/STDs

\begin{tabular}{|c|c|c|c|c|c|c|}
\hline \multirow{2}{*}{$\begin{array}{c}\text { Gram stains indicating cervical } \\
\text { lecocytosis: cervical PMNs } \\
\text { >30/hpf: }\end{array}$} & \multicolumn{2}{|c|}{$\begin{array}{c}\text { Koja } \\
\text { Hospital }\end{array}$} & \multicolumn{2}{|c|}{$\begin{array}{l}\text { Puskesmas } \\
\text { Cilincing }\end{array}$} & \multicolumn{2}{|c|}{$\begin{array}{l}\text { Combined } \\
\text { Clinics }\end{array}$} \\
\hline & $\mathrm{n} / \mathrm{N}$ & $\%$ & $\mathrm{n} / \mathrm{N}$ & $\%$ & $\mathrm{n} / \mathrm{N}$ & $\%$ \\
\hline Elevated PMNs among all clients & $48 / 144$ & (33.3) & $65 / 168$ & $(38.7)$ & $\begin{array}{r}113 / 31 \\
2\end{array}$ & $(36.2)$ \\
\hline $\begin{array}{l}\text { Positive lab test for Chlamydia } \\
\text { among } \\
\text { clients with elevated PMNs*/** }\end{array}$ & $11 / 48$ & $(22.9)$ & $8 / 65$ & $(12.3)$ & $19 / 113$ & $(16.8)$ \\
\hline $\begin{array}{l}\text { Positive lab test for any RTI/STD } \\
\text { among clients with elevated } \\
\text { PMNs*** }\end{array}$ & $11 / 48$ & $(22.9)$ & $6 / 65$ & $(9.2)$ & $17 / 113$ & $(15.0)$ \\
\hline $\begin{array}{l}\text { Positive lab test for Chlamydia } \\
\text { among clients with normal PMNs }\end{array}$ & $7 / 96$ & $(7.3)$ & $5 / 103$ & (4.8) & 12/199 & (6.0) \\
\hline $\begin{array}{l}\text { Positive lab test for any RTI/STD } \\
\text { among clients with normal PMNs }\end{array}$ & $16 / 96$ & (16.7) & $13 / 103$ & (12.6) & 29/199 & (14.6) \\
\hline
\end{tabular}

PMN = Polymorphonuclear Leucocytes

hpf $=$ high power field

* 11 clients did not have chlamydia tests performed.

** 1 client was positive for both gonorrhea and chlamydia

*** i.e., bacterial vaginosis, trichomoniasis and/or candidiasis (1 client had more than $1 \mathrm{RTI})$.

The performance of the amine odor ("whiff") test was originally recommended at the beginning of the study when wet mount microscopy was the only microscope test included in the routine. With the adoption of a combined Gram stain wet mount microscopy procedure, as recommended by the advisory board member who was the chief of the referral laboratory at Cipto Mangunkusumo Hospital (RSCM), the method of performing and evaluating the whiff test was transferred from the HCPs to the Ras. At the Koja hospital, 57 (45.2\%) of 144 "whiff" tests were judged as positive, but only eight clients had confirmed clue cells on their Gram stains. Six of these eight clients had positive "whiff" tests. Factors that contributed to this low sensitivity and specificity included the manner that the test was performed and the inexperience of both the HCPs and RAs in integrating this subjective test into the performance of routine specimen collection.

Inaccurate clinical diagnoses can lead to inappropriate prescription. The impetus to promote a same day accurate diagnosis came from the fact that many RTI/STDs will never be treated if treatment depends on the client returning to the clinic to receive the laboratory results. Follow-up efforts to reach clients who typically do not have telephones or street addresses are a costly and unrealistic option for delivery of treatment. As described in Table 15, the medications that were prescribed as a result of this study's encouragement to make same day clinical diagnoses included a broad range of treatment. Some drugs were given in accordance with the national treatment guidelines and others were inappropriate and 
reflected long standing habits of drug selection by the provider. While it is a possibility that some of these clients with "negative" laboratory results may have benefitted from some of the treatments, it indicated a pattern of "over treatment". We can see that over the course of the study, this over-treatment declined at the hospital but not at the Puskesmas (PHC).

Table 15: Number of Prescriptions Written at Initial Clinical Evaluations for Clients with Final Negative Laboratory Diagnoses

\begin{tabular}{|l|c|c|c|c|c|c|c|c|c|}
\hline \multirow{2}{*}{ Prescriptions } & \multicolumn{3}{|c|}{ Koja Hospital } & \multicolumn{3}{c|}{ Puskesmas Cilincing } & \multicolumn{3}{c|}{ Combined Clinics } \\
\cline { 2 - 11 } & $\begin{array}{c}\text { Week } \\
1-4\end{array}$ & $\begin{array}{c}\text { Week } \\
5-8\end{array}$ & $\begin{array}{c}\text { Week } \\
9-12\end{array}$ & $\begin{array}{c}\text { Week } \\
1-4\end{array}$ & $\begin{array}{c}\text { Week } \\
5-8\end{array}$ & $\begin{array}{c}\text { Week } \\
9-12\end{array}$ & $\begin{array}{c}\text { Week } \\
1-4\end{array}$ & $\begin{array}{c}\text { Week } \\
5-8\end{array}$ & $\begin{array}{c}\text { Week } \\
9-12\end{array}$ \\
\hline Metronidazole & 11 & 2 & 8 & 0 & 13 & 10 & 11 & 15 & 18 \\
\hline Doxycycline & 9 & 5 & 6 & 0 & 0 & 0 & 9 & 5 & 6 \\
\hline $\begin{array}{l}\text { Thiamphenico } \\
\text { l }\end{array}$ & 5 & 4 & 1 & 0 & 0 & 0 & 5 & 4 & 1 \\
\hline Albothyl & 0 & 0 & 1 & 25 & 29 & 16 & 25 & 29 & 17 \\
\hline Vitamins & 2 & 2 & 1 & 0 & 0 & 0 & 2 & 2 & 1 \\
\hline Antifungals* & 0 & 3 & 2 & 0 & 1 & 11 & 0 & 4 & 13 \\
\hline Ciprofloxacin & 4 & 0 & 0 & 0 & 1 & 0 & 4 & 1 & 0 \\
\hline Amoxicillin & 2 & 1 & 0 & 0 & 0 & 0 & 2 & 1 & 0 \\
\hline Tetracycline & 0 & 2 & 0 & 3 & 0 & 0 & 3 & 2 & 0 \\
\hline $\begin{array}{l}\text { Total } \\
\text { Prescriptions }\end{array}$ & 33 & 19 & 19 & 28 & 44 & 37 & 61 & 63 & 56 \\
\hline $\begin{array}{l}\text { Total Clients } \\
\text { with Negative } \\
\text { Diagnosis }\end{array}$ & 38 & 29 & 32 & 39 & 50 & 47 & 77 & 79 & 79 \\
\hline $\begin{array}{l}\text { \% Receiving } \\
\text { unnecessary } \\
\text { prescription }\end{array}$ & 86.8 & 65.5 & 59.4 & 71.8 & 88.0 & 78.7 & 79.2 & 79.7 & 70.9 \\
\hline
\end{tabular}

*Antifungals include Diflucan, Canesten vaginal suppositories and Miconazole cream.

The fact that the study pre-packaged and provided approved treatments, no doubt, raised the level of compliance and accuracy when selecting an approved medication. However, this did not eliminate incorrect choices completely, such as selecting Metronidazole to treat candidiasis. 
The history of using Thiamphenicol for both Gonorrhea and Chlamydia was accompanied by a strong belief by some of the doctors that it worked well for cervical bacterial infections. Some physicians expressed concerns that a single dose therapy such as Ciprofloxacin could not cure a gonorrhea infection in women. Another long standing prescribing habit in Indonesia that is reinforced by the public health system is prescribing antibiotics for a three day regimen. Thus, suggested changes in the length of time a drug is given to either a shorter single dose or a seven day regimen, was not immediately aceptable to HCPs.

\section{III.D.4 Observations of HCP/Client Interactions}

Every one of the 312 clinical evaluations was observed by a trained RA, who immediately recorded her observations on a coded observation form (see Appendix G). At first the HCPs were skeptical and guarded about being observed. The RAs were young, female college graduates from the field of public health. They had all been trained to be neutral and non-threatening. They had also been very involved in the writing of the protocols and study instruments. In addition they had received much $\mathrm{RTI} / \mathrm{STD}$ training during the pre-intervention portion of the study. They all intrinsically possess characteristics that make them appealing team members such as youth, enthusiasm and warm good natures. The final style of the relationship between the HCP and the RAs was similar to that of a benevolent "boss" to a friendly junior "assistant". The HCPs were aware of the knowledge and experience each of the RAs possessed.

During the initial "Round-Table Discussion" training intervention in January, the HCPs expressed reluctance towards filing out the clinical evaluation flow sheet (Appendix A). To promote cooperation, the project manager agreed to let the RAs function as data recorders for the HCPs. At the hospital, this assistance was limited to the risk assessment/history portion. The doctors filled out the physical exam finding themselves. At the health center, partly due to higher case load, the RAs also completed the physical exam portion, filling in to the findings as assessed by the midwives. However, in the last month of the study, when the physician medical director, and a visiting supervisory midwife started performing evaluations at the health center, the midwives were more likely to fill this out themselves. The progression of the RAs role as neutral observer to helpful assistant was influenced by the performance of the HCPs. For some HCPs with weaker clinical skills, especially among midwives at the health center, the roles were often reversed, placing the RAs in the position of mentors to HCPs who often sought their advice on, "what do you think this is?" or, "where should this go?" It should also be mentioned that during the course of the study, at both the hospital and the health center, trainee midwives were sometimes brought in to complete the history portion, instead of the RAs. 
Even with the supportive help and watchful eye of the RAs at each $\mathrm{HCP} /$ client interaction, the HCP's were not compliant in performing or completing the final teaching/counseling component of the RTI/STD evaluation procedure. This has been previously addressed as a very undervalued component of client care. Table 16 describes the frequency with which targeted HCP behaviors were observed. The check list of behaviors is based on the clinical protocols. The desired behavior were repeatly reinforced in each training in a variety of presentations, both written and oral. The minimal desired behaviors were finally written in the self assessment checklist, as previously discussed (Appendix F) which was given to each HCP as a guide to what was expected of them. The observation tool covers optimum history taking, client teaching, partner intervention and infection control practices, and directly mirrors the clinical evaluation tasks. Of interest is the frequency with which the HCPs would direct the RAs to record a negative result on the evaluation form for a task that was not performed, such as a bimanual examination. In cases where HCPs completed the physical exam section themselves, $\mathrm{HCP} /$ client interaction observation records can serve as a testimony to what was actually completed, and what was recorded as being completed. 
Table 16: Observed Frequency of HCP/Client Interaction Behaviors

\begin{tabular}{|c|c|c|c|c|c|c|}
\hline \multirow[t]{2}{*}{ Behavior Observed } & \multicolumn{2}{|c|}{$\begin{array}{c}\text { Koja } \\
\text { Hospital }\end{array}$} & \multicolumn{2}{|c|}{$\begin{array}{c}\text { Puskesmas } \\
\text { Cilincing }\end{array}$} & \multicolumn{2}{|c|}{$\begin{array}{l}\text { Combined } \\
\text { Clinics }\end{array}$} \\
\hline & & Yes & & $\begin{array}{l}168 \\
\text { es } \\
(\%)\end{array}$ & & $(\%)$ \\
\hline $\begin{array}{l}\text { 1.Introduction } \\
\text { Smiles and greets client respectfully } \\
\text { Asks client's reason for coming to clinic }\end{array}$ & $\begin{array}{r}5 \\
144\end{array}$ & $\begin{array}{r}(3.5) \\
(100.0)^{*}\end{array}$ & $\begin{array}{l}104 \\
101\end{array}$ & $\begin{array}{l}(61.9) \\
(60.1)\end{array}$ & $\begin{array}{l}109 \\
245\end{array}$ & $\begin{array}{l}(34.9) \\
(78.5)\end{array}$ \\
\hline $\begin{array}{l}\text { 2.Review of Current Status/Condition } \\
\text { Current contraceptive method } \\
\text { Last menstrual period } \\
\text { Current medications } \\
\text { Allergies to medicine and latex } \\
\text { OB history and potential of current } \\
\text { pregnancy }\end{array}$ & $\begin{array}{l}144 \\
143 \\
124 \\
139 \\
140\end{array}$ & $\begin{array}{r}(100.0) \\
(99.3) \\
(86.1) \\
(96.5) \\
(97.2)\end{array}$ & $\begin{array}{l}167 \\
164 \\
137 \\
160 \\
151\end{array}$ & $\begin{array}{l}(99.4) \\
(97.6) \\
(81.5) \\
(95.2) \\
(89.9)\end{array}$ & $\begin{array}{l}311 \\
307 \\
261 \\
299 \\
291\end{array}$ & $\begin{array}{l}(99.7) \\
(98.4) \\
(83.7) \\
(95.8) \\
(93.3)\end{array}$ \\
\hline $\begin{array}{l}\text { 3. Introductory Education } \\
\text { Reviews RTI/STDs that effect women's } \\
\text { health } \\
\text { Reviews } 7 \text { birth control method \& makes a } \\
\text { connection to STD protection }\end{array}$ & 0 & $\begin{array}{l}(0) \\
(0)\end{array}$ & 1 & $\begin{array}{l}(0.6) \\
(0.6)\end{array}$ & 1 & $\begin{array}{l}(0.3) \\
(0.3)\end{array}$ \\
\hline $\begin{array}{l}\text { 4.Review of Reproductive Health History } \\
\text { Items } \\
\text { Previous history of STD } \\
\text { More than } 1 \text { sex partner in past } 3 \text { months }{ }^{\circledR} \\
\text { Sexual intercourse without condoms } \\
\text { Unusual vaginal discharge } \\
\text { Pain with urination } \\
\text { Lower abdominal pain } \\
\text { Bleeding after intercourse } \\
\text { Genital sores or lumps } \\
\text { Sex partner with unusual discharge from } \\
\quad \text { penis } \\
\text { Sex partner with sores or lumps on penis } \\
\text { Sex partner not monogamous }\end{array}$ & $\begin{array}{l}144 \\
144 \\
144 \\
144 \\
144 \\
143 \\
144 \\
143 \\
142 \\
143 \\
143\end{array}$ & $\begin{array}{r}(100.0) \\
(100.0) \\
(100.0) \\
(100.0) \\
(100.0) \\
(99.3) \\
(100.0) \\
(99.3) \\
(98.6) \\
(99.3) \\
(99.3)\end{array}$ & $\begin{array}{l}161 \\
166 \\
167 \\
167 \\
167 \\
167 \\
167 \\
167 \\
166 \\
165 \\
164\end{array}$ & $\begin{array}{l}(95.8) \\
(98.8) \\
(99.4) \\
(99.4) \\
(99.4) \\
(99.4) \\
(99.4) \\
(99.4) \\
(98.8) \\
(98.2) \\
(97.6)\end{array}$ & $\begin{array}{l}305 \\
310 \\
311 \\
311 \\
311 \\
310 \\
311 \\
310 \\
308 \\
308 \\
307\end{array}$ & $\begin{array}{l}(97.8) \\
(99.4) \\
(99.7) \\
(99.7) \\
(99.7) \\
(99.4) \\
(99.7) \\
(99.4) \\
(98.7) \\
(98.7) \\
(98.4)\end{array}$ \\
\hline $\begin{array}{l}\text { 5. Infection Control } \\
\text { Washes hands before exam } \\
\text { Uses visibly clean instruments } \\
\text { Puts on new/ disinfected glove before pelvic } \\
\text { exam } \\
\text { If rectal exam done, changes glove prior to } \\
\text { rectal } \\
\text { Washes hands after removing glove }\end{array}$ & $\begin{array}{r}11 \\
144 \\
143\end{array}$ & $\begin{array}{r}(7.6) \\
(100.0) \\
(99.3) \\
(0.0) \\
(17.4)\end{array}$ & $\begin{array}{r}47 \\
166 \\
103\end{array}$ & $\begin{array}{l}(28.0) \\
(98.8) \\
(61.3) \\
(0.0) \\
(26.2)\end{array}$ & $\begin{array}{r}58 \\
310 \\
246\end{array}$ & $\begin{array}{r}(18.6) \\
(99.4) \\
(78.8) \\
(0.0) \\
(22.1)\end{array}$ \\
\hline $\begin{array}{l}\text { 6. Physical Exam Steps Performed } \\
\text { Abdomen/skin } \\
\text { Inguinal palpation } \\
\text { Visual external genitalia } \\
\text { Speculum exam } \\
\text { Bimanual exam }\end{array}$ & $\begin{array}{r}144 \\
144 \\
144 \\
144 \\
18\end{array}$ & $\begin{array}{r}(100.0) \\
(100.0) \\
(100.0) \\
(100.0) \\
(12.5)\end{array}$ & $\begin{array}{r}15 \\
16 \\
112 \\
166 \\
70\end{array}$ & $\begin{array}{r}(8.9) \\
(9.5) \\
(66.7) \\
(98.8) \\
(41.7)\end{array}$ & $\begin{array}{r}159 \\
160 \\
256 \\
310 \\
88\end{array}$ & $\begin{array}{l}(51.0) \\
(51.3) \\
(82.1) \\
(99.4) \\
(28.2)\end{array}$ \\
\hline
\end{tabular}

* With assistance from hospital midwives who screen clients and always asked

@ All in this section refer to recall period of the past three months, except the first item 
Table 16: Continued

\begin{tabular}{|c|c|c|c|c|c|c|}
\hline \multirow[t]{2}{*}{ Behavior Observed } & \multicolumn{2}{|c|}{$\begin{array}{c}\text { Koja } \\
\text { Hospital }\end{array}$} & \multicolumn{2}{|c|}{$\begin{array}{c}\text { Puskesmas } \\
\text { Cilincing }\end{array}$} & \multicolumn{2}{|c|}{$\begin{array}{l}\text { Combined } \\
\text { Clinics }\end{array}$} \\
\hline & & es $(\%)$ & & $\begin{array}{l}\text { Yes } \\
\%)\end{array}$ & & $(\%)$ \\
\hline $\begin{array}{l}\text { 7.Counseling } \\
\text { Explains the diagnosis to client } \\
\text { If diagnosed RTI positive, explains the } \\
\text { disease transmission to client } \\
\text { If diagnosed STD positive, makes verbal } \\
\text { plan for partner treatment \& evaluation }\end{array}$ & 11 & $\begin{array}{r}(6.8) \\
(25.6) \\
(24.2)\end{array}$ & 0 & $\begin{array}{l}(1.1) \\
(0.0) \\
(0.0)\end{array}$ & $\begin{array}{l}8 \\
11 \\
8\end{array}$ & $\begin{array}{r}(4.1) \\
(14.9) \\
(9.5)\end{array}$ \\
\hline $\begin{array}{l}\text { 8. Instruction for future STD prevention } \\
\text { Discusses abstinence } \\
\text { Discusses monogamy } \\
\text { Discusses Condoms } \\
\text { Offers condoms } \\
\text { Provides instructions for condom use }\end{array}$ & $\begin{array}{l}9 \\
0 \\
2 \\
1 \\
0\end{array}$ & $\begin{array}{r}(21.4) \\
(0.0) \\
(4.8) \\
(2.4) \\
(0.0)\end{array}$ & $\begin{array}{l}1 \\
0 \\
0 \\
0 \\
0\end{array}$ & $\begin{array}{r}(11.1) \\
(0.0) \\
(0.0) \\
(0.0) \\
(0.0)\end{array}$ & $\begin{array}{r}10 \\
0 \\
2 \\
1 \\
0\end{array}$ & $\begin{array}{r}(19.6) \\
(0.0) \\
(4.0) \\
(2.0) \\
(0.0)\end{array}$ \\
\hline $\begin{array}{l}\text { 9. Advice on treatment } \\
\text { Name of medication } \\
\text { How often to take the drug } \\
\text { Length of drug use } \\
\text { Take entire prescription } \\
\text { Potential side effects (alcohol \& pregnancy) } \\
\text { Assesses client's understanding of } \\
\quad \text { instructions }\end{array}$ & $\begin{array}{c}37 \\
49 \\
39 \\
23 \\
2\end{array}$ & $\begin{array}{r}(40.6) \\
(54.4) \\
(42.8) \\
(25.6) \\
2.2)\end{array}$ & $\begin{array}{r}39 \\
32 \\
29 \\
0 \\
24\end{array}$ & $\begin{array}{r}(61.9) \\
(51.6) \\
(47.5) \\
(0.0) \\
(39.3) \\
(11.7)\end{array}$ & $\begin{array}{l}76 \\
81 \\
68 \\
23 \\
26\end{array}$ & $\begin{array}{r}(49.4) \\
(53.3) \\
(44.7) \\
(18.4) \\
(17.2) \\
(4.1)\end{array}$ \\
\hline $\begin{array}{l}\text { 10. HCP demonstrates positive } \\
\text { communication skills } \\
\text { Open and friendly } \\
\text { Uses understandable terminology } \\
\text { Conveys interest in the client } \\
\text { Listens carefully } \\
\text { Is open to the client's questions }\end{array}$ & $\begin{array}{r}63 \\
2 \\
2 \\
4 \\
4\end{array}$ & $\begin{array}{r}(94.0) \\
(40.0) \\
(50.0) \\
(100.0) \\
(80.0)\end{array}$ & $\begin{array}{r}167 \\
143 \\
165 \\
79 \\
58\end{array}$ & $\begin{array}{r}(100.0) \\
(99.3) \\
(100.0) \\
(98.8) \\
(96.7)\end{array}$ & $\begin{array}{r}230 \\
145 \\
167 \\
83 \\
62\end{array}$ & $\begin{array}{l}(98.3) \\
(97.3) \\
(98.8) \\
(98.8) \\
(95.3)\end{array}$ \\
\hline
\end{tabular}

Note : In this continuation of Table 16, unlike the first portion, denominators vary widely for various reason, such as exclusions based on diagnosis, HCP/Client interactions that did not happen or were not observed, and some inconsistencies in the methods of recording observations among RAs. 
The HCPs first task of making a good impression and establishing a rapport with the FP client at the beginning of the clinical evaluation was observed by any demonstration of smiling and greeting the client respectfully. The midwives, were able to achieve this goal more often than their physician counterparts $(61.9 \%$ vs. $3.5 \%$ respectively). Although the doctors were rated as achieving a $100 \%$ threshold of screening the client's reason for visiting the clinic, this task was delegated to and performed by the nursing staff who automatically documented the chief complaint or reason for visit, in an intake before the client actually sees the doctor (Table 16, section 1). Five separate inquiries about the current status of contraception, menstruation, medications, allergies, and potential pregnancy were similarly achieved by both groups of HCPs at a level of 80-100\% (Table 16, section 2).

Both groups of HCPs ignored the protocols of providing preliminary health education on the existence of RTIs and their connection to selected contraceptive methods (see Table 16, section 3). This step should have preceded the performance of an STD risk assessment, not just to educate the client, but to also allow the client more time to adjust to the concept of a frank discussion of STDs, as well as increasing the opportunity for the HCP to demonstrate his or her particular merits as a professional deserving of the client's trust, before the invasiveness of a sexual STD risk assessment is performed. This step occurred with only one client (by a midwife).

The entire eleven question sexual history was performed $95-100 \%$ of the time in both clinics. However, as described above, the history was actually obtained almost exclusively by the RAs and sometimes by trainee midwives, but not by the primary HCP. Doctors in the hospital would review affirmative history responses with the patient for greater diagnostic clarification.

Five distinct infection control behaviors were itemized with only four behaviors ever being observed since no rectal exam were actually performed during the study. Rates of hand washing before (18.6\%) and after $(22.1 \%)$ performing a pelvic examination were quite low, though higher for the midwives (Cilincing) than the doctors (Koja). Out of the 312 observed examinations, visibly clean instruments were used in all but $2(0.6 \%)$ of the exams. Midwives at the Puskesmas were less consistent than the doctors at Koja in using new or disinfected gloves prior to each pelvic examination (61.3\% vs $99.3 \%$ ). Prior to the study, the Puskesmas regularly re-used gloves after disinfecting them. The project purchased disposable examination gloves for this clinic. In the opinion of the observing RAs, one of the midwives felt reluctant to throw away "perfectly good" gloves and would recycle them by simply washing her hands prior to examining the next client. 
The pelvic examination most often included a speculum examination (99.4\%). Other components of the physical exam were performed much less regularly especially the bimanual exam (28.2\%) (see Table 16, section 6).

As discussed early, regarding the low value placed on counseling and communication, Table 16 shows that rates of performing these behaviors were much lower than for physical exam procedures. In only $14.9 \%$ of RTI positive cases was the disease transmission explained to the client, and in only $4 \%$ of cases were condoms discussed. Only one client was offered condoms (2\%) and no client received instruction on condom use.

With regard to discussion of medication Table 16, section 9 overall about $50 \%$ of the time, HCPs mentioned the name of the drug and described the regimen. Only $18.4 \%$ of the time was emphasized that the entire prescription must be taken (never mentioned at the Puskesmas), and doctors more often neglected to warn of side-effects (2.2\% vs. $39.3 \%$ among midwives at Cilincing ). HCPs almost never bothered to assess the clients' understanding of the instructions (4.1\%). The final section of Table 16 presents especially subjective evaluations by the RAs of the HCPs positive manner and openness. Overall, the results were very high (all, item over $95 \%$ positive), with lower rates among doctors (at Koja) than midwives (at Cilincing) (see Table 16, section 10).

However, overall for this observation evaluation tool, the highly subjective nature of many of the items, along with the fact that the RA's for each site were never switched and the tool was not tested for interater reliability, limits the reliability and value of these data.

\section{Proportions of RTI/STD Positive Clients and Partners Treated}

The anticipated problem of failing to treat many RTI cases due to requiring clients to return to the clinic for result of the final laboratory results, was an expected effect of the decision to perform universal etiologic RTI diagnosis. All those who did return received appropriate treatment. No inappropriate (wrong medication) treatment was given. This is because it was decided to prepackage and label all medications for the study and also, in all cases it was the research assistants who selected the packages of medication based on the confirmatory diagnosis. Thus, we can not assess HCP compliance with treatment guidelines (objective 5). An analysis of return clients visits and appropiate treatments is presented in Table $\mathbf{1 7}$ and $\mathbf{1 8 .}$ 
Table 17: $\quad$ Status of Client Treatment for Non-Sexually Transmitted RTIs

\begin{tabular}{|l|cc|cc|}
\hline \multirow{2}{*}{$\begin{array}{c}\text { RTIs confirmed in both clinic sites that } \\
\text { are non-sexually transmitted: }\end{array}$} & \multicolumn{2}{|c|}{$\begin{array}{c}\text { Appropriate client } \\
\text { treatment }\end{array}$} & \multicolumn{2}{c|}{ Client not treated* } \\
\cline { 2 - 6 } & $\mathbf{n}$ & $\mathbf{( \% )}$ & $\mathbf{n}$ & $(\boldsymbol{\%})$ \\
\hline Candidiasis $(\mathrm{n}=21)$ & 16 & $(76.2)$ & 5 & $(23.8)$ \\
\hline Bacterial Vaginosis $(\mathrm{n}=16)$ & 11 & $(68.8)$ & 5 & $(31.2)$ \\
\hline Total $\quad(\mathrm{n}=37)$ & 27 & $(73.0)$ & 10 & $(27.0)$ \\
\hline
\end{tabular}

* Client had not returned to clinic for final lab results and treatment as of two weeks after study completion on 5/9/97.

Table 18: $\quad$ Status of Client and Partner Treatment for RTIS That are Sexually Transmitted (STDs)

\begin{tabular}{|c|c|c|c|c|c|c|c|c|}
\hline \multirow[t]{2}{*}{$\begin{array}{c}\text { Confirmed STDs at both } \\
\text { clinic sites }\end{array}$} & \multicolumn{2}{|c|}{$\begin{array}{l}\text { Appropriate } \\
\text { client } \\
\text { treatment } \\
(\text { PI6)** }\end{array}$} & \multicolumn{2}{|c|}{$\begin{array}{l}\text { Client not } \\
\text { treated* }\end{array}$} & \multicolumn{2}{|c|}{$\begin{array}{l}\text { Appropriate } \\
\text { partner } \\
\text { treatment } \\
(\mathrm{PI} 7)^{* *}\end{array}$} & \multicolumn{2}{|c|}{$\begin{array}{l}\text { Partner not } \\
\text { treated* }\end{array}$} \\
\hline & $\mathbf{n}$ & $(\%)$ & $\mathbf{n}$ & $\%$ & $\mathbf{n}$ & $\%$ & $\mathbf{n}$ & $\%$ \\
\hline Trichomoniasis $(\mathrm{n}=17)$ & 12 & (70.6) & 5 & (29.4) & 9 & $(53.0)$ & 8 & $(47.0)$ \\
\hline Gonorrhea $(\mathrm{n}=1)$ & 1 & (100.0) & 0 & $(0.0)$ & 0 & $(0.0)$ & 1 & (100.0) \\
\hline Chlamydia (n=31) & 23 & $(74.2)$ & 8 & $(25.8)$ & 18 & $(58.1)$ & 13 & (41.9) \\
\hline Total $(\mathrm{n}=49)$ & 36 & (73.5) & 13 & (26.5) & 27 & $(55.1)$ & 22 & (44.9) \\
\hline
\end{tabular}

* Client had not returned to clinic for final lab results and treatment as of two weeks after study completion on 5/9/97.

** These were calculated according to WHO formulas PI6 and PI7, as shown. Since only two clients received advice on condoms, PI7 was devised to reflect partner treatment alone.

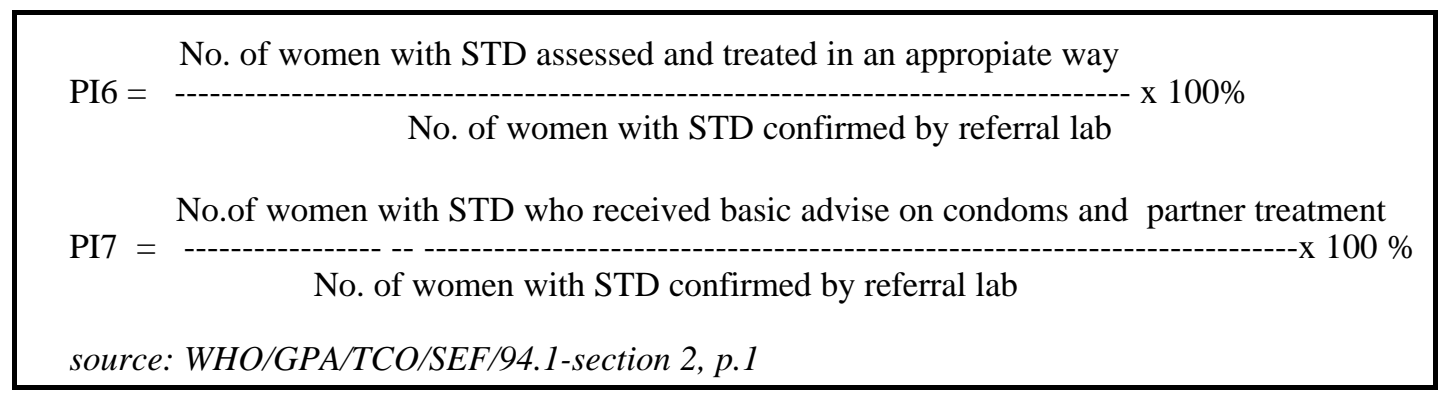

For non-sexually transmitted RTI's, Table 17 shows that approximately one quarter $(26.5 \%)$ went untreated due to the client's failure to return as of two weeks after the study ended. The rate was approximately the same for STDs 73.5\% (36/49 women) received appropriate treatment. However the rate of partner treatment was much lower; just over half of partners of women with STD's received treatment 
(55.1\% or 27 partners). This leaves nine treated women (36-27) exposed to the possibility of reinfection from her partner. Rates were approximately equal for treatment of chlamydia and trichomoniasis. The single case of gonorrhea was treated but the partner was not.

Broken down by clinic site, at Koja Hospital the doctors provided appropriate treatment for $84.4 \%$ of cases but the midwives did so only $52.9 \%$ of the time. This means simply that the Cilincing clients more often failed to return and perhaps the midwives were less firm in their explanation of the need for a follow-up visit.

\section{III.D.5. Existing RTI/STD Reporting and Recording Practices}

A six month retrospective medical review showed that it is an essentially nonexistent practice to catagorize gynecological problem with disease specific diagnosis. In review of chronological register of out-patient visits to combined MCH/FP clinics in the Koja Hospital, there were no recorded reports of trichomoniasis, bacterial vaginosis, candidiasis, gonorrhea, chlamydia, or syphilis during the six months between July 1 and December 31, 1996. There were descriptive syndromic assessment that could very well be sentinels of RTI/STDs. There were 114 diagnoses of vaginitis, 102 of discharge and 67 of adnexitis, 14 of cervicitis, one of cervical cancer and two of genital lumps.

The actual medical records, for each client who was diagnoses with one of the above diagnoses, were reviewed to see if the individual medical recording had a consistent or more precise diagnosis. The records were also reviewed to monitor diagnostic and treatment modalities. In none of the actual records reviewed were there discovered any more etiologically precise labels. A majority (125) of the prescription written in these medical records were illegible and the hospital did not have a computer based formulary to double check actual prescribing practices. In no cases was there any indication that the individual clients were educated on their diagnosis or given instructions for future disease prevention, or for partner treatment.

The six month retrospective medical review of Puskesmas Cilincing did not have a chronological daily clinic visit registration report as Koja Hospital. The medical report were completed by the HCP, who in turn transferred data to a monthly report for disease. This report only includes the client's age and disease, and no client identifiers

that would allow for the retrieval of an individual medical report to survey diagnostic, treatment and education interventions. The only RTI/STDs include in the report are gonorrhea and syphilis. For the entire six month period there were only three reported cases of gonorrhea and no cases of syphilis. 


\section{Conclusion and Recommendations}

A deliberate choice to limit the number of variables used to perform risk assessment was made to promote a feasible standard of history taking for HCPs who were also being asked to perform more client care in their busy practices. The sociodemographic picture of the family planning clients studied in both clinics is strikingly homogenous. The marital status of clients was $97.3 \%$ married, and the age of the majority of studied women (264 or $85 \%$ ) was 25 or over. The most popular contraceptive methods are injectable hormones (36.9\%), IUDs (26.0\%), and pills $(23.0 \%)$.

The risk assessment history revealed that past histories of STDs (1.6\%) and recent multiple partner exposure $(0.6 \%)$, were rarely reported. Almost all women (97.4\%) reported the perception that their partner was monogamous. Despite a low rate of condom use as a contraceptive method (2.6\%), a slightly higher percentage $(7.4 \%)$ of women used condoms during sexual intercourse in addition to other contraceptive methods.

Five inquiries were made regarding the woman's self-reported symptomatology in three months prior to the exam. Fifty nine percent of women reported having abnormal vaginal discharge (bad odor, itching or discolored), $41 \%$ complained of lower abdominal pain, 9.6\% had experienced post-coital bleeding in the past three months, $8.6 \%$ reported genital sores or lumps in the past three months, and $6.3 \%$ reported pain with urination. The woman's perception of her partner's manifestation of RTI symptoms was very low at $1.9 \%$ for discharge from the penis and $1.3 \%$ for sores or lumps on the penis.

From the clinical evaluations of the 312 clients, the HCPs reported that $37.5 \%$ had cervical mucopus, $33.3 \%$ abnormal vaginal discharge, and $32.4 \%$ cervical erythema. Due to the long turn around time for all laboratory reports, except the saline wet mount exam for trichomonads, performed on site, most clients left the FP clinic with an unconfirmed clinical diagnosis and were advised to return to the clinic in approximately two weeks for the final laboratory diagnosis and treatment. In view of the likelihood that some women would not return for follow-up visits, HCPs were encouraged to attempt to provide a correct initial clinical diagnosis and treatment (including treatment for partners) prior to the woman leaving the clinic. This concentration on providing early and correct clinical diagnoses and treatment plans was also made in accordance with national and international STD case management recommendations to interrupt the chain of infection by providing treatment for treatable infections at the earliest possible point with the ultimate goal of reducing STD associated mortality and morbidity (Daili et al., 1996 and WHO, 1994). 
Overall, this target group of low-income housewives was a relatively low-risk group for STDs. However, they self-reported a high rate of genital symptomology, especially abnormal discharge (59\%). HCPs detected signs of infection by speculum examination in roughly one third of the evaluated clients. Final laboratory evaluations confirmed a total prevalence rate of $24,7 \%$ for any RTI/STD among the 312 evaluated clients. Chlamydia was the most common infection $(10.3 \%)$. The prevalence of the sexually transmitted infections (trichomoniasis, chlamydia and gonorrhea) exceeded the rate of non-sexually transmitted RTIs (candidiasis and bacterial vaginosis) among the participants (16\% vs. $11.8 \%$, respectively). Clearly, this "low-risk" group has a need for RTI/STD services that remains unmet.

The initial (syndromic) clinical diagnoses based on the history and physical examination; were compared to the final (etiologic) laboratory results. None of the twelve variables collected during the history, or the seventeen physical examination components, were sensitive or specific enough to accurately predict the presence of these 86 etiologically confirmed infections. The combined rate of correct initial clinical diagnoses (either negative or positive) for both doctors and midwives was $38.3 \%$.

The result of such a large percentage of inaccurate clinical diagnoses contributed to inappropriate treatment and missed treatment opportunities. The wrong clinical diagnosis allows treatable infections to persist and in turn be passed on to other sexual partners. Furthermore, the cost of incorrect diagnosis for women who are not appropriately treated, in terms of consequences to their health and well being, is in itself a compelling reason to direct continued efforts to effectively identify, treat and counsel women with treatable RTIs. As described by Over and Piot (1996), health care intervention can achieve benefits in two distinct ways. The simplest intervention is one that cures or prevents the infection of some people once. The second type of intervention is a sustained one that alters either the sexual behavior of the population or the disease specific transmission and duration parameters. These two interventions of appropriate treatment and risk reduction education are two functions that are within the scope of services that can be feasibly provided by both FP clinics in this study. An improvement in delivering these services to each client should be made.

This study revealed that education for STD risk reduction is a consistently neglected component of FP client care, even after initial and follow-up HCP training. The discussion and offering of condoms should be included in every treatment plan for clients with a confirmed STD as well as for clients who do not use a barrier method during sexual intercourse and are not certain if they are in an infection-free, sexually monogamous relationship. This intervention for clients is analogous to training HCPs in universal precautions, such as wearing gloves before performing pelvic examinations. This promotion of education and condoms only occurred in two of the observed $\mathrm{HCP} /$ client interactions during the twelve week observation period. 
FP clients with the greatest need for intervention are certainly those clients who are found to have a confirmed STD. By definition, these infected clients are members of a core group for STD transmission, including HIV.

Following are recommendations addressing the various areas of study:

\section{Improve risk assessment and counseling}

If HCPs are too busy to perform the task of risk assessment and counseling, and are willing to delegate them to a designated interviewer, resources should be secured to provide appropriate staff for programs that want to include RTI/STD case management. Even though risk assessment is not highly specific for the discovery of RTI/STD's, it is critical for making an initial clinical judgement about suspected gonorrhea and chlamydia, which at this time are only reliably diagnosed by etiologically specific testing. Making a risk assessment requires sensitive questioning of the client. By delegating the risk assessment to non-medical personnel, the HCP subjects the client to scrutiny by more people, which may limit the collection of complete information if the client feels threatened by this. If the sequence of an evaluation starts with a history performed by non-medical personnel, followed by physical assessment and specimen collection from the medical personnel, and concludes with education/counseling from non-medical personnel, care for the client is fragmented. A more logical point to delegate the labor from "busy" doctor/midwives to trained disease intervention specialists, is for the final education/counseling portion of a clinical evaluation.

For history taking, basic communication skills need to be repeatedly reinforced for all personnel who obtain histories, including how to open-ended questions and how to probe for relevant responses. For example, the high rate of claimed abdominal pain (41\%) should discriminate between normal (menstrual) and potentially pathogenic etiologies. Collection of a risk assessment also involves time management issues, and willingness of an HCP to investigate intimate aspects of a client's private life. In order to make the HCP more client oriented, additional strengthening of HCP communication skills in performing risk assessments should be a focus in continued studies in Jakarta.

\section{Improve Partner Treatment}

The rate of providing partner-treatment for clients with confirmed STDs must increase from the $55 \%$ attained in this study/intervention. Following is a recommended hierarchy of health care intervention priorities for partner treatment aimed at breaking the chain of transmission for treatable STDs:

a. educating \& supporting each index client in choosing the best method of partner(s) notification and treatment;

b. providing the partner with medication for a treatable STD; 
c. physically examining the partner to confirm infection and evaluate for other infections that may coexist;

d. Providing the partner with STD education and counseling for future risk reduction.

Confirming a concurrent partner infection is not always reliable or possible, so examination of the partner should never be a prerequisite for providing treatments. Education and counseling for risk reduction are important services to offer interested partners of clients, but they too should not be used as a prerequisite for treatment

Additional strategies to provide follow-up outreach to clients and partners who do not receive concurrent treatment for confirmed STDs should be explored. Previous work in Haiti included a verbal plan with the index client to have a health outreach worker contact partners if they did not present for treatment (Desmormeaux, 1996). Requirements to make the partner present to the clinic to obtain treatment should be waived in favor of supplying the index client with dual partner treatment and instructions for safe use.

\section{Laboratory Testing}

In general it makes sense not to universally screen for infections that have minimal or no incidence in the studied population. In order to select RTIs for universal screening, baseline data on incidence or prevalence of various infections must be available. In this case, the prevalence rates of $0 \%$ for syphilis and $0.3 \%$ for gonorrhea, that were found, do not justify universal testing of all clients in family planning clinics, in this community for these two STDs.

Another important recommendation also aimed at cost effectiveness is, "Do not perform tests that have poor predictive value of actual RTIs". Cervical leukocytosis (increased PMNs) was not found to be associated with increased rates of chlamydial infections. Since chlamydia was the RTI with the highest prevalence $(10.3 \%)$, it should continue to be screened for to increase the understanding of this infection that had never been previously recognized in the target population. Screening for chlamydial infections should adhere to the protocol established in the national guidelines (CDC and Prevention, 1993). HCPs should be provided with follow-up reports of the results of their work demonstrating a higher prevalence of chlamydial infections than any of the other tested RTIs. However, the laboratory test for chlamydia is prohibitively expensive and facilities do not exist yet in the laboratories of primary health centers. Experts from the national STD working group suggested to use "increase of PMNs over 30" as a proxy indicator for providing treatment of chlamydia. In the international literature, the test for increased PMNs was not recognized as a valid predictor of chlamydia. Therefore, it is necessary to investigate further the association between an increase of PMNs and chlamydia infection. 
Similarly the "whiff test" performed by mixing $\mathrm{KOH}$ with vaginal discharge, should be discontinued. If this is performed at all, it should be performed according to the study protocols on a glass slide with an immediate "whiff", not on the speculum. Since exact data are not available for the sensitivity and specificity of this test (Wentworth, 1991), and the results in this study had a low sensitivity and specificity when compared to the microscopic clue cell test, it would be reasonable to eliminate this step in the clinical evaluation for future studies.

Replace Gram stains with wet mount microscopy for more rapid evidence of the presence or absence of candidiasis, bacterial vaginosis and trichomoniasis. The results of the wet mount should be available before the client leaves the clinic. This may involve the procurement of a microscope if unavailable, and a trained staff person to read the slides. The preliminary results of wet mount microscopy can be used by the HCP to interpret the common (32.4\%) yet inconclusive finding of cervical erythema, which can be related to a fungal and protozoal infection as well as a bacterial infection. At a minimum, with "wet mount", more clients should be able to leave the clinic with a correct diagnosis for the cause of vaginitis.

Finally the outmoded practice of applying any disinfectant to the vulva or vagina before inserting a speculum should be discontinued. It is an unnecessary procedure for a pelvic exam and may interfere with the ability to detect infections from wet mounts and also compromise endocervical samples.

\section{HCP training and behavior change.}

As expected, HCP behavior change did not take place after a single training event. An example of the prolonged and repeated efforts required to change HCP practices was observed by one of the research assistant during the first three weeks the study. Experienced physicians would ask her where and how specimens for lab testing should be obtained. Such a request may represent not only a knowledge deficit, but also the need for reassurance that they were complying with the protocols of the study. Considering that these experienced physicians had received two 1- hour classes focusing on this topic during the initial "Round Table Discussion" session, a third competency based training for specimen collection on pelvic models, followed by on-site supervised

practice with volunteer clients, their need for repeated coaching during the first three weeks of the study demonstrates the need for a massive infusion of training before a change in practice can be realized.

Compared to the physicians the midwives were much less confident about making a clinical diagnosis. This is understandable, considering their more limited experience and education. Indonesian nursing curriculums, as elsewhere, embrace the theory of "nursing diagnoses", which preclude etiological diagnostic conclusions. This fact, along with the struggle (evident among some physicians also) 
to make an initial diagnosis motivated the development of an RTI/STD Case Management Manual (see Appendix L). This training manual utilized the exact case management protocols (Protocol VI, Appendix D) previously distributed during the initial "Round Table Discussion", but each RTI specific protocol was accompanied by photographs to provide a visual example for future reference. All training should have a firm foundation in the basic clinical protocols and visual references were found to be very useful.

Training did not seem to "trickle-down" to other HCPs on staff. The hospital physicians work with nurses and midwives who perform intakes, referring the FP clients to the appropriate HCP. During a busy clinic, one of the trained physicians attempted to delegate the clinical evaluation to an untrained midwife who declined to perform it with the statement, "I don't have the training, I don't know how to do it".

It is recommended that training must be:

- $\quad$ Based on a foundation (written protocol);

- $\quad$ Presented in a variety of formats, i.e. didactic, written, visual, case study;

- On-going, until an acceptable level of behavioral change is demonstrated;

- $\quad$ Not only competency based instruction and practice on models, but also at the clinic site with each $\mathrm{HCP} /$ client interaction accompanied by mentoring/ coaching from a person with experience in applying the protocols.

- $\quad$ Repeated practice in recording the written results of an evaluation on a standardized form to reinforce the components of an appropriate evaluation;

- In the context of strong expectations and support from respected leaders in the institution and field of study to facilitate acceptance and cooperation.

\section{Additional recommendations}

In closing, to implement the appropriate integrated reproductive health care package, inter-sectoral cooperation between the top strategic planning levels and the primary health care operational levels needs to be improved. In the near future, health programs must address more attention to maternal morbidity, in addition to maternal mortality issues. 


\section{References}

Behets F, Desormeaux J, et al. "Control of sexually transmitted diseases in Haiti: results and implications of a baseline study among pregnant women living in Cite Soleil Shantytowns". The Journal of Infectious Diseases. 1995;172:764-71.

Cates, Willard Jr. and Katherine M. Stone. Family Planning, Sexually Transmitted Diseases and Contraceptive Choice: A Literature Update - Part II. Family Planning Perspectives 1992; 24(3):122-128.

Centers For Disease Control. Guidelines for Prevention of Transmission of Human Immunodeficiency Virus and Hepatitis B Virus to Health Care and Public Safety Workers. Atlanta: U.S. Department of Health and Human Services, 1989.

Centers for Disease Control and Prevention."1993 Sexually Transmitted Disease Guidelines" MMWR 1993, 42:1-102 (RR-14)

Daili, Sjaiful F., Nuning M.K.Masjkuri and Asri C. Adisasmita. Literature Review on Reproductive Tract Infection in Women Associated with Sexually Transmitted Diseases in Indonesia. Jakarta: University of Indonesia, Perinasia, and The Population Council, 1994.

Daili, Sjaiful F. and Jubianto Judanarso, et al. (eds.). Penatalaksanaan Penyakit Menular Seksual: Berdasarkan Pendekatan Sindrom, Fasilitas Laboratorium Sederhana, Laboratorium Khusus. Jakarta: Direktorat Jendral PPM \& PLP Departemen Kesehatan RI and kelompok Studi Penyakit Menular Seksual, 1996.

Desmormeaux J, Behets F, et al. "Introduction of partner referral and treatment for control of STDs in a poor Haitian Community". International Journal of STD \& AIDS; Vol 7, \#7. 1996;502-506.

Fortney, Judith. Reproductive Morbidity: A Conceptual Framework. Family Health International Working Papers No. WP95-02, September, 1995.

Fox, Laurie J., N. E. Williamson, W. Cates, and G. Dallabetta. "Improving Reproductive Health: Integrating STD and Contraceptive Services." In JAMWA 1995;50 (3\&4): 129-135.

Hardee, K \& K.Yount. "From Rhetoric to Reality : Delivery Reproductive Health Promises through Integrated Services". Family Health International, No. WP. 95-01, August, 1995.

Holtrof, G.W. Jakarta Jabotabek. 11 Eds ‘97/98. Djambatan, PT. Jakarta 1997

Hull, Valerie, Ninuk Widyantoro, and Tamara Fetters. "No problem": Reproductive Tract Infections in Indonesia. (To be published) In P. Rice and L. Masterson (eds). Maternity and Reproductive Health in Asian Societies. Australia: Gordon and Breach Science Publishers (Herwood Academic Publishers), 1996.

Jain, Anrudh. "Implementing the ICPD's Message." Studies in Family Planning 1995; 26(5): 296-298. Yayasan Pelita Ilmu. "Info Kasus." Support No.24/III/Juni 97. Jakarta, 1997

North Jakarta Health Office. Profile Kesehatan Kotamadya Jakarta Utara. Jakarta: North Jakarta Health Office, 1995. 
Over M and Piot P. "Human Immunodeficiency Virus infection and other sexually transmitted diseases in developing countries: public health importance and priorities for resource allocation". The Journal of Infectious Diseases, 1996;(Suppl 2): S162-75.

Pratomo H, Nasrin.K, Sudarti, et al. Intervensi untuk Menurunkan Risiko AIDS/HIV dan Hepatitis B di Kalangan Ibu Berpenghasilan Rendah Pengunjung BP/klinik KIA/KB Puskesmas di DKI Jaya dan Jawa Barat. Jakarta, Dirjen Dikti-Dep. P\&K dan FKMUI. 1994

RamaRao, Saumya, John W. Townsend and M.E. Khan. A Model of Costs of RTI Case Management Services in Uttar Pradesh. Technical Paper. New Delhi: The Population Council, New Delhi, India, November, 1996.

Sadli, Saparinah, Ninuk Widyantoro, et al. Indonesian Women's Perspectives on Reproductive Tract Infections: An Explorative Study in Jakarta and Lombok. Jakarta: The Population Council, November 1994.

Susanti, Inne and Jane Patten. Reproductive Health, Existing Services and Perception of needs Among Rural Balinese Women. Results of a Needs Assessment Survey conducted in July and August 1995, Bali, Indonesia. Jakarta: The Population Council, Jakarta and New York in collaboration with AusAID, May 1996.

Susanti, Inne. "RTI Study in Bali: What Could Be Done about STD in a Remote Area?”. Paper presented in Symposium on Improving Women's Health Through Management of STD in Bali, 1993.

The Jakarta Post. “First HIV baby in RI reported.” Jakarta: The Jakarta Post, October 5, 1996.

Thomas T, S. Choudri, et al. "Identifying cervical infection among pregnant women in Nairobi, Kenya: limitations of risk assessment and symptom-based approaches". Genitourninary Medicine. 1996;72:334-338.

Vuylsteke B, Laga M, Alary M et al. "Clinical algorithms for the screening of women for gonococcal and chlamydial infection: evaluation of pregnant women and prostitutes in Zaire". Clinical Infectious Diseases 1993:17:82-8.

Wasserheit, J.N. and K.K. Holmes. "Reproductive Tract Infections: Challenges for International Health Policy, Programs and Research.” In: Adrienne Germain, K.K. Holmes, P.Piot and J.N. Wasserheit (eds). Reproductive Tract Infections: Global Impact and Priorities for Women's Reproductive Health. New York: Plenum Press, 1992.

Wenworth, Berttina B., et al. Laboratory Methods for the Diagnosis of Sexually Transmitted Disease. American Public Health Association $2^{\text {nd }}$ Edition, 1991.

World Health Organization. Recommendations for the Management of Sexually Transmitted Diseases. Geneva, World Health Organization. 1994 (Report No. WHO/GPA/ TEM/94.1).

Zizic, Lara. "Integration - The Challenge of Incorporating STD Services into Maternal and Child Health (MCH), Family Planning (FP) and Primary Health Care (PHC) Settings.” In: Mother Care Matters 1994; 4(3/4):13. 
Name:

Marital Status: S M D

LMP:

$\mathrm{BCM}$

Study \#

Date:

Antibiotics in the last 14 days ?

\begin{tabular}{|c|c|c|}
\hline \multirow{2}{*}{\multicolumn{3}{|c|}{$\begin{array}{l}\text { History } \\
\text { 1. Age: younger than } 25 \text { years? }\end{array}$}} \\
\hline & & \\
\hline \multicolumn{3}{|l|}{ 2. Past history of STD?. } \\
\hline \multicolumn{3}{|l|}{ 3. More than 1 sex partner ? $^{*}$} \\
\hline \multicolumn{3}{|l|}{4 Sexual intercourse without condoms?* } \\
\hline \multicolumn{3}{|l|}{ 5. An unusual vaginal discharge?(bad odor, green/yellow color, itch) * } \\
\hline \multicolumn{3}{|l|}{ 6. Pain with urination $?^{*}$} \\
\hline \multicolumn{3}{|l|}{ 7. Lower abdominal pain?* } \\
\hline \multicolumn{3}{|l|}{ 8. Bleeding after intercourse?* } \\
\hline \multicolumn{3}{|l|}{ 9. Genital sores or lumps?* } \\
\hline $\begin{array}{l}\text { 10. Does your husband/partner have : } \\
\text { a. Unusual discharge from his penis ? } \\
\text { b. Sores or lumps on penis? } \\
\text { c. Any sex partners other than you? }\end{array}$ & & \\
\hline
\end{tabular}

${ }^{*}=$ the past 3 months

\begin{tabular}{|c|c|c|c|c|}
\hline \multirow{2}{*}{\multicolumn{2}{|c|}{ 1. Systemic exam: Skin }} & Neg. Findings & Pos. Findings & \multirow[t]{2}{*}{ Describe } \\
\hline & & & & \\
\hline 2. & :Abdomen & & & \\
\hline 3. Ext. Genital & : Inguinal palpation & & & \\
\hline 4. & Inflammation & & & \\
\hline 5. & Urethral discharge & & & \\
\hline 6. & : Ulcers & & & \\
\hline 7. & Lesions & & & \\
\hline 8. Vagina & Inflammation & & & \\
\hline 9. & Abnormal discharge & & & \\
\hline 10. & : Lesions/ulcers & & & \\
\hline 11. Cervix & Ectopy & & & \\
\hline 12. & Erythema/inflammation & & & \\
\hline 13. & Mucopus & & & \\
\hline 14. & Friability & & & \\
\hline 15. & :Cervical motion tenderness & & & \\
\hline 16. Uterus & : size/shape. & & & \\
\hline 17. Adnexa & Mass & & & \\
\hline
\end{tabular}

\begin{tabular}{|c|c|c|c|c|c|}
\hline & Laboratory & Obtained & Neg. Findings & Pos. Findings & Describe \\
\hline \multicolumn{6}{|c|}{ Microscope: } \\
\hline 1. & Greater than 30 PMNs/HPF & & & & \\
\hline 2. & GNID & & & & \\
\hline 3. & Hyphae or pseudohyphae & & & & \\
\hline 4. & Clue cells & & & & \\
\hline 5. & Motile Trichomonads & & & & \\
\hline 6. & + Amine odor with $\mathrm{KOH}$ & & & & \\
\hline 7. & Cultures Gonorrhea & & & & \\
\hline 8. & Chlamydia (Eliza) & & & & \\
\hline 9. & RPR & & & & VDRL: \\
\hline
\end{tabular}

\section{Diagnosis:}

Treatment

Is pregnancy a possibility? (Circle one) YES NOT SURE NO

1 No treatment indicated

2. $\mathrm{Rx}$ :

3. Additional tests/referrals:

4. Return to clinic :

5. Partner exam, Rx, and referral plans:

6. Counseled re. RTI/STD etiology, Rx, management, \& prevention.

7. Dispensed condoms with instructions. 
LOG FRAME

\begin{tabular}{|c|c|c|c|}
\hline \multirow[b]{2}{*}{$\begin{array}{l}\text { Goal } \\
\text { To facilitate the development and initial implementation } \\
\text { of National policies supportive of HIVIAIDS control } \\
\text { based on the documented effectiveness of interventions } \\
\text { which reduce HIVIAIDS in the demonstration areas. }\end{array}$} & Objectively Verifiable Indicators & Data & Important Assumptions \\
\hline & & & \\
\hline $\begin{array}{l}\text { Purpose } \\
\text { To reach ordinary housewives/women who are generally } \\
\text { unaware of RTI/STD symptoms and potential sequelae } \\
\text { through an integrated RH care services at one PHC } \\
\text { centre, and one public hospital service. }\end{array}$ & $\begin{array}{l}\text { Purpose Indicator } \\
\text { Relevant } \mathrm{MOH} \text { - Sub Directorates and donor agencies will } \\
\text { review the findings and initiate further planning for the } \\
\text { integration of STD services into Reproductive Health Care. }\end{array}$ & Government planning documents. & \\
\hline $\begin{array}{l}\text { Outputs } \\
\text { 1. Strengthen the skills of HC/FP } \\
\text { providers in STD risk assessment, including } \\
\text { diagnosis, treatment and counseling. }\end{array}$ & $\begin{array}{l}\text { 1. Protocols for STD management developed by mid } \\
\text { October } 1996 \text {. } \\
\text { 2. Provider observation checklistlinstrument developed } \\
\text { by end of October } 1996 \text {. } \\
\text { 3. Questionnaire for provider need assessment } \\
\text { developed by end of October } 1996 \text {. } \\
\text { 4. Base-line data report completed by mid Nov. } 1996 \text {. } \\
\text { 5. Implementation plan completed by end of Nov } 1996 \text {. } \\
\text { 6. Training of HC/FP providers in two study sites } \\
\text { completed by mid December } 1996 \text {. } \\
\text { 7. Weekly monitoring carried out at study sites. } \\
\text { 8. Report with recommendations prepared by end of } \\
\text { June } 1997\end{array}$ & $\begin{array}{l}\text { 1. Written protocols developed. } \\
\text { 2. Observation checklist developed. } \\
\text { 3. Questionnaire developed. } \\
\text { 4. Base-line report submitted to HAPP. } \\
\text { 5. Implementation plan submitted to HAPP. } \\
\text { 6. Training reports and training materials. } \\
\text { 7. Monitoring reports. } \\
\text { 8. Report submitted to HAPP }\end{array}$ & \\
\hline 1. Upgraded RTI/STD laboratory services. & $\begin{array}{l}\text { 1. Lab test protocols developed by mid Oct } 1996 \\
\text { 2. Lab. Current performance observed by mid Nov. } 1996 . \\
\text { 3. Training needs of personnel assessed by mid Nov. } \\
\text { 1996. } \\
\text { 4. Training provided to lab. Staff by mid Dec. } 1996 \text {. } \\
\text { 5. Logistic and service delivery upgrading completed by } \\
\text { end of February } 1996 .\end{array}$ & $\begin{array}{l}\text { 1. Written protocols developed. } \\
\text { 2. Current performance reported. } \\
\text { 3. Training needs identified. } \\
\text { 4. Training evaluation report } \\
\text { 5. Logistic and cost estimate reported to HAPP. }\end{array}$ & \\
\hline $\begin{array}{l}\text { 1. Formulation of a strategy for } \\
\text { integrating STD risk assessment into } \\
\text { family planning services. }\end{array}$ & $\begin{array}{l}\text { 1. Committee of MOH officials directly involved in } \\
\text { MCH/FP services formed (\#) by end of October } 1996 \text {. } \\
\text { 2. Advisory committee meetings held every other month, } \\
\text { by November } 1996 \text {. } \\
\text { 3. Strategic plan developed by Advisory Committee and } \\
\text { disseminated to relevant Directorates and donors by } \\
\text { June } 1997 \text {. }\end{array}$ & $\begin{array}{l}\text { Written recommended strategy for integrating STD risk } \\
\text { assessment into FP services. }\end{array}$ & \\
\hline
\end{tabular}


LOG FRAME

\begin{tabular}{|c|c|c|c|}
\hline & Objectively Verifiable Indicators & Data & Important Assumptions \\
\hline $\begin{array}{ll}1.1 & \text { Carry out preparatory work } \\
\text { - } & \text { develop protocols } \\
\text { - } & \text { develop instruments } \\
\text { set up field activities }\end{array}$ & & $\begin{array}{l}\text { (a) } 1 \text { week discussion to review; } \\
\text { (a) } 1 \text { week writing of protocols \& instrument; } \\
\text { (c) } 1 \text { week pre-test } \\
\text { (a) } 1 \text { week revision of protocols \& instrument; } \\
\text { (a) Printing of protocols \& instruments. }\end{array}$ & \\
\hline 1.2 Pre-intervention baseline data & & (a) 1 week direct observation. & \\
\hline $\begin{array}{l}1.3 \text { Develop recording/reporting system for STD } \\
\text { management. }\end{array}$ & & $\begin{array}{l}\text { (a) Recording \& Reporting system documentation } \\
\text { (retrospective } 6 \text { months prior to the study). }\end{array}$ & \\
\hline $\begin{array}{l}\text { 1.4 Prepare for and carry out training of FP workers } \\
\text { in selected facilities. }\end{array}$ & & $\begin{array}{l}\text { (a) Training on risk assessment for all FP clients; } \\
\text { (a) Training on Pelvic; Exams, and detection of } \\
\text { Cervicitis; } \\
\text { (a) Training on treatment guidelines; } \\
\text { (a) Training on client follow-up instruction, and } \\
\text { counseling to obtain treatment compliance, partner } \\
\text { referral and risk reduction behavior. }\end{array}$ & \\
\hline $\begin{array}{l}1.5 \text { Monitor the use of protocols and completion of } \\
\text { record keeping. }\end{array}$ & & $\begin{array}{l}\text { (a) } 6 \text { months observation of the usage of new } \\
\text { protocols; } \\
\text { (a) } 6 \text { regular meetings with counter-part to examine } \\
\text { records, discuss problems, and refresh KAP; } \\
\text { (a) } 6 \text { supervisory visits by Advisory Board Members to } \\
\text { raise awareness of HC/FP.providers of the } \\
\text { importance of protocols usage. } \\
\text { (a) Writing of compiled documents based on weekly } \\
\text { progress reports. }\end{array}$ & \\
\hline 11 Evaluate the impact of the intervention. & & $\begin{array}{l}\text { (a) Analysis of data collected. } \\
\text { (b) Writing overall final report. }\end{array}$ & \\
\hline 21 Carry out laboratory assessment. & & $\begin{array}{l}\text { (a) } 6 \text { months direct observation; } \\
\text { (a) Regular open discussion with laboratory personnel; } \\
\text { (a) Logistic inventory documentation (past } 6 \text { months, } \\
\text { current state, and what is needed in the future. }\end{array}$ & \\
\hline
\end{tabular}


LOG FRAME

\begin{tabular}{|c|c|c|c|}
\hline & Objectively Verifiable Indicators & Data & Important Assumptions \\
\hline $\begin{array}{l}21 \text { Arrange the acquisition of needed } \\
\text { supplies and equipment. }\end{array}$ & & $\begin{array}{l}\text { (a) List of supplies/equipment to purchase is } \\
\text { completed by mid October 1996; } \\
\text { (a) Procurement completed by February } 1997 . \\
\end{array}$ & \\
\hline $\begin{array}{l}21 \text { Develop reporting/recording system for laboratory } \\
\text { test ordered by FP services. }\end{array}$ & & (a) RR system mechanism established by June 1997. & \\
\hline 21 Establish scale of charges for laboratory tests. & & $\begin{array}{l}\text { (a) Record of price/cost charged to clients for } \\
\text { laboratory test and client's ability \& willingness to } \\
\text { pay. }\end{array}$ & \\
\hline $\begin{array}{l}21 \text { Carry out training needs assessment among } \\
\text { laboratory personnel. }\end{array}$ & & (a) List of identified personnel needs to improve skills. & \\
\hline 21 Provide training for laboratory personnel. & & $\begin{array}{l}\text { (a) Training on STD laboratory-Test (wet mount) \& } \\
\text { interpretation; }\end{array}$ & \\
\hline $\begin{array}{l}21 \text { Monitor and supervise the implementation of } \\
\text { upgraded STD laboratory tests. }\end{array}$ & & $\begin{array}{l}\text { (a) } 6 \text { months observation of implementing new } \\
\text { laboratory protocols on Wet-Mount test; } \\
\text { (a) } 6 \text { regular meetings with laboratory personnel to } \\
\text { examine records and discuss problems; } \\
\text { (a) } 6 \text { supervisory visits by Advisory Boards members } \\
\text { to raise awareness of laboratory personnel on the } \\
\text { importance of protocols usage. }\end{array}$ & \\
\hline $\begin{array}{l}21 \text { Prepare post-intervention report on } \\
\text { laboratory test activity results. }\end{array}$ & & $\begin{array}{l}\text { (a) Analysis of data collected. } \\
\text { (b) Writing of overall report. }\end{array}$ & \\
\hline 31 Develop an Advisory Committee & & $\begin{array}{l}\text { (a) Preparatory ( } 2 \text { days) workshop to obtain MOH } \\
\text { officials inputs; } \\
\text { (a) Develop supervisory checklist for field visit; } \\
\text { (c) Develop time-plan; } \\
\text { (d) Arrange visits with counterpart. }\end{array}$ & \\
\hline 31 Intervention implementation and monitoring & & $\begin{array}{l}\text { (a) Advisory Boards Members will visit the study sites; } \\
\text { (a) Supervisory checklist will be used to record } \\
\text { progress and to help counterparts solve daily } \\
\text { problems. }\end{array}$ & \\
\hline $\begin{array}{l}31 \text { Formulation of a strategy to integrate STD risk } \\
\text { assessment in FP services. }\end{array}$ & & $\begin{array}{l}\text { (a) Analysis of problems encountered; } \\
\text { (a) Inventory of suggestions or solutions } \\
\text { recommended/ practiced; } \\
\text { (a) Strategy recommended and endorsed by relevant } \\
\text { MOH officials. }\end{array}$ & \\
\hline
\end{tabular}




\section{PEDOMAN TEKNIS DALAM UJI COBA PENCEGAHAN DAN PENANGGULANGAN PENYAKIT MENULAR SEKSUAL MELALUI PELAYANAN KIA DI TINGKAT PELAYANAN DASAR}

Direktorat Bina Kesehatan Keluarga Ditjen Binkesmas Depkes RI

Disajikan pada:

Pertemuan Persiapan Uji Coba Pencegahan dan Penanggulangan PMS melalui Pelayanan KIA di Tingkat Pelayanan Dasar Jakarta, 4 - 6 April 1997 


\section{Evidence of "Improved Reproductive Health and STD Service for Women Presenting to Family Planning Services \\ in North Jakarta" Protocol Adoption by MOH- Directorate of Family Health-Dir.Gen. of Community Health.}

Formally Announced on April 1997. 


\section{Reproductive Tract Infections / Sexually Transmitted Diseases Clinical Protocols}

The Population Council - Jakarta and the Indonesian Ministry of Health HIV/AIDS Prevention Project under USAID Funding Coordinated by Family Health International/AIDSCAP in collaboration with The U.S.

Centers for Diseases Control

The Population Council

Asia \& Near East Operations Research and

Technical Assistance Project 


\section{Types of Protocol}

II Diseases of Women's Reproductive Organs

III Taking an Effective Reproductive Health History

IV Providing a Reproductive Health Physical Examination

12-15

V Laboratory Tests

VI Diagnosis and Case Management

21-26

VII

RTI/STD Treatment Guidelines

27-30

VIII Client Education and Counseling

31-32

IX Infection Control

33-36

Abbreviations

References 


\section{List of Tables}

Table

Number

Contraceptive Method Review

2

Contraceptive Linkage With STD Prevention

3 Diseases of Women's Reproductive Organs

4 Summary of Laboratory Tests for Specific Infections

5

6

7

8 Partner Interventions

RTI/STD Diagnosis and Case Management Protocol

Health Care Provider Communication Behaviors

Inventory of HCP Components of an STD Education

Session

9

Universal Precautions

10 Glove Requirements for Medical and Surgical Procedural

11 Procedural Specific Antiseptic Steps

$2-3$

5

33

Page

$6-10$

16

22

$23-26$

31

32

34

35 
Appendix D

\section{I. \\ Contraceptive Education}

Optimum reproductive health and infectious disease prevention are very dependent on the individual behavior of contraceptive choice. All FP clients will receive a contraceptive method information review of the most frequently used methods in Jakarta: oral contraceptives (OC's), hormonal injections, intrauterine devices (IUD's), hormonal implants, condoms and surgical sterilization. The informational content will include a description of the contraceptive, it's mechanism of action, effectiveness rates, and a comparison of the method's advantages and disadvantages. The following outlines provides summary points for each commonly used contraceptive in the study area. Methods are presented in their order of use in the population studied.
A. Oral Contraceptives
B. Hormon Injection
C. IUDs
D. Hormonal Implants
E. Condoms
F. Surgical Sterilization 
Table 1. Contraceptive Method Review

\begin{tabular}{|c|c|c|c|c|c|c|}
\hline & $\begin{array}{l}\text { Birth Control } \\
\text { Pills }\end{array}$ & $\begin{array}{l}\text { Hormonal } \\
\text { Injections }\end{array}$ & $\begin{array}{l}\text { Intrauterine Device } \\
\text { (IUD) }\end{array}$ & Hormonal Implant & Condoms & $\begin{array}{l}\text { Surgical } \\
\text { Sterilization }\end{array}$ \\
\hline Description & $\begin{array}{l}\text { Hormones, usually } \\
\text { estrogen and } \\
\text { progestin, taken by } \\
\text { mouth daily for } 21 \text { or } \\
28 \text { days }\end{array}$ & $\begin{array}{l}\text { The hormone, } \\
\text { progestin, is injected } \\
\text { into a muscle in the } \\
\text { upper arm/buttocks } \\
\text { every three months }\end{array}$ & $\begin{array}{l}\text { A small plastic object } \\
\text { which may contain copper } \\
\text { or hormones that is } \\
\text { inserted into the uterus } \\
\text { and left in place for one } \\
\text { year, (some brands may } \\
\text { be left in longer) }\end{array}$ & $\begin{array}{l}\text { Six slender rubber capsules } \\
\text { (match stick in size), that are } \\
\text { surgically inserted under the } \\
\text { skin in the arm and slowly } \\
\text { release the hormone } \\
\text { progestin over a } 5 \text { year } \\
\text { period }\end{array}$ & $\begin{array}{l}\text { A thin latex covering for the penis } \\
\text { that collects semen after a man } \\
\text { ejaculates }\end{array}$ & $\begin{array}{l}\text { The fallopian tubes } \\
\text { are surgically blocked } \\
\text { either by cutting, tying, } \\
\text { clipping or applying } \\
\text { electrical cautery }\end{array}$ \\
\hline $\begin{array}{l}\text { Method of } \\
\text { Action }\end{array}$ & $\begin{array}{l}\text { Primarily by stopping } \\
\text { ovulation }\end{array}$ & $\begin{array}{l}\text {-Inhibits ovulation and } \\
\text { thickens cervical mucus } \\
\text {-Prevents implantation } \\
\text { uterus by disrupting } \\
\text { development of uterine } \\
\text { membrane }\end{array}$ & $\begin{array}{l}\text {-Prevents implantation of } \\
\text { the egg in the uterus } \\
\quad \text { and/or } \\
\text {-Prevents spermatozoa } \\
\text { from reaching fallopian } \\
\text { tubes }\end{array}$ & $\begin{array}{l}\text {-Inhibit ovulation and } \\
\text { thickens cervical mucus } \\
\text {-Prevents implantation in the } \\
\text { uterus by disrupting } \\
\text { development of uterine } \\
\text { membrane }\end{array}$ & $\begin{array}{l}\text { The condom acts as a barrier } \\
\text { preventing direct contact with } \\
\text { semen, genital lesions or } \\
\text { infectious discharge. The condom } \\
\text { blocks the passage of sperm from } \\
\text { the penis into the vagina }\end{array}$ & $\begin{array}{l}\text { The fallopian tube } \\
\text { blockage prevents } \\
\text { sperm and } \\
\text { eggs uniting }\end{array}$ \\
\hline Effectiveness & $98-99 \%$ & More than $99 \%$ effective & $98-99 \%$ & More than $99 \%$ effective & $\begin{array}{l}89-90 \% \text { effectiveness can be } \\
\text { increased with concurrent use of } \\
\text { intravaginal spermicide }\end{array}$ & $\begin{array}{l}\text { More than } 99,5 \% \\
\text { effective }\end{array}$ \\
\hline Advantages & $\begin{array}{l}\text { 1. Reversible } \\
\text { 2. Decreased } \\
\text { menstrual cramps } \\
\text { and pain } \\
\text { 3. Protects against } \\
\text { PID } \\
\text { 4. Can be used for } \\
\text { emergency } \\
\text { contraception }\end{array}$ & $\begin{array}{l}\text { 1. No estrogen } \\
\text { 2. Decreased menstrual } \\
\text { cramps and pain } \\
\text { 3. Decreased risk of } \\
\text { developing } \\
\text { endometrial cancer, } \\
\text { ovarian cancer and } \\
\text { PID } \\
\text { 4. Reversible, but not } \\
\text { immediately } \\
\text { 5. Doesn't interfere with } \\
\text { breast-feeding }\end{array}$ & $\begin{array}{l}\text { 1. Doesn't interfere with } \\
\text { breast-feeding } \\
\text { 2. Reversible } \\
\text { 3. Easy to use }\end{array}$ & $\begin{array}{l}\text { 1. No estrogen } \\
\text { 2. Decreased } \\
\text { menstrual cramps } \\
\text { and pain } \\
\text { 3. Reversible with } \\
\text { surgical removal } \\
\text { 4. Low risk of ectopic } \\
\text { pregnancy } \\
\text { 5. Easy to use } \\
\text { 6. Doesn't interfere with } \\
\text { breast feeding }\end{array}$ & $\begin{array}{l}\text { 1. Prevents the transmission } \\
\text { of STD's and HIV } \\
\text { 2. Effective, if used correctly } \\
\text { 2. Easy to obtain } \\
\text { 3. Inexpensive } \\
\text { 4. Hygienic } \\
\text { 5. Involves both men and } \\
\text { women } \\
\text { 6. No systemic side effects } \\
\text { 7. Doesn't interfere with } \\
\text { breast feeding }\end{array}$ & $\begin{array}{l}\text { 1. Highly effective } \\
\text { 2. Permanent } \\
\text { 3. Nothing to buy or } \\
\text { remember } \\
\text { 3. Partner } \\
\text { compliance not } \\
\text { required } \\
\text { 4. No interruption in } \\
\text { love making } \\
\text { 5. Very private/ } \\
\text { personal }\end{array}$ \\
\hline
\end{tabular}


Table 1. Contraceptive Method Review

\begin{tabular}{|c|c|c|c|c|c|c|}
\hline & Birth Control Pills & Hormonal Injection & $\begin{array}{l}\text { Intrauterine Device } \\
\text { (IUD) }\end{array}$ & Hormonal Implant & Condoms & $\begin{array}{c}\text { Surgical } \\
\text { Sterilization }\end{array}$ \\
\hline $\begin{array}{l}\text { Disadvantages } \\
\text { and Cautions }\end{array}$ & $\begin{array}{l}\text { 1. Pills must be taken } \\
\text { daily } \\
\text { 2. Spotting the first } 2 \\
\text { months } \\
\text { 3. Temporary nausea* } \\
\text { 4. Headaches } \\
\text { 5. Depression* } \\
\text { 6. Cervical ectopy and } \\
\text { chlamydia } \\
\text { infections (if } \\
\text { exposed) } \\
\text { 7. No protection } \\
\text { against other STDs, } \\
\text { including HIV } \\
\text { 8. Fluid retention } \\
\text { 9. Gallbradder } \\
\text { disease } \\
\text { 10. Benign liver } \\
\text { tumors** } \\
\text { 11. Circulatory } \\
\text { complications which } \\
\text { may be dangerous, } \\
\text { particularly for } \\
\text { people who } \\
\text { smoke** }\end{array}$ & $\begin{array}{l}\text { 1. No protection from } \\
\text { STDs, including HIV } \\
\text { 2. Menstrual cycle } \\
\text { disturbance, (increased } \\
\text { spotting and } \\
\text { amenorrhea) } \\
\text { 3. Weight gain, (1 kg. per } \\
\text { year) } \\
\text { 4. Breast tenderness } \\
\text { 5. Decreased bone density } \\
\text { 6. Must return every three } \\
\text { months }\end{array}$ & $\begin{array}{l}\text { 1. PID. Especially if } \\
\text { gonorrhea \&/ } \\
\text { chlamydia } \\
\text { is not recognized and } \\
\text { treated before insertion } \\
\text { 2. HIV, increased risk of } \\
\text { transmission if } \\
\text { exposed } \\
\text { 3. No protection from } \\
\text { other } \\
\text { STDs, including HIV } \\
\text { 4. Menstrual problems } \\
\text { (increased bleeding } \\
\text { and cramping)* } \\
\text { 5. Expulsions } \\
\text { 6. Risk of uterine } \\
\text { perforation during } \\
\text { insertion** }\end{array}$ & $\begin{array}{l}\text { 1. No protection from } \\
\text { STDs including HIV } \\
\text { 2. Menstrual cycle } \\
\text { disturbance, (increased } \\
\text { spotting and amenorrhea) } \\
\text { 3. Weight gain - less than } \\
\text { 2.5 kg. in } 5 \text { years } \\
\text { 4. Breast tenderness* } \\
\text { 5. Difficult removal } \\
\text { 6. Local infection at implant } \\
\text { site }^{\star} \\
\text { 7. Increased rate of benign } \\
\text { ovarian cysts* }\end{array}$ & $\begin{array}{l}\text { 1. Interruption at foreplay } \\
\text { to put condom on penis } \\
\text { 2. Latex allergies } \\
\text { 3. Male involvement } \\
\text { 4. Embarrassment } \\
\text { 5. Breakage }\end{array}$ & $\begin{array}{l}\text { 1. Permanent } \\
\text { 2. Reversibility } \\
\text { difficult and } \\
\text { expensive } \\
\text { 3. No protection } \\
\text { against STDs } \\
\text { and HIV } \\
\text { 4. Sterilization } \\
\text { procedure is } \\
\text { difficult } \\
\text { 5. Requires } \\
\text { hospitalization } \\
\text { 6. Surgical risks- } \\
\text { infection, } \\
\text { bleeding, } \\
\text { anesthesia, etc }\end{array}$ \\
\hline
\end{tabular}

Adapted from :

Hatcher, R. et al, 1994. Contraceptive Technology and

JHPIEHO, 1994. International Family Planning Guide A Prototypic Reference Manual 


\section{II. \\ Diseases of \\ Women's Reproductive Organs}

All study participants will also receive information on infectious diseases that are specific to reproductive health. An inclusive review of every potential pathogen and disease related to the reproductive tract is beyond the scope of this initial study. The diseases that will be discussed will include RTI's that may be endogenous, iatrogenic, and or sexually transmitted. Some sexually transmitted infections may be acquired non-sexually. The specific infections this study will address are:

\section{Trichomoniasis \\ Bacterial Vaginosis \\ Candidiasis \\ Gonorrhea \\ Chlamydia \\ Syphilis \\ Chancroid \\ Herpes Simplex Virus II (HSV II) \\ Human Papilloma Virus (HPV) \\ Human Immunodeficiency Virus (HIV).}

An effort will be made to link this theoretical infectious disease knowledge to human sexual behavior. The purpose of this infectious disease review will be done to enable the FP client to self assess her potential of RTI infection. A connection between the women's contraceptive method choice and her protection from an STD if exposed will also be discussed. See Table 2. 
Table 2. Contraceptive Linkage with STD Prevention

\begin{tabular}{|l|c|}
\hline \multicolumn{1}{|c|}{ Contraceptive Method } & STD Prevention? \\
\hline Oral Contraceptives & No \\
\hline Injections & No \\
\hline IUDs & $\begin{array}{r}\text { No - Plus, carries an increased risk of causing } \\
\text { PID with IUD insertion }\end{array}$ \\
\hline Implant & No \\
\hline Condoms & Yes \\
\hline Surgical Sterilization & No \\
\hline
\end{tabular}

Adapted from Cates, W. and Katherine M. Stone. "Family Planning, Sexually Transmitted Diseases and Contraceptive Choice: a Literature Update-Part I." Family Planning Perspectives, March/April 1992, 24: 75-84.

Each RTI informational session will include a review of:

- The causative organism;

- Potential for sexual transmission;

- Signs and symptoms of the disease;

- Summary of potential complications;

- Ability to be treated.

See also Table 3 for a description teaching content. 
Table 3. Diseases of Women's Reproductive Organs*

\begin{tabular}{|c|c|c|c|c|c|}
\hline Disease & Caused by & $\begin{array}{c}\text { Sexually } \\
\text { Transmitted } \\
?\end{array}$ & Signs \& Symptoms & Potential Complications & $\begin{array}{l}\text { Is Disease } \\
\text { Treatable? }\end{array}$ \\
\hline Trichomoniasis & $\begin{array}{l}\text { Trichomonas } \\
\text { Vaginalis; } \\
\text { (protozoa) }\end{array}$ & Yes & $\begin{array}{l}\text { 1. Abnormal vaginal } \\
\text { discharge: green, } \\
\text { yellow color, foamy, } \\
\text { foul odor } \\
\text { 2. Vulvar swelling, } \\
\text { itching, and discomfort }\end{array}$ & $\begin{array}{l}\text { 1. Skin can become excoriated } \\
\text { 2. Pregnancy may be associated } \\
\text { with premature deliveries } \\
\text { 3. Facilitates HIV infection }\end{array}$ & Yes \\
\hline $\begin{array}{l}\text { Bacterial Vaginosis } \\
\text { (BV) }\end{array}$ & $\begin{array}{l}\text { A syndrome } \\
\text { caused by } \\
\text { several species } \\
\text { of bacteria }\end{array}$ & $\begin{array}{l}\text { Not most of } \\
\text { the time }\end{array}$ & $\begin{array}{l}\text { 1. Excessive "fishy" } \\
\text { smelling vaginal } \\
\text { discharge } \\
\text { 2. Occasionally has } \\
\text { vulvar itching }\end{array}$ & $\begin{array}{l}\text { 1. Pregnancy may be } \\
\text { associated with premature } \\
\text { deliveries } \\
\text { 2. May increase the chance of } \\
\text { tubal infections }\end{array}$ & Yes \\
\hline $\begin{array}{r}\text { Candidiasis } \\
\text { ("yeast") }\end{array}$ & $\begin{array}{l}\text { Candida } \\
\text { albicans; } \\
\text { (fungus) }\end{array}$ & $\begin{array}{l}\text { Not most of } \\
\text { the time }\end{array}$ & $\begin{array}{l}\text { 1. Curdy white "spoiled } \\
\text { milk" vaginal } \\
\text { discharge } \\
\text { 2. Itching } \\
\text { 3. Redness and swelling } \\
\text { of the vulva }\end{array}$ & $\begin{array}{l}\text { 1. Skin can become excoriated } \\
\text { 2. Facilitates HIV infection }\end{array}$ & Yes \\
\hline
\end{tabular}


Table 3. Diseases of Women's Reproductive Organs

\begin{tabular}{|l|l|l|l|l|l|}
\hline Disease & Caused by: & $\begin{array}{c}\text { Sexually } \\
\text { Transmitted } \\
\boldsymbol{?}\end{array}$ & Signs \& Symptoms & \multicolumn{1}{|c|}{ Potential Complications } & Is Disease \\
Treatable?
\end{tabular}


Table 3. Diseases of Women's Reproductive Organs

\begin{tabular}{|c|c|c|c|c|c|}
\hline Disease & Caused by: & $\begin{array}{c}\text { Sexually } \\
\text { Transmitted } \\
?\end{array}$ & Signs \& Symptoms & Potential Complications & $\begin{array}{l}\text { Is Disease } \\
\text { Treatable? }\end{array}$ \\
\hline Syphilis & $\begin{array}{l}\text { Treponema } \\
\text { pallidum; } \\
\text { a spirochete }\end{array}$ & Yes & $\begin{array}{l}\text { A chronic and systemic } \\
\text { infection with } 3 \text { stages: } \\
\text { 1. Primary-painless } \\
\text { genital sore called a } \\
\text { "chancre" } \\
\text { 2. -Secondary- } \\
\text { generalized skin rash, } \\
\text { or } \\
\text {-Latent time without } \\
\text { symptom } \\
\text { 3. Tertiary-neurologic, } \\
\text { cardiovascular, \&/or } \\
\text { skin }\end{array}$ & $\begin{array}{l}\text { 1. Can seriously damage the brain \& } \\
\text { heart if not treated } \\
\text { 2. During pregnancy can be passed } \\
\text { to the unborn baby \& cause } \\
\text { miscarriages \&/or birth defects } \\
\text { 3. Facilitates HIV infection }\end{array}$ & Yes \\
\hline Chancroid & $\begin{array}{l}\text { Hemophilus } \\
\text { ducreyi; } \\
\text { a bacteria }\end{array}$ & Yes & $\begin{array}{l}\text { Often asymptomatic, or } \\
\text { 1. Single painful sore } \\
\text { 2. Painful swollen lump } \\
\text { in the groin that can } \\
\text { rupture }\end{array}$ & $\begin{array}{l}\text { 1. Sore can become infected and } \\
\text { cause tissue death } \\
\text { 2. Sore facilitates HIV infection } \\
\text { if exposed }\end{array}$ & Yes \\
\hline
\end{tabular}


Table 3. Diseases of Women's Reproductive Organs

\begin{tabular}{|c|l|l|l|l|l|}
\hline Disease & Caused by: & $\begin{array}{c}\text { Sexually } \\
\text { Transmitted ? }\end{array}$ & Signs \& Symptoms & Potential Complications & $\begin{array}{c}\text { Is Disease } \\
\text { Treatable? }\end{array}$ \\
\hline $\begin{array}{c}\text { Genital Herpes } \\
\text { (HSV II) }\end{array}$ & $\begin{array}{l}\text { Herpes } \\
\text { Simplex } \\
\text { Virus }\end{array}$ & Yes & $\begin{array}{l}\text { Initial infections: } \\
\text { 1. Painful single or multiple } \\
\text { blisters on the genitals } \\
\text { 2. Blisters pop \& leave sores } \\
\text { that crust, then disappear } \\
\text { Recurrent outbreaks: } \\
\text { 1. Blisters as described above, } \\
\text { but not as painful which can } \\
\text { be triggered by stress, } \\
\text { menstruation, alcohol } \\
\text { consumption }\end{array}$ & $\begin{array}{l}\text { 1. Nerve pain } \\
\text { 2. Can be transmitted to a newborn } \\
\text { at birth if active lesions are } \\
\text { present and cause a serious } \\
\text { systemic infection to the baby } \\
\text { which could result in death } \\
\text { 3. Facilitates HIV infection }\end{array}$ & $\begin{array}{l}\text { No, but antiviral } \\
\text { meds can shorten } \\
\text { pain\& length of } \\
\text { outbreak }\end{array}$ \\
\hline $\begin{array}{c}\text { Genital warts } \\
\text { (HPV) }\end{array}$ & $\begin{array}{l}\text { Human } \\
\text { Papilloma } \\
\text { virus }\end{array}$ & Yes & $\begin{array}{l}\text { 1. Single or multiple fleshy } \\
\text { wart-like growths on the } \\
\text { genitals }\end{array}$ & $\begin{array}{l}\text { 1. Lesions may enlarge and grow } \\
\text { together } \\
\text { 2. Some types of HPV may be } \\
\text { related to cervical cancer }\end{array}$ & $\begin{array}{l}\text { Only to remove } \\
\text { the wart, it doesn't } \\
\text { kill HPV }\end{array}$ \\
\hline
\end{tabular}


Table 3. Diseases of Women's Reproductive Organs

\begin{tabular}{|c|c|c|c|c|c|}
\hline Disease & Caused by: & $\begin{array}{c}\text { Sexually } \\
\text { Transmitted ? }\end{array}$ & Signs \& Symptoms & Potential Complications & $\begin{array}{l}\text { Is Disease } \\
\text { Treatable? }\end{array}$ \\
\hline HIVIAIDS & $\begin{array}{l}\text { Human } \\
\text { Immuno- } \\
\text { deficiency } \\
\text { Virus }\end{array}$ & $\begin{array}{l}\text { Yes, also by } \\
\text {-Blood } \\
\text { transfusion } \\
\text {-Injection } \\
\text {-Maternal fetal } \\
\text { transmission in } \\
\text { pregnancy or } \\
\text { perinatally }\end{array}$ & $\begin{array}{l}\text { 1. May have a flu-like illness } 2 \\
\text { weeks after infection } \\
\text { 2. Recover and be } \\
\text { asymptomatic } \\
\text { for } 5 \text { - } 10 \text { yrs followed by: } \\
\text { 3. Minor symptoms: fever, night } \\
\text { sweats, yeast infections, } \\
\text { fatigue, \& weight loss, which } \\
\text { progresses to: } \\
\text { 4. Multiple illnesses: cancers, } \\
\text { neurologic diseases, } \\
\text { bacterial, viral, fungal, \& } \\
\text { parasitic infections }\end{array}$ & $\begin{array}{l}\text { 1. If pregnant, HIV also may be } \\
\text { spread to the unborn baby } \\
\text { 2. End stage HIV infection = } \\
\text { "AIDS": causing severe } \\
\text { illnesses and death }\end{array}$ & $\begin{array}{l}\text { No, however, new } \\
\text { combinations of } \\
\text { antiviral } \\
\text { medications may } \\
\text { prolong the } \\
\text { asymptomatic } \\
\text { period of infection }\end{array}$ \\
\hline
\end{tabular}


Appendix D

\section{III. \\ Taking an Effective Reproductive Health History}

A comprehensive reproductive health history is the foundation for the provision of quality health care for the woman seeking FP services. It must include relevant data that will :

- focus the direction of clinical services to meet the needs of the client;

- support future contact with the client if laboratory or examination results indicate the need for followup;

- identify previous contraceptive problems;

- reveal contraindications for specific contraceptive use;

- direct the HCP to identify potential RTI's, (this process is often referred to as "risk assessment");

- support effective and safe use of prescriptive medications.

The content of a woman's reproductive health history is of an intense personal nature. It involves highly confidential information about her pregnancy, contraceptive and sexual history. Therefore, it is imperative that the interviewing HCP is perceived as an advocate and not an interrogator. This will require skill and tact from the HCP performing the interview. To support a philosophical position of client advocacy, the HCP must demonstrate the following communication principals to the FP client:

- greet the client warmly and with respect;

- interview clients in a private environment;

- establish confidentiality;

- use understandable language;

- ask questions in a non threatening, non judgmental manner;

- listen carefully.

It is always best to conduct a reproductive health history when the patient is fully dressed and prior to the start of the physical examination. Even though the eventual answer to most of the history questions is either a "no" or a "yes", it will behave the HCP to frame these questions in an open ended style.

The HCP will attempt to gain knowledge of the client's particular:

- obstetric history and current potential pregnancy status;

- contraceptive history;

- medical history (critical for contraceptive and pharmaceutical contraindications);

- risk markers (age, marital status, past history of STDs, contraceptive behavior);

- RTI/STD symptomatology;

- perceptions of her partner's potential for STD symptomatology and risk behavior. 


\section{IV. \\ Providing a Reproductive Health Physical Examination}

All study participants will receive physical examinations (PE) as part of their clinical evaluation. The standardized PE will be targeted toward contraceptive and RTI assessment, diagnosis, and treatment. The four main components of a PE will include a generalized reproductive assessment, external genital exam, speculum exam, and a bimanual exam. Prior to starting the PE, the HCP will give a verbal explanation of the exam procedures and purpose to the client. Any questions or concerns the client has regarding the procedures will be discussed and answered to her satisfaction. The principal that should guide all PE procedures performed on the client should be service delivery via interactive education as opposed to task accomplishment. The following outline describes PE procedures and rationales. An empty bladder before an exam will help reduce discomfort.

\section{A. Generalized Reproductive Target Organ Assessment}

1. Skin. The HCP will inspect skin for rashes, with special attention to rule out macularpapular rashes of the trunk, palms, and feet characteristic of secondary syphilis.

2. Abdomen. Palpate while client is supine for hepatomegaly, organomegaly, \&/or abnormal tenderness and pain

\section{B. External Genitalia}

This part of the PE is performed while the client is undressed from the waist down, covered in a disposable or clean drape and in the lithotomy position. The examiner must have his or her predominant hand gloved in a clean, previously unused or disinfected glove. Effective visual inspection requires the presence of an additional light source, like a goose neck lamp, which can be aimed at the clients genitalia. The HCP will then visually inspect and palpate the external genitals for the presence or absence of any signs of :

1. Inguinal area.

Palpation must be done with a gloved hand to rule out lymphadenopathy.

2. Inflammation

Erythema, edema, excoriation.

3. Urethral discharge

After separating and retracting the labiums majora and minora, strip the urethra with a gloved middle finger by milking the anterior vaginal wall once, and observe for discharge 


\section{Ulceration}

Note the approximate number, size, distribution pattern, and client's perception of pain to the ulcer when it is palpated with a sterile cotton swab. Describe the margin style of the ulcer border.

\section{Vesicles}

Note again the quality and characteristics as described above. Review the client's history for any pattern recurrence (HSV II).

\section{Lesions}

Describe the type and quality of skin lesions. If suspicious lesions are verruciform (wart like), but not classic, the area can be swabbed with acetic acid (one part plain vinegar to three parts uncontaminated water) to render any HPV lesions to turn a more visible white than the surrounding area.

\section{Additional Findings}

Document any additional areas of variation.

\section{Speculum Exam}

Using an educational approach to task performance, describe techniques the examined woman can use to minimize discomfort during speculum insertion and placement i.e. advising her that abducting her knees to a wide angle opens the perineal muscles as opposed to constricting them when the knees are adducted (Note: never tell a woman to "relax" during a pelvic exam). It's easy for the examiner to say this, but it is not educational, doesn't promote relaxation, and doesn't give the woman the skills to cope with future pelvic examinations.

Always use a clean speculum that has been sterilized since it's previous client use. If possible, warm the unlubricated speculum with warm, uncontaminated, water prior to insertion. Test the speculum temperature on the inner thigh of the examined woman and determine if the temperature of the speculum is satisfactory to her. Adjust the temperature if necessary.

Insert the gloved index finger of the predominate hand into the vagina and locate the cervix to determine the angle of speculum insertion. Next, lower the posterior vaginal floor with the same inserted gloved index finger. Slide the closed speculum over the internal finger, and withdraw the gloved index finger. With your "external" or non-predominate hand, open the blades of the speculum until the cervix is visible, then secure the speculum to allow visual inspection of the vagina and cervix. The vagina and cervix can now be inspected for signs of:

\section{Vaginal mucosa inflammation}

Erythema, edema

\section{Abnormal vaginal discharge}

The following clinical signs signal the judgement of abnormal vaginal discharge:

a. $\quad$ curdy white exudate (like spoiled milk), (suspect candidiasis);

b. foul (fishy) smelling homogenous white or greyish discharge that coats the walls of the vagina, (suspect Bacterial Vaginosis).

c. frothy gray or green discharge with a strawberry cervix, (suspect Trichomoniasis). 
All of the above mentioned types of abnormal vaginal discharge may or may not be accompanied by signs of tissue inflammation, although inflammation signs are usually more common in cases of candidiasis or trichomoniasis. The symptomatic complaint of vulvar pruritis can also be found in any of these three vaginal RTI's, although it is more classically indicative of either candidiasis or trichomoniasis. The existence of any abnormal vaginal discharge must be accompanied by wet mount microscopy to confirm or rule out a RTI diagnosis of candidiasis, bacterial vaginosis or trichomoniasis. Clinical findings can be misleading and only microscopy can be relied on for diagnosis.

Obtain wet mount specimens at this time

\section{Ulcers}

As previously described in "External Genitalia".

\section{Lesions}

Also as previously described.

\section{Cervical ectopy}

The cervix should be inspected after any excessive vaginal discharge has been removed with a clean disposable scopette. Cervical ectopy is detected by noting the junction between smooth columnar tissue and "grape-like" endocervical tissue. Ectopy is more common in oral combined contraceptive use due to the influence of estrogen.

Obtain any indicated cervical specimens at this time

\section{Cervical erythema}

A reddened, angry appearance.

7. Cervical friability

The cervix bleeds easily when touched with a sterile swab.

8. Cervical mucopus

A tenacious cloudy or yellow discharge from the cervical os.

\section{Additional findings}

Describe any additional variations.

\section{Bimanual Exam}

The bimanual exam is necessary to rule out uterine enlargement suggestive of pregnancy as well as uterine and or adnexal masses indicating the need for additional evaluation to rule out pathology. After careful removal of the speculum, the first two fingers of the vaginal examining hand are lubricated and inserted into the vagina. Locate and palpate the cervix. Proceed with an assessment of the pelvic organs.

\section{Cervical Motion Tenderness (CMT)}

Can be demonstrated if moving the cervix side to side causes pain. 


\section{Uterus size}

Can be determined by locating the fundus with the outside hand while palpating the abdomen medially in the direction of the cervical neck. Record the size of the uterus in centimeters. Note any abnormal uterine mobility or contour.

\section{Uterus position}

Record one of the following uterine positions:

a. $\quad$ Anteverted (AV);

b. $\quad$ Midline (Mid);

c. $\quad$ Retroverted (RV).

\section{Uterine tenderness}

Note the presence or absence of unusual pain when palpating the uterus.

\section{Ovaries/Adnexa}

The abdominal hand produces pressure on the lower abdomen and the fingers of the vaginal hand are swept to the side to evaluate the adnexal structures of the fallopian tubes and ovaries. Only the ovaries should be palpable in a normal exam, and often they are not even felt. A normal ovary in a menstruating woman measures approximately $3 \times 3 \times 2 \mathrm{~cm}$. Any enlargement above 5 to $6 \mathrm{~cm}$ is an abnormal (ABN) finding.

\section{Adnexal pain}

Note unusual tenderness.

\section{Rectal}

It is not necessary to do a rectal-vaginal exam if the uterus is anteverted, because adequate palpation of the posterior fundus is possible. If the uterus is midline or retroverted, inform the client that you will examine her rectally. Change gloves, and with a well lubricated middle finger in the rectum and the index finger in the vaginal vault, evaluate for nodularity and polyps. Pressure from the abdominal hand brings the uterus down so that it's entire posterior surface can be palpated with the rectal finger.

\section{Additional findings}

Record any additional abnormalities. 


\section{V. \\ Laboratory Tests}

Laboratory specimens to aid in the diagnosis of an RTI will be obtained by clinical staff at the study site. All clients enrolled in the study should have specimens collected as described in Table 4.

Table 4. Summary of Laboratory Tests for Specific Infections

\begin{tabular}{|l|l|l|}
\hline \multicolumn{1}{|c|}{ Organism/Syndrome } & \multicolumn{1}{|c|}{ Lab Tests } & \multicolumn{1}{|c|}{ Testing Site } \\
\hline Trichomoniasis & Saline Wet Mount & Clinic, \\
\hline Bacterial Vaginosis & $\begin{array}{l}\text { Saline Wet Mount or } \\
\text { Gram-stain }\end{array}$ & $\begin{array}{l}\text { Clinic, with } \\
\text { Referral lab validation } \\
\text { of Gram stains. }\end{array}$ \\
\hline Candidiasis & $\begin{array}{l}\text { KOH Wet Mount or } \\
\text { Gram-stain }\end{array}$ & $\begin{array}{l}\text { Clinic, with } \\
\text { Referral lab validation } \\
\text { of Gram stain. }\end{array}$ \\
\hline Chlamydia & ELISA (not confirmatory) & Referral lab. \\
\hline Gonorrhea & Gram-stain (Not confirmatory) & $\begin{array}{l}\text { Clinic, with referral } \\
\text { lab validation. } \\
\text { Referral lab }\end{array}$ \\
\hline Syphilis & Cervical Culture (Confirmatory) & $\begin{array}{l}\text { Referral Lab } \\
\text { TPHA if RPR/VDRL is + }\end{array}$ \\
\hline HIV & ELISA and Western Blot & $\begin{array}{l}\text { This study will not } \\
\text { include HIV } \\
\text { screening. If in the } \\
\text { judgement of the } \\
\text { HCP, this screening is } \\
\text { indicated, outside } \\
\text { referral to existing } \\
\text { alternative test sites } \\
\text { will be recommended. }\end{array}$ \\
\hline
\end{tabular}

\section{Cervical Specimens}

Endocervical swabs will be obtained on all enrolled clients. Endocervical specimens should especially be obtained to back-up a judgement of MPC, which is a clinical diagnosis based on the visible presence of either cervical erythema, friability, and or mucopus. If any of these three clinical signs are present along with the presence of cervical ectopy, a higher index of suspicion of MPC should be maintained. The two most frequent etiologies of MPC are infections with N. Gonorrhoeae or Chlamydia Trachomatis. 
These two specimens should be collected in the following order:

one swab for the gonorrhea culture and Gram-stain, followed by a separate dacron swab for the chlamydia enzyme test.

An outline for procedural steps necessary to accomplish the collection of endocervical specimens follows.

\section{Cervical preparation}

Use a large swab or scopette to remove any vaginal discharge from the os, use great care to avoid contaminating the endocervical specimen with vaginal discharge.

\section{Endocervical swab for gonorrhea culture and gram stain}

Insert sterile cotton swab 1-2 cm, into the endocervical canal (past the squamo-columnar junction). Rotate the swab 5 to 10 times to permit the absorption of exudate.

\section{Swab color check}

Check the color of the swab and be aware that a yellow exudate indicates an increased number of polymorphonuclear (PMN) leukocytes.

\section{Gonorrhea culture}

Immediately inoculate the swab onto the culture plate using a "Z" streak for a modified Thayer Martin (MTM) plate. Cross streak the inoculated plate immediatly with a sterile, wire loop and place in a candle extinction jar.

\section{Gram-stain slide preparation}

Roll (don't rub), the swab onto a clean dry glass slide labeled with the patients ID. All aspects of the swab head should come in contact with the slide. Smears should cover at least one square centimeter of the slide. They should be air dried and heat fixed. Slides should be carefully stained by the Gram method and examined for the presence of characteristic gram negative intracellular diplococci.

\section{Chlamydia enzyme specimen}

Use only the sterile swab that comes with the commercially pre-packaged test kit. Insert this swab $1-2 \mathrm{~cm}$ into the endocervical canal (past the squamo-columnar junction). Rotate the swab against the wall of the endocervical canal several times for $\mathbf{1 0}$ - $\mathbf{3 0}$ seconds. Withdraw the swab without touching any vaginal surfaces and place it in the appropriate transport medium.

Note: Do not prep or wash the vulva or vagina with any solution prior to the collection of vaginal or endocervical specimens. 
Appendix D

\section{Wet Mount Microscopy}

All clients will have vaginal discharge specimens analyzed within the clinic site by wet mount microscopy or Gram stain. HCP's which may include the examining doctor, midwife, or nurse can perform this simple "in-house" test if existing staffing patterns do not include a laboratory technologist.

A wet mount specimen will consist of a small amount of vaginal fluid collected on a clean cotton swab from the vaginal fornix during the speculum exam. Separate slides will be prepared for saline and $10 \%$ potassium hydroxide $(\mathrm{KOH})$ analysis. Place a sample of vaginal discharge on one of the glass slides and combine with 2 drops of normal saline then cover with a glass cover slip (combine the reagent + discharge by mixing with the wooden tip of the swab, not the cotton). Place a second sample of vaginal discharge on a separate slide and combine with 2 drops of $10 \%$ potassium hydroxide $(\mathrm{KOH})$. The HCP will note during this process the presence or absence of a positive $(+)$ amine (fishy) odor. This is commonly referred to as the "Whiff test" and is suggestive of the RTI, bacterial vaginosis.

The HCP will microscopically under low power and scan the prepared slides for the presence or absence of:

- Hyphae, pseudohyphae or budding yeast (candidiasis), \&/or:

- motile trichomonads (trichomoniasis), \&/or;

- clue cells (bacterial vaginosis), \&/or;

- increased number of white blood cells, more than 30 WBC's/HPF (inflammatory vaginitis i.e., trichomoniasis or candidiasis, as well as a mucopurulent cervicitis).

During the microscopic scan, it is important to scan the slides thoroughly and remember that the identification of one vaginal pathogen does not rule out the discovery of a second or third organism, indicative of concurrent, multiple infections.

\section{Gram Stain}

A direct Gram stain of vaginal fluid may also be used to detect the presence of vaginal yeast and clue cells. Use a cotton-tipped applicator to transfer vaginal fluid to a glass microscope slide, heat fix, Gram stain and examine under oil immersion.

Note:

If a Gram stain is performed as a screen for Neisseria gonorrhoeae, the specimen must be collected from the endocervix with careful technique to avoid vaginal discharge contamination. Prepare a thin uniform smear by gently rolling the swan on a slide. Slides should be scanned by the zig-zag method for at least 2 minutes before caulling them negative for gram-negative intra cellular diplococci (GNID). The description GNID should be used only when typical pairs of gram-negative, kidney beam-shaped diplococci are found within polymorphonuclear leucocytes. Since the sensitivity of a Gram stain from an endocervix is so low (50-70\%, Adimora et all. 1994) a culture should always be used to diagnose cases of $\mathrm{N}$. gonorrheae in women. 
Appendix D

\section{Serology}

\section{Syphilis}

All participants will have a $5 \mathrm{ml}$. sample of blood ascetically drawn for syphilis serology using the RPR as a screen. In the event that an RPR is reactive, a titrated VDRL will be automatically run and if positive, the same sample of blood will be retested for confirmation by TPHA.

\section{HIV}

It is beyond the scope of this initial study to provide serological testing for HIV. If, in the judgement of the HCP this further testing is indicated, the patient will be advised that she should obtain serological testing in an alternate test site.

\section{Laboratory Logistical Requirements}

Both permanent and consumable supplies will be necessary to obtain vaginal wet mount, endocervical, and serological specimens. The following lists describe the projected supplies required to complete the tests.

\section{Wet Mount Microscopy:}

- Microscope

- Frosted glass slides

- Glass cover slips

- Cotton swabs

- Normal saline solution

- $10 \%$ potassium hydroxide $(\mathrm{KOH})$

Gram-stain specimens: (For male partners)

- Frosted glass slides

- Sterile urethal swabs

- Crystal violet solution ( $85 \%$ dye)

- Ethanol (95\%)

- Ammonium oxalate

- Distilled water

- Iodine crystals

- Potassium iodine

- Sodium bicarbonate $5 \%$ aqueous solution

- Acetone

- Safranin O 


\section{Gonorrhea cultures:}

- Refrigerator to store culture plates

- Anaerobic Incubator

- Culture plates

\section{Chlamydia tests:}

- $\quad$ Prepackaged comprehensive test kits

\section{Serology Tests}

- Vacuum tube

- Tube $5 \mathrm{cc}$ with red cover (without anticoagulant)

- Sterile needles

- Glove hands

- Cotton with ethanol alcohol

- Cotton ball

- Band aid 
Appendix D

\section{VI. \\ Diagnosis and Case Management}

\section{STD Diagnosis}

The impact of an STD diagnosis on the client has medical as well as emotional implications. It is of paramount importance that an STD diagnosis is based on good historical, clinical, and when possible, laboratory evidence. A conceptual model of STD diagnostic realms recognizes the interdependence of the three evaluations of history, examination, and laboratory results that must be simultaneously considered to reach a fair and accurate diagnosis of an STD. Such a diagnosis requires scrupulous attention on the part of the HCP to the client's history, chief complaint(s), and demonstration of objective physical signs. The evidence that is acquired during this process should be documented in a standardized evaluation in the client's medical record.

All evaluations must start from the client's history. The subjective history is a vital foundation for a correct diagnosis. Next, objective data discovered during the physical examination will serve to guide the HCP in the collection of laboratory specimens. Data yielded from the physical examination and the laboratory must be balanced and are often equally important in leading the HCP to a legitimate diagnosis. Particularly in the case of cervicitis, powers of human observation and laboratory testing are imperfect. In the case of the viral infections of HSVII and HPV, where no treatment regimens for pathogen eradication are in existence, it is legitimate to rely of the presence of classically symptomatic signs to conclude an empiric diagnosis.

Please see Table 6 (pp.23-26) for a collective view of optional indicators and mandatory lab results to label a client with a particular RTI or STD.

\section{Case Management}

Indiscriminate and incorrect use of antibiotics have created international concern about the emergence of drug resistant microorganisms. This crisis underscored the importance of appropriate and ethical prescriptive practices. When a prescriptive decision is based on evidence gathered from an STD clinical evaluation that includes investigation of history, symptoms, physical signs and laboratory analysis, the prescriptive choice is more likely to be an appropriate choice. Prescriptive regimens are made in accordance with recommendations from the MOH-RI STD Management Guidelines (Daili, et al., 1996).

The range of RTIs targeted by this study will often require sexual partner treatment and evaluation. This is an important step necessary to reduce or eliminate future reproductive disease for the infected woman and possible future morbidity and mortality to her unborn children. However, this can only be done with clients' consent and considerations about the possible risks and benefits. Table 5 compares and contrasts partner treatment requirements for the RTIs addressed by this study. 
Table 5. Partner Interventions

\begin{tabular}{|l|c|c|c|}
\hline \multicolumn{1}{|c|}{ RTI/STD: } & $\begin{array}{c}\text { Partner Rx. } \\
\text { is NOT indicated: }\end{array}$ & $\begin{array}{c}\text { Concurrent } \\
\text { partner Rx. } \\
\text { needed: }\end{array}$ & $\begin{array}{c}\text { Medical } \\
\text { evaluation of } \\
\text { partner offered }\end{array}$ \\
\hline Trichomoniasis & & $X$ & \\
\hline Bacterial Vaginosis & $X$ & & \\
\hline Candidiasis & $X$ & & \\
\hline Gonorrhea & & $X$ & $X$ \\
\hline Chlamydia & & $X$ & $X$ \\
\hline MPC & & $X$ & $X$ \\
\hline Syphilis & & $X$ & $X$ \\
\hline Chancroid & & $X$ & $X$ \\
\hline HSV II & & & $X$ \\
\hline HPV & & & $X$ \\
\hline
\end{tabular}

Family planning clients who require sex partner evaluation and treatment will be coached and supported to develop a plan of partner notification and treatment prior to leaving the clinic. However, this will take into account clients consent and considerations about the possible risks and benefits of this consent. 
Table 6. RTI/STD Diagnosis and Case Management Protocol*

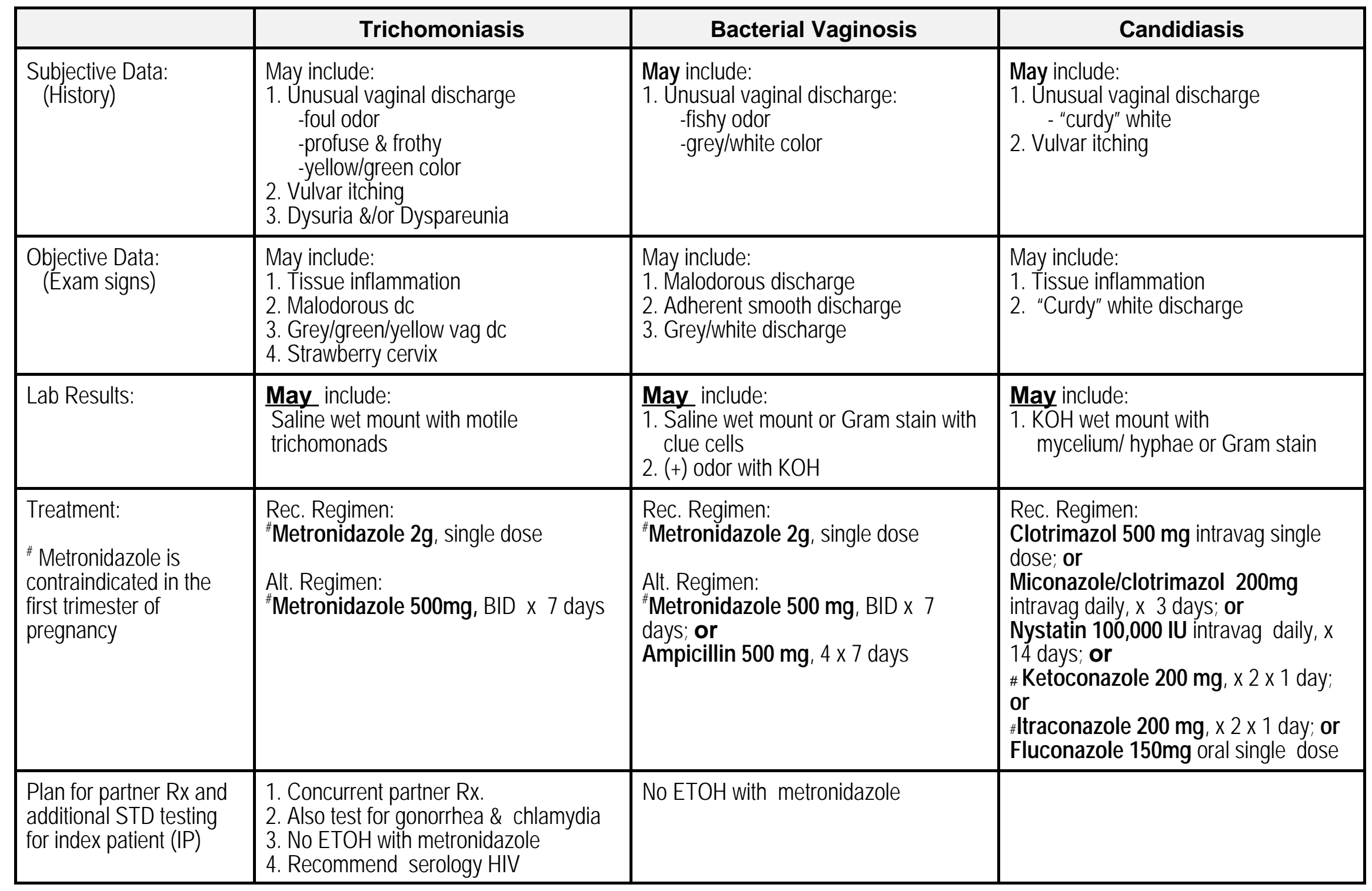


Table 6. RTI/STD Diagnosis and Case Management Protocol*

\begin{tabular}{|c|c|c|c|}
\hline & Gonorrhea & Chlamydia & MPC-Mucopurulent Cervicitis \\
\hline $\begin{array}{r}\text { Objective Data: } \\
\text { (Exam Signs) }\end{array}$ & $\begin{array}{l}\text { May include: } \\
\text { 1. Increased vaginal discharge } \\
\text { 2. Cervix with erythema } \\
\text { 3. Cervical ectopy } \\
\text { 4. Friable cervix } \\
\text { 5. Cervix with cloudy mucopus } \\
\text { 6. CMT } \\
\text { 7. Tender/painful palpation to uterus } \\
\text { and/or adnexa }\end{array}$ & $\begin{array}{l}\text { May include: } \\
\text { 1. Increased vaginal discharge } \\
\text { 2. Cervix with erythema } \\
\text { 3. Cervical ectopy } \\
\text { 4. Friable cervix } \\
\text { 5. Cervix with cloudy mucopus } \\
\text { 6. CMT } \\
\text { 7. Tender/painful palpation to uterus } \\
\text { and/or adnexa }\end{array}$ & $\begin{array}{l}\text { May include: } \\
\text { 1. Increased vaginal discharge } \\
\text { 2. Cervix with erythema } \\
\text { 3. Cervical ectopy } \\
\text { 4. Friable cervix } \\
\text { 5. Cervix with cloudy mucopus } \\
\text { 6. CMT } \\
\text { 7. Tender/painful palpation to uterus and } \\
\text { / or adnexa }\end{array}$ \\
\hline Lab Results: & $\begin{array}{l}\text { May include: } \\
\text { wet mount }>30 \text { WBC's/HPF } \\
\text { MUST include a }(+) \text { culture for } \\
\text { gonorrhea }\end{array}$ & $\begin{array}{l}\text { May include: } \\
\text { wet mount }>30 \text { WBC's/HPF } \\
\text { MUST include a }(+) \text { enzyme test for } \\
\text { chlamydia }\end{array}$ & $\begin{array}{l}\text { May include: } \\
\text { wet mount }>30 \text { WBC's/HPF, remainder } \\
\text { of the diagnosis is empiric. }\end{array}$ \\
\hline $\begin{array}{l}\text { Treatment: } \\
\text { \#contraindicated in } \\
\text { pregnancy }\end{array}$ & $\begin{array}{l}\text { Rec. Regimen: } \\
\text { \#Ciprofloxacin } 500 \mathrm{mg} \text { single dose; } \\
\text { or } \\
\text { \#Ofloxacin } 400 \mathrm{mg} \text { single dose; or } \\
\text { \#Tiamfenikol } 3.5 \mathrm{~g} \text { single dose; or } \\
\text { Ceftriaxone } 250 \mathrm{mg} \text { IM; or } \\
\text { Canamicyn } 2 \mathrm{gr} \mathrm{IM} \text { single dose; or } \\
\text { Spectinomicyn } 2 \mathrm{gr} \text { IM single dose }\end{array}$ & $\begin{array}{l}\text { Rec. Regimen: } \\
\text { \#Doxycycline } 100 \text { mg BID x } 7 \text { days; } \\
\text { or } \\
\text { \#Azitromycin } 1 \text { gr single dose; or } \\
\text { \#Tetracycline } 500 \mathrm{mg} \text { QID x } 7 \text { days; or } \\
\text { Erythromycin } 500 \text { mg QID x } 7 \text { days }\end{array}$ & $\begin{array}{l}\text { Rec. Regimen: } \\
\text { Should include regimens equally effective } \\
\text { against Gonorrhea and Chlamydia as } \\
\text { previously described. }\end{array}$ \\
\hline $\begin{array}{l}\text { Plan for partner Rx and } \\
\text { additional STD testing } \\
\text { for index patient (IP): }\end{array}$ & $\begin{array}{l}\text { 1. Partner must be notified, examined, } \\
\text { and treated. } \\
\text { 2. Also test for chlamydia. } \\
\text { 3. Recommend HIV screening test }\end{array}$ & $\begin{array}{l}\text { 1. Partner must be notified, } \\
\text { examined and treated. } \\
\text { 2. Also test for gonorrhea } \\
\text { 3. Recommend HIV screening test }\end{array}$ & $\begin{array}{l}\text { 1. Partner should be examined and } \\
\text { treated IAW IP's regimen. } \\
\text { 2. Also test for gonorrhea and chlamydia. } \\
\text { 3. Recommend serology HIV test }\end{array}$ \\
\hline
\end{tabular}


Table 6. RTI/STD Diagnosis and Case Management Protocol ${ }^{\star}$

\begin{tabular}{|c|c|c|}
\hline & Syphilis & Chancroid \\
\hline $\begin{array}{l}\text { Subjective Data: } \\
\text { (History) }\end{array}$ & $\begin{array}{l}\text { Asymptomatic infection is common, but may include: } \\
\text { 1. Genital ulcer } \\
\text { 2. Generalized skin rash }\end{array}$ & $\begin{array}{l}\text { May include: } \\
\text { 1. Genital ulcer } \\
\text { 2. Tender swollen areas in groin }\end{array}$ \\
\hline $\begin{array}{l}\text { Objective Data: } \\
\text { (Exam signs) }\end{array}$ & $\begin{array}{l}\text { May include: } \\
\text { 1. Single painless ulcer } \\
\text { 2. } 5 \text { - } 15 \mathrm{~mm} \text { diameter of ulcer } \\
\text { 3. Raised round clearly defined ulcer borders } \\
\text { 4. Ulcer base: smooth and clean } \\
\text { 5. Ulcer: firm and rubbery to touch } \\
\text { 6. Lymph glands: firm, non-tender } \\
\text { 7. After ulcer heals, appearance of a red symmetrical rash on } \\
\text { trunk, palms, and soles }\end{array}$ & $\begin{array}{l}\text { May include: } \\
\text { 1. Multiple painful ulcers } \\
\text { 2. } 2 \text { - } 20 \text { mm diameter of ulcers } \\
\text { 3. Rough, irregular ulcer borders } \\
\text { 4. Ulcer base: dirty and purulent } \\
\text { 5. Ulcer soft to touch. } \\
\text { 6. Lymph glands: tender, unilateral buboes }\end{array}$ \\
\hline Lab results: & $\begin{array}{l}\text { Must include: } \\
\text { A reactive VDRL or RPR with TPHA confirmation. RPR, may } \\
\text { take } 3 \text { to } 4 \text { months to react after ulcer "chancre" onset }\end{array}$ & $\begin{array}{l}\text { Specific lab confirmation not available at study } \\
\text { site. Diagnose Empirically. }\end{array}$ \\
\hline $\begin{array}{l}\text { Treatment } \\
\text { \#See Rx guidelines for } \\
\text { alternate regimens for allergies } \\
\text { and pregnancy }\end{array}$ & $\begin{array}{l}\text { Rec. Regimen for primary syphilis: } \\
\text { \#Benzathine PCN G, } 2.4 \text { million U, IM in a single dose; or } \\
\text { Penicylin Procain } 600.000 \text { IU, IM, } 10 \text { days } \\
\text { If allergic to Penicylin: } \\
\text { \#Tetracycline } 500 \mathrm{mg} \text { QID x } 15 \text { days; or } \\
\text { Erythromycin } 500 \mathrm{mg} \text { QID x } 15 \text { days; or } \\
\text { \#Doxycycline } 100 \mathrm{mg} \text { BID x } 15 \text { days }\end{array}$ & $\begin{array}{l}\text { Rec. Regimen: } \\
\text { \#Ciprofloxacin } 500 \mathrm{mg} \text { a single dose; or } \\
\text { \#Ofloxacin } 400 \mathrm{mg} \text { a single dose; or } \\
\text { Azitromycin } 1 \mathrm{gr} \text { a single dose; or } \\
\text { Erythromycin } 500 \mathrm{mg} \text {, QID } \times 7 \text { days; or } \\
\text { Ceftriaxon } 250 \mathrm{mg} \text { IM a single dose; or } \\
\text { Trimetoprim-Sulfametoksasol 80-400 } \mathrm{mg} 2 \times \\
\text { BID x } 7 \text { days }\end{array}$ \\
\hline $\begin{array}{l}\text { Plan for partner Rx and } \\
\text { additional STD testing for } \\
\text { index patient (IP) }\end{array}$ & $\begin{array}{l}\text { 1. Concurrent partner notification, exam, and Rx is critical. } \\
\text { (Syphilis is a serious systemic disease) } \\
\text { 2. Also test for gonorrhea and chlamydia } \\
\text { 3. Recommend HIV Elisa testing }\end{array}$ & $\begin{array}{l}\text { 1. Concurrent partner notification, exam, and } \\
\text { Rx is indicated. } \\
\text { 2. Also test for gonorrhea and chlamydia. } \\
\text { 3. Recommend Syphilis and HIV screening test }\end{array}$ \\
\hline
\end{tabular}


Table 6. RTI/STD Diagnosis and Case Management Protocol*

\begin{tabular}{|c|c|c|}
\hline & HSV II & HPV \\
\hline $\begin{array}{l}\text { Subjective Data: } \\
\text { (History) }\end{array}$ & $\begin{array}{l}\text { May include: } \\
\text { 1. Initially painful genital sores } \\
\text { 2. Dysuria } \\
\text { 3. Malaise and myalgia } \\
\text { 4. Recurrence of symptoms }\end{array}$ & $\begin{array}{l}\text { May include: } \\
\text { Painless genital warts }\end{array}$ \\
\hline $\begin{array}{r}\text { Objective Data: } \\
\text { (Exam signs) }\end{array}$ & $\begin{array}{l}\text { May include: } \\
\text { 1. Multiple fluid filled blisters that } \\
\text { 2. Ulcerate, and are } \\
\text { 3. } 1-5 \mathrm{~mm} \text { in diameter. }\end{array}$ & $\begin{array}{l}\text { May include: } \\
\text { Verruciform genital lesions. }\end{array}$ \\
\hline Lab Results: & Empiric diagnosis & Empiric diagnosis \\
\hline $\begin{array}{l}\text { Treatment: } \\
\text { (Contraindicated in } \\
\text { pregnancy) }\end{array}$ & $\begin{array}{l}\text { *Eradication of virus not possible, but treatment to } \\
\text { relieve symptoms includes: } \\
\text { Initial outbreak: } \\
\text { Acyclovir } 200 \mathrm{mg} 5 \times \text { day for } 7-10 \text { days } \\
\text { Recurrences: } \\
\text { Acyclovir } 200 \mathrm{mg} 5 \times \text { day for } 5 \text { days }\end{array}$ & $\begin{array}{l}\text { Eradication of virus not possible, but removal of external } \\
\text { warts may be done by: } \\
\text { \#Podophyllin } 10 \text { - } 25 \% \text {; or } \\
\text { Trichloracetic Acid (TCA) } 40-50 \% \text {; } \\
\text { Liquid Nitrogen } 20 \% \text { - } 40 \%\end{array}$ \\
\hline $\begin{array}{l}\text { Plan for partner Rx } \\
\text { and additional STD } \\
\text { testing for index } \\
\text { patient (IP) }\end{array}$ & $\begin{array}{l}\text { 1. Partner(s) may benefit from evaluation and } \\
\text { counseling. } \\
\text { 2. Also test IP for gonorrhea, and chlamydia. } \\
\text { 3. Recommend for HIV and Syphilis screening test }\end{array}$ & $\begin{array}{l}\text { 1. Partner (s) may benefit from evaluation and counseling. } \\
\text { 2. Also test IP for chlamydia. } \\
\text { 3. Recommend for HIV and Syphilis screening test }\end{array}$ \\
\hline
\end{tabular}

Note:

*The diagnostic process for HIV is beyond the scope of this initial study patients will be educated (protocol 2) if the HCP judges the individual client to be at risk and a referral to an alternate test sites will be made 


\section{VII. \\ RTI/STD Treatment Guidelines}

The recommended treatment guidelines have been prepared from a combination of recommendations from the World Health Organization (WHO), the Centers for Disease Control and Prevention (CDC) and the MOH-RI STD Management Guidelines. Guidelines are given for the confirmed RTIs of Trichomoniasis, Bacterial Vaginosis, Candidiasis, Neisseria Gonorrhea, Chlamydia Trachomatis, Syphilis, Chancroid, Herpes Simplex Virus, and Human Papilloma Virus. It is beyond the scope of this study to make treatment management recommendations for confirmed infections with HIV. Guidelines are also presented for the clinically recognized syndrome of mucopurulent cervicitis (MPC).

\section{Trichomonas vaginalis:}

Recommended regimen : Metronidazole 2 grams (g) orally in a single dose

Alternative regimen

: Metronidazole 500 milligrams (mg) twice daily for 7 days

Management of sex partners

: Treatment of sex partners is recommended

\section{Bacterial Vaginosis:}

Recommended regimen

Alternative regimen

: Metronidazole $2 \mathrm{~g}$ orally in a single dose

: Metronidazole $500 \mathrm{mg}$ orally twice daily for 7 days, or

Ampicillin $500 \mathrm{mg}$ orally four times daily for 7 days

Management of sex partners

: Routine treatment of sex partners is not recommended

\section{Note:}

1. Metronidazole is contraindicated during the first trimester of pregnancy.

2. Do not drink alcohol while taking metronidazole.

\section{Candidiasis:}

Recommended regimen

Management of sex partners

Note : Ketokonazole and Itraconazole are contraindicated for pregnancy.
Clotrimazole $500 \mathrm{mg}$ intravaginally a single dose

: Miconazole or Clotrimazole, 200 mg intravaginally, daily for 3 days; or

Nystatin, 100,000 IU intravaginally, daily for 14 days; or:

Clotrimazole, $500 \mathrm{mg}$ intravaginally, as a single dose

Ketoconazole $200 \mathrm{mg} \mathrm{BID,} 5$ days-oral

Itraconazole $200 \mathrm{mg}$ BID 1 day-oral

Flukonazole $150 \mathrm{mg}$, single dose-oral

: Not usually recommended. 
Gonorrhea:

Recommended regimens: Ciprofloxacin $500 \mathrm{mg}$ orally in a single dose (Contraindicated in pregnancy); or

Ofloxacin $400 \mathrm{mg}$, orally, single dose

Ceftriaxone $250 \mathrm{mg}$ intramuscular (IM) in a single dose; or

Cefixime $400 \mathrm{mg}$ orally in a single dose; or

Spectinomycin $2 \mathrm{~g} \mathrm{IM}$ in a single dose;

PLUS:

A regimen effective against possible coinfection with Chlamydia Trachomatis, such as Doxycycline $100 \mathrm{mg}$ orally 2 times a day for 7 days. Doxycycline is contraindicated in pregnancy, so use Erythromycin $500 \mathrm{mg}$ orally 4 times a day for 7 days.

Alternate regimens which may be useful in some countries, depending on the prevalence of resistant gonococci: Kanamycin $2 \mathrm{~g}$ IM in a single dose;

Management of sex partners : Concurrent partner exam/referral and treatment is indicated.

Note:

Ciprofloxacin and Ofloxacin are contraindicated in pregnancy.

Chlamydia:

Recommended regimens: Doxycycline $100 \mathrm{mg}$ orally 2 times a day for 7 days; or Tetracycline $500 \mathrm{mg}$ orally 4 times a day for 7 days; or Azithromycin $1 \mathrm{~g}$ orally in a single dose.

Alternative regimens

: Erythromycin base $500 \mathrm{mg}$ orally 4 times a day for 7 days.

Note:

Tetracycline, Doxycycline and Azithromycin are contraindicated in pregnancy; use Erythromycin.

Management of sex partners : Concurrent partner exam/referral and treatment is indicated.

\section{Syphilis: (Primary and Secondary)}

Recommended regimens: Benzathine penicillin G, 2.4 million units IM in a single dose

Alternative regimens: Procaine Penicillin G, 600.000 IU by IM injection for 10 consecutive days.

Alternative regimens for penicillin allergic non-pregnant patients:

Doxycycline $100 \mathrm{mg}$ orally 2 times a day for 14 days; or

Note:

Tetracycline $500 \mathrm{mg}$ orally 4 times a day for 14 days.

1. Syphilis in pregnancy: due to the serious consequences to the fetus, pregnant women require close surveillance of follow-up serology and epidemiologic investigation to rule out reinfection. Alternative regimen for penicillin allergic pregnant patients: Erythromycin 500 mg orally 4 times a day for 15 days. 
2. The Indonesian STD Guidelines (Daili, et. al., 1996) also include a recommendation of Thiamphenicol treatment for Gonorrhea. However, John S. Moran, MD, MPH, STD Advisor HAPPIAIDSCAP, May 1997 stated that, "Single dose thiamphenicol regimens have not been proven to be reliably effective against gonorrhea"..

\section{Management of syphilis sex partners:}

\section{All stages of syphilis require concurrent examination and treatment of all} partners

Latent Syphilis (more than 2 years duration or of indeterminate duration):

Recommended regimen : Benzathine penicillin G, 2.4 million units IM injection given weekly for 3 weeks.

Alternative regimen : Procaine penicillin G, 600.000 IU by IM injection once a day for 20 consecutive days.

\section{Tertiary Syphilis}

All patients with latent syphilis should be evaluated clinically for evidence of tertiary disease (e.g., aortitis, neuro syphilis, gumma, and iritis). These patients should have a cerebral-spinal fluid (CSF) examination before treatment. It is beyond the scope of the study clinical sites to provide such service, and as such, these patients must be referred to a specialist at the hospital level to monitor status, and provide treatment.

Chancroid:

Recommended regimen

Alternative regimens
: Erythromycin base $500 \mathrm{mg}$ orally 4 times a day for 7 days.

: Ciprofloxacin $500 \mathrm{mg}$ orally as a single dose; or Ceftriaxone $250 \mathrm{mg}$ by IM injection as a single dose; or Trimethoprim (80 mg)/Sulfamethoxazole (400 mg) 2 tablets orally, twice a day for 7 days; or

Ofloxacin $400 \mathrm{mg}$ orally, single dose; or

Azithromycin $1 \mathrm{~g}$ orally, single dose.

Management of sex partners : Concurrent exam/referral and treatment of sex partners is indicated.

Note:

Ciprofloxacin and Ofloxacin are contraindicated in pregnancy

Herpes Simplex Virus:

Recommended regimen for first clinical episode (determined by careful clinical history):

Acyclovir 200 mg orally 5 times a day for 7-10 days.

Recommended regimen for recurrent episodes :

Acyclovir $200 \mathrm{mg}$ orally 5 times a day for 5 days. 
Note:

After one year of continuous Acyclovir treatment, the drug should be discontinued to allow assessment of the patient's rate of recurrent episodes. Acyclovir must be carefully used in pregnancy. Refer all pregnant women with herpes to a physician for careful prenatal observation and status evaluation is indicated to minimize perinatal transmission.

Management of sex partners : Sex partners of patients who have genital herpes are likely to benefit from evaluation and counseling. Since acyclovir is a suppressive treatment and not an eradication of the disease, concurrent partner treatment is not indicated.

Human Papilloma Virus (HPV) (Genital Warts):

No therapy has been shown to eradicate HPV, therefore the goal of removal should be guided by patient preference. Current treatment methods range from 22\%-94\% efficacy in clearing external exophytic warts with high recurrence rates. Avoid expensive or toxic therapies that can result in scarring.

Recommended Chemical regimens :

- $\quad$ Podophyllin 10-25\% in compound tincture of benzoin. Wash off in 1-4 hours. Repeat weekly if necessary spread vaseline on the skin around the lesion before applying Podophyllin. If warts persist after 6 applications, discontinue this method. Avoid normal tissue; or

- $\quad$ Trichloracetic acid (TCA) (80-90\%). Apply only to warts; powder with talc or baking soda to remove unreacted acid. Repeat weekly if necessary. If warts persist after 6 applications, other therapies should be considered.

Note:

Podophyllin is contraindicated during pregnancy.

Recommended Physical regimens:

Cryotherapy with liquid nitrogen or cryoprobe; or

Electrocautery; or Surgical removal.

Management of sex partners : Partners could benefit from evaluation and counseling. Concurrent treatment is not recommended unless the partner is symptomatic. 


\section{VIII. \\ Client Education and Counseling}

Educating and counseling the client who receives a diagnosis of RTI/STD is a vital part of disease prevention for both the individual client and also the greater community. The process of education, supported by good communication skills, begins with the initial introduction between HCP and client, continuing through the exam and culminates with dialogue. As with the history and exam, the final teaching stage of the clinic visit should also be performed in an environment of privacy and confidentiality.

The main goal of STD education is to promote the client's understanding of:

- $\quad$ what her diagnosis is

- $\quad$ how her infection was transmitted

- $\quad$ steps she can take to manage \&/or eradicate the infection

- $\quad$ options she can use for future prevention from repeat or new STD infection.

Because the reality of an STD diagnosis carries more psychological weight than an infection that is not sexually transmitted, the opportunity to have an optimum "teachable moment" may be challenged by emotional reactions that arise from the client as well as from the HCP. Many HCP's express concern that a frank discussion of an STD diagnosis will cause the client to feel shame or "loose face". The most important start to break this cycle of silence which is the result of a fear of causing shame is for the HCP to demonstrate comfort and acceptance of the client's sexuality and diagnosis. Clients will not benefit or be served by a HCP who is projecting his or her fear onto the client. The correct use of communication skills and styles will help reduce the intensity of an emotional reaction and allow for a greater exchange of information. If a HCP is able to demonstrate concern and competence in a receptive and nonjudgmental manner, the client will be more receptive to instructional interventions. Table 7 contrasts communication behaviors of HCP's.

Table 7. HCP Communication Behaviors

\begin{tabular}{|l|l|}
\hline \multicolumn{1}{|c|}{ Negative Impact } & \multicolumn{1}{c|}{ Positive Impact } \\
\hline $\begin{array}{l}\text { HCP does not personally greet the client } \\
\text { before plunging into chart or exam. }\end{array}$ & $\begin{array}{l}\text { HCP smiles, shakes hand, uses welcoming } \\
\text { words }\end{array}$ \\
\hline Does not listen to client (interrupts) & Listens carefully \\
\hline Uses jargon & Uses clear language \\
\hline Depersonalizes client & Conveys interest in the client \\
\hline Angry, hostile, or impatient & Warm, friendly, \& accepting \\
\hline Doesn't answer questions & Is open to questions \\
\hline
\end{tabular}




\section{Teaching Content}

A comprehensive, personalized STD teaching plan has many separate teaching points. The HCP should avoid the temptation of delivering an hour long lecture. The HCP should be mindful of the overall goal of STD teaching, specifically the client's understanding of the disease diagnosis, etiology, treatment, management, and prevention. By simply asking the client at the start of the education session "what can I tell you about your infection", the door can be opened to the "teachable moment" that will be of greatest service to the client. The following inventory presents components of communicative and instructional content that should be included in an education session.

\section{Table 8. Inventory of HCP Components of an STD Education Session}

\begin{tabular}{|l|l|}
\hline 1. & Demonstrates professionalism (competence, tolerance). \\
\hline 2. & Emphasizes privacy, confidentiality. \\
\hline 3. & Establishes rapport \& demonstrates concern for the client. \\
\hline 4. & Listens to client's concerns without interrupting. \\
\hline 5. & Uses open ended questions. \\
\hline 6. & Avoids jargon, communicates at the client's level. \\
\hline 7. & Provides accurate and correct information re. diagnosis, etiology \& transmission. \\
\hline 8. & $\begin{array}{l}\text { Gives instructions on when, how often, \& how long to take medication; the importance of } \\
\text { completing the Rx, and possible side effects. }\end{array}$ \\
\hline 9. & Ensures any required partner(s) notification, exam \& Rx. \\
\hline 10. & Abstain from sexual intercourse for duration of medication (Both client \& partner). \\
\hline 11. & $\begin{array}{l}\text { Discusses future risk reduction behaviors (A,B,C's) \& dispenses condoms with instructions for } \\
\text { correct use. }\end{array}$ \\
\hline 12. & Recommends a return clinic visit (RTC) if symptoms worsen or recur. \\
\hline 13. & Ensures that client's concerns are addressed \& that she has an understanding of instructions. \\
\hline
\end{tabular}

The client's adherence to treatment recommendations will be higher if the client has been asked to repeat the instructions, and if the HCP repeats the instructions more than once during the education session. The importance of education during all health care encounters can not be overestimated. Such a philosophy is based on the belief that knowledge is power. Sharing this power with the client will contribute to disease reduction and contribute to health promotion. 


\section{IX. \\ Infection Control}

The integration of RTI/STD services into existing FP clinical practice will require few changes in infection control procedures. With a greater awareness of the importance of reducing exposure to blood borne pathogens such as HBV \& HIV, all FP clinics should utilize Universal Precautions (UP) as standard operating procedures in the examination room and the laboratory. A clinical practice that values and uses UP's will minimize procedural infections to clients and minimize transmission of infections to clinic staff. See Table 9 for a review of required UP in daily FP clinical practice.

\section{Table 9. Universal Precautions Highlights}

\begin{tabular}{|l|l|}
\hline 1. & Handle all specimens of blood and body substances as potentially infectious. \\
\hline 2. & Wash hands before and after contact with patients or specimens of blood and body substances. \\
\hline 3. & Wash hands before and after use of gloves. \\
\hline 4. & Do not recap or manipulate needles. \\
\hline 5. & $\begin{array}{l}\text { Place used syringes, needles, scalpel blades and other sharp items in puncture-proof } \\
\text { containers marked BIOHAZARD. Do this immediately after use. }\end{array}$ \\
\hline 6. & For surgical procedures wear laboratory gowns, rubber gloves, protective goggles and masks. \\
\hline
\end{tabular}

\section{Protective Barriers}

Placing a mechanical or chemical barrier between microorganisms and a person is a good way to prevent the spread of the disease. Protective barriers in infection prevention include:

1. Hand-washing with soap;

2. Wearing gloves, either for surgery or to protect clinic staff when handling contaminated waste materials or soiled instruments;

3. Using antiseptic solutions for cleaning wounds or preparing the skin prior to invasive procedures, i.e. injections, IUD or Norplant insertions, and surgery;

4. Decontaminating, cleaning and sterilizing surgical instruments i.e., vaginal speculums, uterine sounds, trocars, tenacula, and forceps.

Hand-washing is probably the single most important infection prevention practice in a FP clinic. Hand-washing is indicated:

- before examining a client;

- before putting on sterile gloves for surgical procedures;

- in any situation in which hands may be contaminated;

- after removing gloves (because gloves may have invisible holes or tears).

Gloves must be worn by all staff prior to contact with blood and body fluids from any client. In the FP clinic, this occurs prior to the start of the pelvic exam. A separate pair of gloves must be used for each client to avoid cross contamination. Table 10 shows procedure specific glove requirements. 
Table 10 : Glove Requirements For Medical \& Surgical Procedures*

\begin{tabular}{|l|c|c|c|}
\hline \multicolumn{1}{|c|}{ Task or Activity: } & $\begin{array}{c}\text { Gloves } \\
\text { Needed? }\end{array}$ & $\begin{array}{c}\text { Hi-Level Disinfected } \\
\text { Gloves (1) }\end{array}$ & $\begin{array}{c}\text { Sterile } \\
\text { Gloves }\end{array}$ \\
\hline Measuring blood pressure & no & & \\
\hline Measuring temperature & no & & \\
\hline Giving an injection & no & & \\
\hline Pelvic exam & yes & yes & no \\
\hline Contact w. vaginal secretions & yes & yes & no \\
\hline IUD insertion \& removal & yes & yes & no \\
\hline Norplant insertion \& removal & yes & acceptable (2) & preferable \\
\hline Blood drawing & yes & yes (3) & no \\
\hline Handling \& cleaning contaminated instruments & yes & no & no \\
\hline Handling contaminated specimens or waste & yes & no & no \\
\hline Cleaning blood or body fluid spills & yes & no & no \\
\hline
\end{tabular}

(1) This includes" never used" individual or bulk packaged gloves

(2) When autoclave is not available HLD is the only acceptable alternative

(3) It is not necessary for gloves to be routinely worn by experienced phlebotomists

*Adapted from: Tietjen et al, 1992. Infection Prevention for Family Planning Service Programs: A Problem-Solving Reference Manual. 


\section{Antisepsis}

Antisepsis is the prevention of infection by killing or inhibiting the growth of microorganisms on the skin or other body tissues. For the tasks of performing pelvic exams to collect lab specimens for the diagnosis of RTI/STDs, no antiseptic procedure are indicated. Antisepsis is a very necessary part of invasive FP practices which in this study includes:

- injections

- IUD insertions

- Norplant insertions.

See the following summary of steps involved in these three procedures that do require antiseptic applications to the client.

\section{Table 11. Procedural Specific Antiseptic Steps}

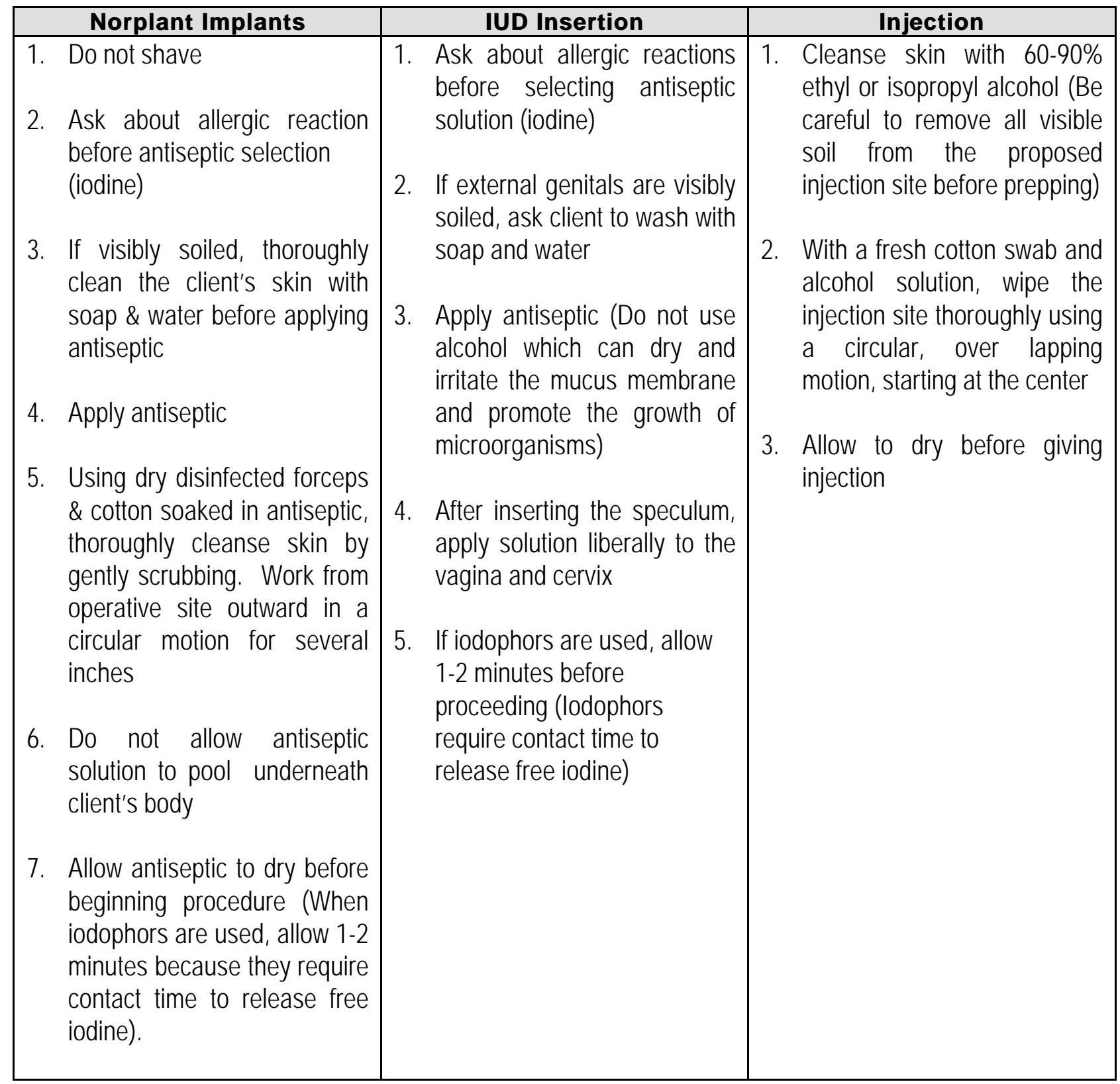




\section{Decontaminating, Cleaning, \& Sterilizing Instruments \& other Items}

The basic process of decontamination to prevent disease transmission from contaminated instruments is to:

1. Decontaminate with a soak in $0.5 \%$ chlorine ( I part bleach to 9 parts water) solution for 10 minutes;

2. Thoroughly wash and rinse instruments with a brush in soapy water;

3. Sterilize at 121 degrees Celsius (250 degrees F) for 20 minutes if unwrapped or 30 minutes if wrapped.

The most common instruments in FP practice that requires decontamination is the vaginal speculum. Other instruments that also require sterilization are: uterine sounds, trocars, tenacula, forceps, etc.

The other clinical item that will need routine daily decontamination is the pelvic exam table. This is done by a 2 step procedure which includes:

1. wiping off the table with a $0.5 \%$ chlorine solution.

2. followed by a wash with detergent and water if organic material remains after decontamination procedures. 


\section{ABBREVIATIONS}

\begin{tabular}{|c|c|c|c|}
\hline A.B.C & - Abstinence, Be faithful, Condoms & MID & - midline \\
\hline ABN & - abnormal & $\mathrm{mm}$ & - millimeter \\
\hline AIDS & - Acquired Immunodeficiency Syndrome & MPC & - Mucopurulent Cervicitis \\
\hline AV & - anteverted & MTM & - Modified Thayer Martin \\
\hline $\mathrm{BCM}$ & - Birth Control Method & PC & - Post Coital \\
\hline BID & - twice a day & PE & - Physical Exam \\
\hline $\operatorname{CDC}$ & - Centers for Disease Control Prevention & PID & - Pelvic Inflammatory Disease \\
\hline $\mathrm{cm}$ & - centimeters & $\mathrm{OC}$ & - Oral Contraceptive \\
\hline CMT & - Cervical Motion Tenderness & QID & - four times a day \\
\hline dc & - discharge & RPR & - Rapid Plasma Reagin \\
\hline EAB & - elective abortion & RTI & - Reproductive Tract Infections \\
\hline ETOH & - alcohol & $\mathrm{RV}$ & - retroverted \\
\hline FP & - Family Planning & $\mathrm{Rx}$ & - treatment \\
\hline$g$ & - gram & $S A B$ & - Spontaneous Abortion \\
\hline Gc & - Gonococcus & STD & - Sexually Transmitted Disease \\
\hline $\mathrm{HCP}$ & - Health Care Provider & TCA & - Trichloracetic Acid \\
\hline HIV & - Human Immunodeficiency Virus & TID & - three times a day \\
\hline HPF & - High Power Field & TPHA & - Treponema Palidum \\
\hline HPV & - Human Papilloma Virus & & Hemagglutination Assay \\
\hline HSV & - Herpes Simplex Virus & U & - unit \\
\hline IAW & - in accordance with & WBC & - White Blood Cell \\
\hline IDE & - identification & WHO & - World Health Organization \\
\hline IM & - intramuscular & WNL & - within normal limits \\
\hline IP & - Index Patient & & \\
\hline IU & - International Unit & & \\
\hline IUD & - Intra Uterine Device & & \\
\hline $\mathrm{KOH}$ & - Potassium Hydroxide & & \\
\hline LMP & - Last Menstrual Period & & \\
\hline & - milligram & & \\
\hline
\end{tabular}


Appendix D

\section{References}

Adimora, Adaora. et al. Sexually Transmitted Diseases. 2nd Edition, Companion Handbook. New York: McGraw-Hill, Inc., 1994.

Ament, L. and E. Whalen. "Sexually Transmitted Diseases in Pregnancy: Diagnosis, Impact, and Intervention." Journal of Obstetric, Gynecologic, and Neonatal Nursing. October 1996, 25: $657-666$.

Aral, S., K. Holmes, N., Padian, and W. Cates. "Overview: Individual and Population Approaches to the Epidemiology and Prevention of Sexually Transmitted Diseases and Human Immunodeficiency Virus Infection." The Journal of Infectious Diseases. October 1996, 174:S127-33.

Benenson, Abram (ed.). Control of Communicable Diseases Manual. 16th Edition. Washington D.C.: American Public Health Association, 1995.

Cates, W. and Katherine M. Stone. "Family Planning, Sexually Transmitted Diseases and Contraceptive Choice: a Literature Update-Part I." Family Planning Perspectives, March/April 1992, 24 (2): 75-84.

Centers for Disease Control and Prevention. "Recommendations for the Prevention and Management of Chlamydia Trachomatis Infections, 1993.” MMWR 1993: 42 (No. RR-12).

Centers for Disease Control and Prevention. "1993 Sexually Transmitted Disease Guidelines." MMWR 1993, 42: 1-102 (RR-14).

Daili, Sjaiful Fahmi et.al.(eds.). Penatalaksanaan Penyakit Menular Seksual: Berdasarkan Pendekatan Sindrom, Fasilitas Laboratorium Sederhana, Laboratorium Khusus. Jakarta: Direktorat Jendral PPM \& PLP Departemen Kesehatan RI \& Kelompok Studi Penyakit Menular Seksual, 1996.

Decosas, S. and V. Pedneault. "Preventing Sexually Transmitted Diseases through Individual and Population-Based Public Health Approaches: Social and Political Implications." The Journal of Infectious Diseases 1996,174: S248-52.

Falagas, M. and S. Gorbach. "ICPD Guidelines: Sexually Transmitted Diseases, Part II." Infectious Diseases in Clinical Practice, 1996 (5):6-11.

Hatcher, R. et al. Contraceptive Technology. 16th Revised Edition. New York: Irvington Publishing Inc., 1994. 
Hatcher, R. et al. Contraceptive Technology. Atlanta: Printed Matter Inc.,1989.

JHPIEGO. International Family Planning Guide A Prototypic Reference Manual. 1994.

King, Holmes K., et al (eds.). Sexually Transmitted Diseases. New York: McGraw-Hill, 1990.

Over, M. and P. Piot. "Human Immunodeficiency Virus Infection and Other Sexually Transmitted Diseases in Developing Countries: Public Health Importance and Priorities for Resource Allocation." The Journal of Infectious Diseases. 1996: S:162-75.

Tietjen, L., et al. Infection Prevention for Family Planning Service Programs: A Problem-Solving Reference Manual. Oklahama : Essential Medical Information Systems, Inc., 1992.

Wasserheit, J. and S. Aral. "The Dynamic Topology of Sexually Transmitted Disease Epidemics: Implications for Prevention Strategies." The Journal of Infectious Diseases. 1996, 174: S201-13. 
ROUND TABLE DISCUSSION AGENDA

24 - 25 January 1997

Koja Hospital

Jakarta, Indonesia

Friday, January 24, 1997, Day 1

\begin{tabular}{|c|c|c|}
\hline Time & Topic & Presenter \\
\hline $9: 00-9: 15$ & INTRODUCTORY REMARKS & $\begin{array}{l}\text { Dr. Umar Wahid, Director, Koja } \\
\text { Hospital }\end{array}$ \\
\hline $9: 15-9: 30$ & PROJECT REVIEW & $\begin{array}{l}\text { Dr. Meiwita B. Iskandar, Ph.D. - } \\
\text { Resident Advisor, Population Council }\end{array}$ \\
\hline 9:30-10:00 & $\begin{array}{l}\text { ESSENTIAL REPRODUCTIVE } \\
\text { HEALTH CARE PACKAGE: The } \\
\text { Linkage of Contraceptive Choice to } \\
\text { RTI/STDs }\end{array}$ & $\begin{array}{l}\text { Dr. Ardi Kaptiningsih, MPH - } \\
\text { MOH, BINKESGA, Subdirectorate of } \\
\text { OB/GYN }\end{array}$ \\
\hline 10:00-10:30 & $\begin{array}{l}\text { THE ROLE OF STDS IN THE } \\
\text { NATIONAL HIV/AIDS PREVENTION } \\
\text { PROGRAM }\end{array}$ & $\begin{array}{l}\text { Dr. H. Sigit Priohutomo, MPH - } \\
\text { MOH, CDC, Subdirectorate of STDs } \\
\text { and Yaws }\end{array}$ \\
\hline 10:30-11:00 & $\begin{array}{l}\text { ESTABLISHING A REPRODUCTIVE } \\
\text { HEALTH SERVICES SYSTEM IN } \\
\text { FAMILY PLANNING SERVICES }\end{array}$ & $\begin{array}{l}\text { Dr. Djajadilaga, DSOG, The Indonesian } \\
\text { OB/GYN Association (POGI Jaya) }\end{array}$ \\
\hline 11:00-11:30 & $\begin{array}{l}\text { QUALITY RECORDING \& } \\
\text { REPORTING FOR STD MONITORING }\end{array}$ & $\begin{array}{l}\text { Dr. Hariadi Wibisono, MPH - } \\
\text { MOH, CDC, Subdirectorate of STD } \\
\text { Surveillance }\end{array}$ \\
\hline 11:30-13:00 & Sholat Jumat & \\
\hline 13:00-14:00 & $\begin{array}{l}\text { PRACTICING NON-JUDGEMENTAL } \\
\text { CLIENT COUNSELING }\end{array}$ & $\begin{array}{l}\text { Dr. Frans Sumampouw, DAJ, MPH - } \\
\text { MOH BINKESGA, Subdirectorate of } \\
\text { Mental Health }\end{array}$ \\
\hline
\end{tabular}




\section{ROUND TABLE DISCUSSION AGENDA}

24 - 25 January 1997

Koja Hospital

Jakarta, Indonesia

Saturday, January 25, 1997, Day 2

\begin{tabular}{|c|l|l|}
\hline \multicolumn{1}{|c|}{ Time } & \multicolumn{1}{|c|}{ Topic } & \multicolumn{1}{c|}{ Speaker } \\
\hline 9:00-9:45 & $\begin{array}{l}\text { NATIONAL STD GUIDELINES: } \\
\text { Comparison of Syndromic, Clinical } \\
\text { \& Etiological Approaches to STD } \\
\text { Case Management }\end{array}$ & $\begin{array}{l}\text { Dr. Sjaiful Fahmi Daili, } \\
\text { DSKK (Dermato- } \\
\text { venereologist), National STD } \\
\text { Study Group }\end{array}$ \\
\hline 9:45-10:30 & $\begin{array}{l}\text { CLINICAL DIAGNOSIS } \\
\text { THROUGH PHYSICAL } \\
\text { EXAMINATIONS }\end{array}$ & $\begin{array}{l}\text { Dr. Wresti Indriatmi B. } \\
\text { Makes, DSKK, National STD } \\
\text { Stud Group }\end{array}$ \\
\hline 10:30-11:15 & $\begin{array}{l}\text { SIMPLE BUT POWERFUL } \\
\text { RTI/STD LABORATORY } \\
\text { TESTS }\end{array}$ & $\begin{array}{l}\text { Dr. Farida Zubier DSKK, } \\
\text { National STD Study Group }\end{array}$ \\
\hline 11:15-12:15 & $\begin{array}{l}\text { INDONESIAN RTI/STD } \\
\text { TREATMENT GUIDELINES }\end{array}$ & $\begin{array}{l}\text { Dr. Jubianto Judanarso DSKK } \\
\text { National STD Study Group }\end{array}$ \\
\hline 12:15-12:45 & $\begin{array}{l}\text { CREATING CHANGES IN } \\
\text { EXISTING CLINICAL } \\
\text { PRACTICE }\end{array}$ & $\begin{array}{l}\text { Dr. Djajadilaga, DSOG, } \\
\text { Indonesian OB/GYN } \\
\text { Association (POGI Jaya) }\end{array}$ \\
\hline 12:45-13:15 & $\begin{array}{l}\text { KOJA HOSPITAL } \\
\text { INTEGRATED } \\
\text { REPRODUCTIVE HEALTH } \\
\text { CARE PACKAGE: a Model } \\
\text { Protocol for a District Hospital } \\
\text { Family Planning Unit }\end{array}$ & $\begin{array}{l}\text { Dr. Basuki Muliono, DSOG, } \\
\text { Department of MCH/FP, } \\
\text { Koja Hospital }\end{array}$ \\
\hline
\end{tabular}

\section{Round Table Discussion Synopsis}

The two day round table discussion was held in the large conference room of the Koja Hospital. The facility was comfortably equipped with conference tables, chairs, and microphones for all speakers and students. The hospital also furnished overhead and slide projectors, along with technicians to arrange audio-visual equipment. This large conference room on the fourth floor of the hospital is used as a mosque not only for hospital staff and 
patients, but for the surrounding community as well. Since this training event was conducted during the fasting month of Ramadhan, there were no scheduled logistical breaks for food and drinks. Because the first day of the training was a Friday, it was necessary to schedule a long break for men during the communal noon prayer. The midwives and female medical staff took advantage of this time to discuss counseling STD clients.

This initial combined training for medical, midwife, and laboratory staff was attended by representatives from both KojaHospital and Puskesmas Cilincing. A breakdown of the attendees by institution included:

$\begin{array}{ll}\text { Koja Hospital } & \text { Puskesmas Cilincing } \\ 1 \text { hospital director } & 1 \text { medical director } \\ 3 \text { doctors } & 3 \text { midwives } \\ 2 \text { laboratory technicians } & 2 \text { laboratory technicians } \\ 0 \text { midwives } & \end{array}$

Dr. Umar Wahid, medical director of RS Koja opened the round table discussion and established a tone of pride in being involved with a program that would improve services to clients. He expressed an institutional willingness to work to promote the integration of STD services into existing family planning care.

The Population Council Resident Advisor introduced the main purpose of the program and outlined the steps that would be necessary to achieve integration. She also served as a moderator and discussant for the remainder of the program.

Dr. Ardi reviewed the highlights of the study protocols II and III which encompass introducing the topic of RTI/STDs to family planning clients, and continuing the discussion to linking sexual and contraceptive behavior to potential RTI/STD exposure. This leads to the initial component of a clinical evaluation, taking an effective reproductive health history. Bridging the two worlds of contraceptive technology and infectious diseases were the main goals of this presentation. This call for integration provoked the first of many spirited discussions from one of the doctors who wanted the instructors to realize that several NGO's are conducting studies on counseling for STD's and HIV. He felt that counseling and client education are difficult and time consuming tasks. Furthermore, he felt that telling a client she had an STD disturbed the client's privacy. He went on to discuss his feeling of discomfort when he felt he was making a client uncomfortable. Other participants acknowledged that education and counseling require a great deal of the HCP's time during a busy schedule of seeing clients. One doctor reported that he prefers to just prescribe a medicine for treatment without telling the client why it is being prescribed. Several instructors responded and concluded that HCP's have an ethical responsibility to not withold information from the client, regardless of the way it makes the HCP feel.

Dr. Sigit furnished the participants with the most current HIV/AIDS estimates based on sentinel surveillance research in Indonesia. The participants responded to the information 
with a personal concern for occupational safety. This was used as an opportunity to direct attention to upcoming infection control practices in the clinical setting. Much discussion ensued about who was responsibile for the resource allocation to purchase barriers, disinfectants and autoclaves in the field. Dr. Sigit also took the opportunity to teach about the occupational transmission of HIV/AIDS and emphasized the need for HCPs to follow universal precautions. A candid discussion about forgetting to comply with universal precautions when busy followed. Dr. Sigit answered the HCPs questions about national HIV screening policies and procedures. Dr. Sigit refocused the participant's attention to the fact that STDs facilitate HIV transmission as well as a quicker progression to AIDS. $\mathrm{He}$ felt that STD case management could be performed by primary health care providers and not just STD specialists. He felt that primary health care is the entry point for most contacts with the medical system, and that client's deserved to be treated at the point of entry. $\mathrm{He}$ acknowledged that many primary HCPs lack knowledge of STDs. He explored the advantages and disadvantages of the syndromic model of care for STDs.

Dr. Djajadilaga focused his discussion on how FP could contribute to the improvement of reproductive health. He also stated his belief that FP should contribute to STD case management and prevention. He discussed the impact that the 1994 International Conference on Population and Development in Cairo had on changing the expectations for quality FP services to include more than just birth spacing. He felt that an improved program of FP services could reduce maternal mortality rates by $50 \%$. For the successful introduction of STD case management into FP services, Dr. Djajadilaga felt that there was a need for greater HCP knowledge, skills as well as access to diagnostic tools like microscopes for wet mount microscopy. He stressed the critical need for HCP motivation to include STD case management with FP services. He endorsed the Problem Oriented Medical Record (POMR) for quality diagnostic services that included the sequential collection of subjective $\&$ objective data, followed by standardized assessment and plans to treat and educate. 


\section{Training Curricula Implemented as an Intervention of "Improved Reproductive Health and STD Service for Women Presenting to Family Planning Services in North Jakarta"}


RTI/STD Case Management (Trouble Shooting Training)
March 21, 1997- Puskesmas Cilincing

March 27, 1997- Koja Hospital

Participants: Clinical and laboratory personnel

Objectives: 1) To provide feedback to health care providers (HCPs) and laboratory staff about mid-term results of their work in the program to integrate RTI/STD case management into routine family planning services.

2) To identify clinical strengths and weaknesses discovered during project monitoring of the implementation of the project protocols.

3) To receive input from clinical staff about protocol feasibility and intervention progress.

4) To review etiologically specific RTI/STD identification for HCPs, see slide show lesson plan.

Instructors: Meiwita Iskandar, $\mathrm{MD}, \mathrm{PhD}$, project manager

Cathy Vickers, RN, CNP, consultant

Format: $\quad$ Group discussion

Interactive Slide Presentation Curriculum:

\begin{tabular}{|l|l|l|}
\hline $\begin{array}{l}\text { Slide } \\
\#\end{array}$ & Content & Teaching Point \\
\hline 1 & STD symptom chart & may be ASYMPTOMATIC! \\
\hline 2 & Female anatomy & Minimal dysuria; normal vaginal environment \\
\hline 3 & Male anatomy & Dysuria more anatomically common \\
\hline 4 & $\begin{array}{l}\text { Exam technique: insertive } \\
\text { finger* }\end{array}$ & $\begin{array}{l}\text { helps locate cervix \& reduces speculum } \\
\text { discomfort }\end{array}$ \\
\hline 5 & Speculum insertion* & $\begin{array}{l}\text { Cervical visualization must be included for } \\
\text { each evaluation }\end{array}$ \\
\hline 6 & Endocervical swab collection & $\begin{array}{l}\text { Sterile cotton for GC, Dacron for chlamydia; } \\
\text { duration- } 10 \text { sec. min; rotate } \text { x } 3 .\end{array}$ \\
\hline 7 & "Z” streak-culture* & gently roll (culture 1st, slide 2nd) \\
\hline 8 & Cross streak culture* & Sterile loop, Cipto will do this \\
\hline 9 & Gram stain swab & gentle roll \\
\hline 10 & Bimanual exam* & to rule out obvious pregnancy/pathology \\
\hline 11 & Candle jar* & must be re-lit after each specimen \\
\hline 12 & Cultures in candle jar* & media on top to reduce condensation flood \\
\hline 13 & BV-external genitalia & "coaty"- smooth, white-grey \\
\hline
\end{tabular}




\begin{tabular}{|c|c|c|}
\hline $\begin{array}{l}\text { Slide } \\
\#\end{array}$ & Content & Teaching point \\
\hline 14 & Gram stain & normal flora, clear epithelial cell \\
\hline 15 & BV-Clue cell, gram stain & pepper on an egg \\
\hline 16 & BV-Clue cells, wet mount & done with normal saline \\
\hline 17 & TRICH-external genitalia & frothy \\
\hline 18 & TRICH-close up of discharge & frothy w. Tissue inflammation \\
\hline 19 & Trichomonads on wet mount* & flagellates \\
\hline 20 & $\begin{array}{l}\text { Trichomonads- } \\
\text { electomagnification }\end{array}$ & flagella obvious \\
\hline 21 & TRICH- strawberry cervix & inflamed tissue \\
\hline 22 & $\begin{array}{l}\text { CANDIDIASIS- } \\
\text { discharge,external }\end{array}$ & thick w. Inflammation \\
\hline 23 & $\begin{array}{l}\text { CANDIDIASIS- } \\
\text { discharge,speculm }\end{array}$ & “chunky”-sour milk \\
\hline 24 & $\begin{array}{l}\text { CANDIDIASIS- } \\
\text { discharge,speculm }\end{array}$ & (smooth)-eyes can be fooled-need microscope \\
\hline 25 & HYPHAE- Gram stain & circus -skinny balloons \\
\hline 26 & HYPHAE- Wet mount* & done with $\mathrm{KOH}$ \\
\hline 27 & GO-urethra, female & strip with gloved hand \\
\hline 28 & $\begin{array}{l}\text { GO-urethritis male,colpo. } \\
\text { magnify }\end{array}$ & yellow \& erythema \\
\hline 29 & GO- urethritis male & classic yellow drip (Does spouse have dc ?) \\
\hline 30 & Cervical culture technique & wipe cervix off first \\
\hline 31 & Gram stain w. + GNID & INTRACELLULAR \\
\hline 32 & $\begin{array}{l}\text { CHLAMYDIA, cartoon time } \\
\text { bomb }\end{array}$ & Asymptomatic infections common \\
\hline 33 & $\begin{array}{l}\text { Chlamydial cervix before \& } \\
\text { after } \mathrm{Rx}\end{array}$ & $8+$ tests for CHLAMYDIA first 3 weeks \\
\hline 34 & MPC cervix & Rx for GO \& CHLAMYDIA \\
\hline 35 & MPC-non-gonnoccal & Can't visually distinguish GO from CHLAM \\
\hline 36 & T. Pallidum- spirochete & a systemic access, corkscrew \\
\hline 37 & SYPHILIS stages & MUST have serology \\
\hline 38 & Chancre- female & clean, rubbery (All genital ulcers need STS) \\
\hline 39 & Chancre- male & clean, rubbery (All genital ulcers need STS) \\
\hline
\end{tabular}


Appendix $E$

\begin{tabular}{|c|c|c|}
\hline $\begin{array}{l}\text { Slide } \\
\#\end{array}$ & Content & Teaching Point \\
\hline 40 & $\begin{array}{l}\text { Secondary syphilis rash- } \\
\text { female }\end{array}$ & do systemic exams; trunk,abdomen,palms,soles \\
\hline 41 & Secondary syphilis rash-male & systemic exams plus STS \\
\hline 42 & $\begin{array}{l}\text { Untreated syphilis } \\
\text { consequences }\end{array}$ & FU Rx w. titres for 1 year \\
\hline 43 & Fetus and placenta & systemic connection-pregnancy is critical \\
\hline 44 & $\begin{array}{l}\text { Congenital syphilis- } \\
\text { abortion** }\end{array}$ & treatment of pt. \& contacts w. close monitor \\
\hline 45 & Chancroid-female & dirty, irregular ulcer \\
\hline 46 & Chancroid-male & dirty with exudate \\
\hline 47 & HERPES (HSV) cartoon & stages with changing appearances \\
\hline 48 & HSV - females, primary & painful small papules \\
\hline 49 & HSV - female, primary & painful ulcers in various stages \\
\hline 50 & Cervical ectopy from HSV & visual ID difficult \\
\hline 51 & HSV-primary outbreak, male & vesicles and ulcers- painful \\
\hline 52 & Neonatal HSV & very serious \\
\hline 53 & Warts (HPV)-external female & varies from discrete to: \\
\hline 54 & HPV- external female & moderate \\
\hline 55 & HPV- external female & fulminating, coalescing \\
\hline 56 & HPV-internal female & refer to GYN, no podophyllin \\
\hline 57 & HPV-external male & various sizes \\
\hline 58 & HPV-external male & flat warts \\
\hline 59 & HPV-external male & flat, spiky \\
\hline 60 & RISK REDUCTION & $\mathrm{A}, \mathrm{B}, \mathrm{C}-\mathrm{ask}$, don't tell, then fill in gaps \\
\hline 61 & Condom barrier- they work!!! & Verbally discuss, physically offer \\
\hline
\end{tabular}

*-slides loaned from PATH

**- slide loaned from Mothercare 


\section{Communication and Infection Control Skills}

Supervisory Visit by

Dr. Frans Sumampouw, DAJ, MPH and Midwife Coos Leiwakabessy

April 21, 1997- Puskesmas Cilincing

Participants : Clinical and laboratory personel

Objective: To offer the midwives a forum to identify problems and successes they are experiencing in providing RTI/STD case management to family planning clients.

\section{Dr. Frans Sumampouw, DAJ, MPH - Comminication Skills}

1. Explore with the midwives any problematic areas they may be experiencing in the areas of:

- $\quad$ client history taking

- client education

- $\quad$ artner notification and treatment

- $\quad$ initiating a discussion on condoms, and offering them.

2. Consciousness raising on the subject of privacy.

- Visual privacy:

1) minimize the number of staff, students, and observers in the exam room;

2) restrict entrance of other staff members into the exam room while an exam is being done. A closed curtain should symbolize "no entrance" to other staff;

3) includes medical records and clinical evaluations, they should not be left out for other clients to see .

- Auditory privacy:

1) especially important when visual privacy is not possible, such as taking a history in the outside room;

2) critical when giving results of exam, whether positive or negative;

3) critical when making a plan for partner treatment;

4) requires a soft voice.

3. Reinforce the gathering of the history (questions 1-10c on the clinical evaluation) by the midwife, not the research assistant.

1) Is asking the questions (1-10c), getting easier than when the program started?

2) How do the midwives introduce the history to the client?

- if a professional explanation is given that the history is an important part of the evaluation, it will be more acceptable to the client; 


\section{Appendix $E$}

- Does the introduction of the history always include assurances that the answers will be kept confidential?

- Have the midwives experienced any negative consequences from the clients to this part of the evaluation? (Hopefully, the experience of the midwives or research assistants in the past 10 weeks will bear out the fact that clients are willing and capable of furnishing the sexual history without loosing face).

3) If important information is revealed during the history, the midwife should record it under the "Comments" section. Example: if a client was referred for an evaluation because she is a contact to a confirmed STD, this will guide the diagnosis and treatment. It must be recorded on the history for any additional intervention to occur.

4. Why is the discussion and provision of condoms not being done for each client who has a sexually transmitted infection? The client is free to decline condoms, but they must first be freely talked about and physically offered before she has an opportunity to choose them or not.

\section{Midwife Kos- Infection Control Skills}

Midwife Kos reviewed procedures for speculum sterilization. She stressed importance of through scrubbing before autoclaving to remove visible contaminants. She discussed the importance of maintaining an adequate supply of disinfected speculums. With purchases made trough this study. There are now 12 speculums. Midwife Kos stressed the importance of not reusing disposable gloves. 


\section{RTI/STD Clinical Evaluation Guide}

Health Care Provider Skills Inventory:

\begin{tabular}{|c|c|c|}
\hline$\checkmark$ & \# & Skill: \\
\hline & 1. & Professionally introduces self \& establishes rapport with client. \\
\hline & 2. & $\begin{array}{l}\text { Introduces purpose of program \& starts discussion of RTI/STD's \& their link to } \\
\text { contraceptive choice. }\end{array}$ \\
\hline & 3. & $\begin{array}{l}\text { Solicits participation in research study using the informed consent principals of: } \\
\text { a) voluntariness; b) anonymity; c) confidentiality; d) privacy. }\end{array}$ \\
\hline & 4. & If client agrees to participate in study, $\mathrm{HCP}$ signs consent form. \\
\hline & 5. & $\begin{array}{l}\text { Obtains a targeted risk assessment history by asking the following questions: } \\
\text { a) Age: younger than } 25 \text { years? }\end{array}$ \\
\hline & & b) Past history of STD? \\
\hline & & c) More than 1 sex partner (in the past 3 months)? \\
\hline & & d) Sexual intercourse without condoms (in the past 3 months)? \\
\hline & & $\begin{array}{l}\text { e) Unusual vaginal discharge: odor, green/yellow color, itching, etc. (in the past } 3 \\
\text { months)? }\end{array}$ \\
\hline & & f) Pain with urination (in the past 3 months)? \\
\hline & & g) Lower abdominal pain (in the past 3 months)? \\
\hline & & h) Bleeding after intercourse (in the past 3 months)? \\
\hline & & i) Genital sores or lumps (in the past 3 months)? \\
\hline & & j) Does husband/partner have unusual discharge from penis? (past 3 months) \\
\hline & & k) Does husband/partner have sores or lumps on penis? (past 3 months) \\
\hline & & 1) Does husband/partner have other sex partners? \\
\hline & 6. & Visually inspects skin. \\
\hline & 7. & Inspects \& palpates abdomen. \\
\hline & 8. & Inspects \& palpates inguinal area. \\
\hline & 9. & Performs speculum examination. \\
\hline & 10. & Performs bimanual examination. \\
\hline & 11. & Obtains laboratory specimens for microscopy, culture, ELISA \& serological tests. \\
\hline & 12. & Uses infection control practices: \\
\hline
\end{tabular}




\begin{tabular}{|c|c|}
\hline & a) washes hands before exam; \\
\hline & b) uses visibly clean speculum; \\
\hline & c) puts on new or disinfected glove before pelvic exam; \\
\hline & d) if rectal exam done, changes glove prior to rectal; \\
\hline & e) washes hands after removing glove; \\
\hline & f) does not re-use glove on another client. \\
\hline 13. & Explains exam findings \&/or diagnosis to client. \\
\hline 14. & If diagnosed RTI positive, explains disease to client. \\
\hline 15. & $\begin{array}{l}\text { If diagnosed STD positive, explains disease transmission \& makes a verbal plan for } \\
\text { partner treatment. }\end{array}$ \\
\hline 16. & $\begin{array}{l}\text { Selects an approved treatment } \& \text { prescribes the correct amount } \& \text { length of drug use } \\
\text { if client is diagnosed with a treatable infection. }\end{array}$ \\
\hline 17. & $\begin{array}{l}\text { If a prescription is written, gives instructions on: } \\
\text { a) when to take the drug; }\end{array}$ \\
\hline & b) length of drug use; \\
\hline & c) the importance of finishing the entire prescription; \\
\hline & d) potential side effects (alcohol \& pregnancy). \\
\hline 18. & Assesses the clients understanding of the instructions. \\
\hline 19. & $\begin{array}{l}\text { Provides instructions for future RTI/STD prevention: } \\
\text { a) abstinence; }\end{array}$ \\
\hline & b) monogamy; \\
\hline & c) condoms. \\
\hline 20. & Offers condoms and provides instructions for use. \\
\hline 21. & Demonstrates positive communication skills throughout the entire interaction: \\
\hline & a) open \& friendly attitude; \\
\hline & b) uses understandable terminology; \\
\hline & c) conveys an interest in the client; \\
\hline & d) listens carefully; \\
\hline & e) is open to the client's questions. \\
\hline
\end{tabular}




\section{HCP/Client Interaction Observation Form}

\begin{tabular}{|c|c|c|c|c|}
\hline NO & OBSERVATION & $(+)$ & $(-)$ & EXPLANATION \\
\hline 1. & Smiles and greets client respectfully & & & \\
\hline 2. & Asks client's reason for coming to the clinic & & & \\
\hline \multirow[t]{5}{*}{3.} & Client's current status/condition & & & \\
\hline & a. Contraceptive method & & & \\
\hline & b. Last menstruation & & & \\
\hline & c. Current medications & & & \\
\hline & d. Allergies to medications or latex & & & \\
\hline 4. & . OB history and potential of current pregnancy & & & \\
\hline 5. & $\begin{array}{l}\text { Reviews contraceptive methods and } \\
\text { relationship with RTI }\end{array}$ & & & \\
\hline 6. & $\begin{array}{l}\text { Review STDs/RTIs that potentially influence } \\
\text { women's reproductive organs }\end{array}$ & & & \\
\hline 7. & Past history of STD & & & \\
\hline \multirow[t]{3}{*}{8.} & Sexual history (in the last 3 months) & & & \\
\hline & a. Sexual intercourse without condoms & & & \\
\hline & b. $>1$ partner & & & \\
\hline \multirow[t]{6}{*}{9.} & RTI /STD symptoms (in the last 3 months) & & & \\
\hline & a. Vaginal discharge & & & \\
\hline & b. Vaginal itching & & & \\
\hline & c. Pain with urination & & & \\
\hline & d. Bleeding after intercourse & & & \\
\hline & e. Genital sores or lumps & & & \\
\hline \multirow[t]{4}{*}{10.} & Perception of partner's symptoms and risks & & & \\
\hline & a. Unusual discharge from penis & & & \\
\hline & b. Sores or lumps on penis & & & \\
\hline & c. Any partners other than you? & & & \\
\hline 11. & Explains exam before starting procedures & & & \\
\hline \multirow[t]{6}{*}{12.} & Sterilization & & & \\
\hline & a. Washes hands before exam & & & \\
\hline & b. Visibly clean instruments & & & \\
\hline & $\begin{array}{l}\text { c. Puts on new or disinfected glove before } \\
\text { pelvic exam }\end{array}$ & & & \\
\hline & $\begin{array}{l}\text { d. If rectal exam done, changes glove prior to } \\
\text { rectal }\end{array}$ & & & \\
\hline & e. Washes hands after removing glove & & & \\
\hline \multirow[t]{6}{*}{13.} & Physical exam & & & \\
\hline & a. Abdomen, skin & & & \\
\hline & b. Inguinal palpation & & & \\
\hline & c. Visualizes external genitalia & & & \\
\hline & d. Speculum exam & & & \\
\hline & e. Bimanual exam & & & \\
\hline \multirow[t]{3}{*}{14.} & $\begin{array}{l}\text { Counseling } \\
\text { a. Explains the diagnosis to client }\end{array}$ & & & \\
\hline & $\begin{array}{l}\text { b. If diagnosed RTI positive, explains disease } \\
\text { transmission }\end{array}$ & & & \\
\hline & $\begin{array}{l}\text { c. If diagnosed STD positive, makes a verbal } \\
\text { plan for partner treatment and evaluation. }\end{array}$ & & & \\
\hline
\end{tabular}




\begin{tabular}{|l|l|l|l|l|}
\hline NO & \multicolumn{1}{|c|}{ OBSERVATION } & $(+)$ & $(-)$ & \\
\hline 15. & Provides instruction for future RTI prevention & & & \\
\hline & a. Discusses Abstinence & & & \\
\hline & b. Discusses Be Faithful & & & \\
\hline & c. Discusses Condom & & & \\
\hline 16. & a. Offers condoms & & & \\
\hline & b. Provides instructions for condom use & & & \\
\hline 17. & $\begin{array}{l}\text { If RTI is positive, gives instruction on infection } \\
\text { treatment }\end{array}$ & & & \\
\hline & a. Prescribed medication & & & \\
\hline & b. How often to take the drug & & & \\
\hline & C. Length of the drug use & & & \\
\hline & d. Take entire prescription & & & \\
\hline & e. Potential side effect (alcohol and pregnancy) & & & \\
\hline f. Assess client's understanding of instruction & & & \\
\hline 18. & $\begin{array}{l}\text { HCP demonstrates positive communication } \\
\text { skills }\end{array}$ & & & \\
\hline & a. Open and friendly & & & \\
\hline & b. Uses understandable terminology & & & \\
\hline & c. Conveys interest in the client & & & \\
\hline & d. Listens carefully & & & \\
\hline & e. Is open to client's questions & & & \\
\hline
\end{tabular}

Research Assistant 


\section{STD Treatment Guidelines :}

\section{A Partial Comparison of Three Guidelines}

Diseases Compared :

Trichomoniasis

Bacterial vaginosis

Candidiasis

Gonorrhea

Chlamydia

Syphilis

Chancroid

Sources :

Daili, Sjaiful Fahmi et.al.(eds). Penatalaksanaan Penyakit Menular Seksual :

Berdasarkan Pendekatan Sindrom, Fasilitas Laboratorium Sederhana,

Laboratorium Khusus. Jakarta : Direktorat Jendral PPM \& PLP Departemen

Kesehatan RI dan Kelompok Studi Penyakit Menular Seksual, 1996

(Listed in tables as MOH-RI)

Centers for Disease Control and Prevention. “ 1993 Sexulally Transmitted Disease Guidelines” MMWR 1993, 42:1-102 (RR-14).

(Listed in tables as CDC-US)

World Health Organization Recommendations. Management of Sexually Transmitted Diseases. Geneva: WHO, 1994 (Report No. WHO/GPA/TEM/94.1)

(Listed in tables as WHO) 
STD Treatment Guidelines: Trichomoniasis

\begin{tabular}{|l|l|l|}
\hline MOH RI & CDC US & WHO \\
\hline $\begin{array}{l}\text { Metronidazole 2g po } \\
\text { single dose }\end{array}$ & $\begin{array}{l}\text { Metronidazole 2g po } \\
\text { single dose }\end{array}$ & Metronidazole 2g po single dose \\
\hline $\begin{array}{l}\text { Metronidazole 500 } \\
\text { mg po BID x 7 days }\end{array}$ & $\begin{array}{l}\text { Metronidazole 500 } \\
\text { mg BID x 7days }\end{array}$ & $\begin{array}{l}\text { Metronidazole 400-500 mg po BID } \\
\text { x 7 days }\end{array}$ \\
\hline
\end{tabular}

STD Treatment Guidelines: Bacterial vaginosis

\begin{tabular}{|c|c|c|}
\hline MOH RI & CDC US & WHO \\
\hline $\begin{array}{l}\text { Metronidazole* } 2 \mathrm{~g} \\
\text { po single dose }\end{array}$ & $\begin{array}{l}\text { Metronidazole } 500 \\
\text { mg po BID x } 7 \text { days }\end{array}$ & $\begin{array}{l}\text { Metronidazole* } 400-500 \mathrm{mg} \text { po } \\
\text { BID x } 7 \text { days }\end{array}$ \\
\hline $\begin{array}{l}\text { Metronidazole } 500 \\
\text { mg po BID x } 7 \text { days }\end{array}$ & $\begin{array}{l}\text { Alt Reg: } \\
\text { Metronidazole* } 2 \mathrm{~g} \\
\text { po single dose }\end{array}$ & Metronidazole, $2 \mathrm{~g}$ po single dose \\
\hline \multirow[t]{3}{*}{$\begin{array}{l}\text { Ampicillin } 500 \mathrm{mg} \text { po } \\
\text { QID x } 7 \text { days }\end{array}$} & $\begin{array}{l}\text { Alt Reg: Clindamycin } \\
\text { cream** } 2 \% \text {, full } \\
\text { applicator }(5 \mathrm{~g}) \\
\text { intravag @ HS x } 7 \\
\text { days }\end{array}$ & \\
\hline & $\begin{array}{l}\text { Alt Reg (AR): } \\
\text { Metronidazole gel, } \\
0.75 \% 1 \text { full } \\
\text { applicator }(5 \mathrm{~g}) \\
\text { intravag, BID x } 5 \\
\text { days }\end{array}$ & \\
\hline & $\begin{array}{l}\text { AR: Clindamycin } 300 \\
\text { mg po BID x } 7 \text { days }\end{array}$ & \\
\hline
\end{tabular}

* Contraindicated in first trimester pregnancy

** Oil based, may weaken latex 
STD Treatment Guidelines: Candidiasis

\begin{tabular}{|c|c|c|}
\hline MOH RI & CDC US & $\mathrm{WHO} * * *$ \\
\hline $\begin{array}{l}\text { Clotrimazole } 500 \mathrm{mg} \\
\text { tab/vag x } 1 \text { day }\end{array}$ & $\begin{array}{l}\text { Butoconazole } 2 \% \\
\text { cream } 5 \mathrm{~g} \text { intravag } \mathrm{x} \\
3 \text { days } * *\end{array}$ & $\begin{array}{l}\text { Nystatin } 100,000 \text { IU intravag daily } \\
\text { for } 14 \text { days }\end{array}$ \\
\hline $\begin{array}{l}\text { Miconazole or } \\
\text { Clotrimazole } 200 \mathrm{mg} \\
\text { tab/vag per day for } 3 \\
\text { days }\end{array}$ & $\begin{array}{l}\text { Clotrimazole } 1 \% \\
\text { cream } 5 \mathrm{~g} \text { intravag } \mathrm{x} \\
7-14 \text { days }\end{array}$ & $\begin{array}{l}\text { Miconazole or Clotrimazole, } 200 \\
\text { mg, daily for } 3 \text { days }\end{array}$ \\
\hline $\begin{array}{l}\text { Nystatin } 100,000 \mathrm{U} \\
\text { tab/vag Daily x } 2 \\
\text { weeks }\end{array}$ & $\begin{array}{l}\text { Clotrimazole } 100 \mathrm{mg} \\
\mathrm{vag} / \mathrm{tab} \text { x } 7-14 \text { days }\end{array}$ & $\begin{array}{l}\text { Clotrimazole, } 500 \mathrm{mg} \text { intravag as a } \\
\text { single dose }\end{array}$ \\
\hline $\begin{array}{l}\text { Ketoconazole* } 200 \\
\text { mg p.o BID x } 5 \text { days }\end{array}$ & $\begin{array}{l}\text { Clotrimazole } 100 \mathrm{mg} \\
\text { vag/tab x } 2 \text { tabs x } 3 \\
\text { days }\end{array}$ & \\
\hline $\begin{array}{l}\text { Itraconazole* } 200 \mathrm{mg} \\
\text { p.o x once }\end{array}$ & $\begin{array}{l}\text { Clotrimazole } 500 \mathrm{mg} \\
\mathrm{vag} / \mathrm{tab}, 1 \mathrm{x}\end{array}$ & \\
\hline \multirow[t]{7}{*}{$\begin{array}{l}\text { Fluconazole } 150 \mathrm{mg} \\
\text { p.o. x once }\end{array}$} & $\begin{array}{l}\text { Miconazole } 2 \% \\
\text { cream } 5 \text { g intravag } 7 \mathrm{x} \\
\text { days } * *\end{array}$ & \\
\hline & $\begin{array}{l}\text { Miconazole } 200 \mathrm{mg} \\
\text { vag supp daily for } \\
3 \text { days }\end{array}$ & \\
\hline & $\begin{array}{l}\text { Miconazole } 100 \mathrm{mg} \\
\text { vag supp daily for } 7 \\
\text { days } * *\end{array}$ & \\
\hline & $\begin{array}{l}\text { Tioconazole } 6.5 \% \\
\text { ointment } 5 \mathrm{~g} \text { intravag, } \\
\text { single dose } * *\end{array}$ & \\
\hline & $\begin{array}{l}\text { Terconazole } 0.4 \% \\
\text { cream } 5 \mathrm{~g} \text { intravag x } 7 \\
\text { days }\end{array}$ & \\
\hline & $\begin{array}{l}\text { Terconazole } 0.8 \% \\
\text { cream } 5 \text { g intravag x } 3 \\
\text { days }\end{array}$ & \\
\hline & $\begin{array}{l}\text { Terconazole } 80 \mathrm{mg} \\
\text { supp daily x } 3 \text { days } * *\end{array}$ & \\
\hline
\end{tabular}

This drug should not be used by pregnant or lactating women

** These creams and suppositories are oil-based and many weaken latex condoms and diagphagms

*** Ketoconazole and fluconazole have been studied in variety of oral regimens for Rx of VVC.

Although effective, they are not recommended as primary therapy because of cost and toxicity. Oral therapy does not prevent relapse. 
Appendix $\mathrm{H}$

STD Treatment Guidelines: Gonorrhea

\begin{tabular}{|l|l|l|}
\hline MOH RI & CDC US & WHO \\
\hline $\begin{array}{l}\text { Ciprofloxacin* } 500 \mathrm{mg} \\
\text { po single dose }\end{array}$ & $\begin{array}{l}\text { Ceftriaxone } 125 \mathrm{mg} \\
\text { IM single dose }\end{array}$ & $\begin{array}{l}\text { Ciprofloxacin 500 mg po single } \\
\text { dose }\end{array}$ \\
\hline $\begin{array}{l}\text { Ofloxacin* } 400 \mathrm{mg} \text { po } \\
\text { single dose }\end{array}$ & $\begin{array}{l}\text { Cefixime } 400 \mathrm{mg} \text { po } \\
\text { single dose }\end{array}$ & $\begin{array}{l}\text { Ceftriaxone 250 mg IM single } \\
\text { dose }\end{array}$ \\
\hline $\begin{array}{l}\text { Thiamphenicol* } 3.5 \mathrm{~g} \\
\text { po single dose }\end{array}$ & $\begin{array}{l}\text { Ciprofloxacin } 500 \mathrm{mg} \\
\text { po single dose }\end{array}$ & Cefixime 400 mg po single dose \\
\hline $\begin{array}{l}\text { Ceftriaxone 250 mg } \\
\text { IM single dose }\end{array}$ & $\begin{array}{l}\text { Ofloxacin 400 mg po } \\
\text { single dose }\end{array}$ & Spectinomycin 2 g IM single dose \\
\hline $\begin{array}{l}\text { Kanamycin 2 g IM } \\
\text { single dose }\end{array}$ & $\begin{array}{l}\text { PLUS DUAL RX } \\
\text { FOR CHLAMYDIA }\end{array}$ & $\begin{array}{l}\text { AR: which may be useful in some } \\
\text { resistance: }\end{array}$ \\
\hline $\begin{array}{l}\text { Spectinomycin 2 g IM } \\
\text { single dose }\end{array}$ & & Kanamycin 2 g IM single dose \\
\hline & & $\begin{array}{l}\text { TMP (80mg)/SMZ (400mg), 10 } \\
\text { tabs po, once daily for 3 days }\end{array}$ \\
\hline & Concurrent antichlamydial Rx \\
\hline
\end{tabular}

STD Treatment Guidelines: Chlamydia

\begin{tabular}{|l|l|l|}
\hline MOH RI & CDC US & WHO \\
\hline $\begin{array}{l}\text { Doxycycline } 100 \mathrm{mg} \\
\text { po BID x 7 days }\end{array}$ & $\begin{array}{l}\text { Doxycycline 100 mg } \\
\text { po BID x 7 days }\end{array}$ & $\begin{array}{l}\text { Doxycycline 100 mg po BID x 7 } \\
\text { days }\end{array}$ \\
\hline $\begin{array}{l}\text { Azithromycin 1 g po } \\
\text { single dose }\end{array}$ & $\begin{array}{l}\text { Azithromycin 1 g po } \\
\text { single dose }\end{array}$ & $\begin{array}{l}\text { Tetracycline 500 mg po QID x 7 } \\
\text { days }\end{array}$ \\
\hline $\begin{array}{l}\text { Erythromycin 500 mg } \\
\text { po QID x 7 days }\end{array}$ & $\begin{array}{l}\text { AR: Ofloxacin 300 } \\
\text { mg po BID x 7 days }\end{array}$ & $\begin{array}{l}\text { AR: Erythromycin } 500 \text { mg QID x } \\
7 \text { days }\end{array}$ \\
\hline & $\begin{array}{l}\text { AR: Erythromycin } \\
\text { base 500 mg po QID } \\
\text { x 7 days }\end{array}$ & $\begin{array}{l}\text { AR: Sulfafurazole 500 mg po QID } \\
\text { x 10 days }\end{array}$ \\
\hline $\begin{array}{l}\text { AR: Sulfisoxazole } \\
500 \text { mg po QID x 10 } \\
\text { days (inferior regimen } \\
\text { to others) }\end{array}$ & \\
\hline
\end{tabular}


STD Treatment Guidelines : Syphilis-Primary \& Secondary

\begin{tabular}{|c|c|c|}
\hline MOH RI & CDC US & $\mathrm{WHO} * *$ \\
\hline $\begin{array}{l}\text { Benzathine Penicillin } \\
2.4 \text { million U IM, } \\
\text { single dose, or }\end{array}$ & $\begin{array}{l}\text { Benzathine Penicillin } \\
2.4 \text { million U IM, } \\
\text { single dose* }\end{array}$ & $\begin{array}{l}\text { Benzathine Penicillin } 2.4 \text { million U } \\
\text { IM, single dose }\end{array}$ \\
\hline $\begin{array}{l}\text { Procaine Penicillin } \\
600,000 \text { U IM q.Day x } \\
10 \text { days }\end{array}$ & $\begin{array}{l}\text { if Non-pregnant \& } \\
\text { PCN allergic : }\end{array}$ & $\begin{array}{l}\text { (AR) : Aqueous procaine } \\
\text { benzathine PCN G. } 1.2 \text { million U } \\
\text { IM daily x } 10 \text { days }\end{array}$ \\
\hline if allergic can give: & $\begin{array}{l}\text { (AR): Doxycycline } \\
100 \mathrm{mg} \text { po BID x } 14 \\
\text { days }\end{array}$ & if Non-pregnant \& PCN allergic : \\
\hline $\begin{array}{l}\text { Tetracycline } 500 \mathrm{mg} \\
\text { po QID x } 15 \text { days, or }\end{array}$ & $\begin{array}{l}\text { Tetracycline } 500 \mathrm{mg} \\
\text { po QID x } 14 \text { days }\end{array}$ & $\begin{array}{l}\text { (AR): Tetracycline } 500 \mathrm{mg} \text { po } \\
\text { QID x } 15 \text { days }\end{array}$ \\
\hline $\begin{array}{l}\text { Erithromycin } 500 \mathrm{mg} \\
\text { po QID x } 15 \text { days }\end{array}$ & $\begin{array}{l}\text { if PCN Allergic, \& } \\
\text { pregnant, } \\
\text { desensitization then } \\
\text { Rx w. PCN }\end{array}$ & $\begin{array}{l}\text { (AR) : Doxycycline } 100 \mathrm{mg} \text { po } \\
\text { BID x } 15 \text { days }\end{array}$ \\
\hline $\begin{array}{l}\text { Doxycycline } 100 \mathrm{mg} \\
\text { po BID x } 15 \text { days }\end{array}$ & & $\begin{array}{l}* *_{\text {- recommends this regimen for }} \\
\text { primary, secondary or latent } \\
\text { syphilis of not more than } 2 \text { years' } \\
\text { duration }\end{array}$ \\
\hline
\end{tabular}

* Follow-up exam and labs at 3 AND 6 months

STD Treatment Guidelines : Late Latent Syphilis

Benzathine PCN G 7.2 million U administered in 3 doses of 2.4 million U IM weekly at 1 week intervals Benzathine PNC G, 2.4 million U IM weekly for 3 weeks 
Appendix $\boldsymbol{H}$

STD Treatment Guidelines :Chancroid

\begin{tabular}{|l|l|l|}
\hline MOH RI & CDC US & WHO \\
\hline $\begin{array}{l}\text { Ciprofloxacin 500 mg po } \\
\text { single dose, or, }\end{array}$ & $\begin{array}{l}\text { Azithromycin 1 g po } \\
\text { single dose, or, }\end{array}$ & $\begin{array}{l}\text { Erythromycin } 500 \mathrm{mg} \text { po TID } \\
\text { x 7 days, or }\end{array}$ \\
\hline $\begin{array}{l}\text { Ofloxacin } 400 \mathrm{mg} \text { po single } \\
\text { dose, or, }\end{array}$ & $\begin{array}{l}\text { Ceftriaxone 250 mg } \\
\text { IM single dose, or }\end{array}$ & $\begin{array}{l}\text { (AR) : Ciprofloxacin } 500 \mathrm{mg} \\
\text { po single dose }\end{array}$ \\
\hline $\begin{array}{l}\text { Azithromycin 1 g po single } \\
\text { dose, or, }\end{array}$ & $\begin{array}{l}\text { Erythromycin base } \\
500 \text { mg po QID x } 7 \\
\text { days, or }\end{array}$ & $\begin{array}{l}\text { Ceftriaxone 250 mg IM single } \\
\text { dose }\end{array}$ \\
\hline $\begin{array}{l}\text { Erythromycin } 500 \mathrm{mg} \text { po } \\
\text { QID x 7 days, or }\end{array}$ & $\begin{array}{l}\text { Ceftriaxone 250 mg IM } \\
\text { single dose, or }\end{array}$ & dose \\
\hline $\begin{array}{l}\text { TMP/SMZ 80/400 mg, 2 } \\
\text { tabs BID x 7 days }\end{array}$ & $\begin{array}{l}\text { TMP(80 mg)/SMZ (400 mg), } \\
\text { tabs BID x 7 days* }\end{array}$ \\
\hline
\end{tabular}

* TMP/SMZ has been shown to be less effective in some parts of Asia and Africa. It should only be used in areas where in vitro resistant rates are low and monitored at regular levels. Where compliance is likely, Erythromycin is definitely the treatment of choice. 
RTI/STD Treatment Cost Implication

\begin{tabular}{|c|c|c|c|c|c|c|c|}
\hline \multirow[t]{2}{*}{ No } & \multirow[t]{2}{*}{ Disease } & \multirow[t]{2}{*}{ Drug } & \multirow[t]{2}{*}{ Dose/Person } & \multicolumn{4}{|c|}{ Range of Cost for Treatment (Rp) } \\
\hline & & & & Min.Cost/Unit & Tot Min. Cost/Reg. & Max.Cost/Unit & Tot. Max Cost/Reg. \\
\hline 1 & Trichomoniasis & Metronidazole 500 mg, orally & $\begin{array}{l}2 \text { grams, single dose } \\
500 \mathrm{mg} \text { BID for } 7 \text { days }\end{array}$ & $\begin{array}{l}106 \\
106\end{array}$ & $\begin{array}{r}424 \\
1,484 \\
\end{array}$ & $\begin{array}{l}1,747 \\
1,747\end{array}$ & $\begin{array}{r}6,988 \\
24,458\end{array}$ \\
\hline 2 & Bacterial vaginosis & $\begin{array}{l}\text { 1) Metronidazol } 500 \text { mg, orally } \\
\text { 2) Ampicillin } 500 \text { mg, orally }\end{array}$ & $\begin{array}{l}2 \text { grams, single dose } \\
500 \text { mg BID for } 7 \text { days } \\
500 \text { mg QID for } 7 \text { days }\end{array}$ & $\begin{array}{l}106 \\
106 \\
206\end{array}$ & $\begin{array}{r}424 \\
1,484 \\
5,768\end{array}$ & $\begin{array}{l}1,747 \\
1,747 \\
1,695\end{array}$ & $\begin{array}{r}6,988 \\
24,458 \\
47,460\end{array}$ \\
\hline 3 & Candidiasis & $\begin{array}{l}\text { 1) Clotrimazole } 500 \mathrm{mg} \text {, vaginal tablet } \\
\text { 2) Nystatin } 10,000 \mathrm{IU} \text {, vaginal tablet } \\
\text { 3) Ketokonazole } 200 \mathrm{mg} \text {, orally } \\
\text { 4) Itrakonazole } 200 \mathrm{mg} \text {, orally } \\
\text { 5) Fluconazole150 mg, orally }\end{array}$ & $\begin{array}{l}\text { single dose } \\
1 \text { times daily for } 14 \text { days } \\
2 \text { times daily for } 5 \text { days } \\
2 \text { times daily for } 1 \text { day } \\
\text { single dose }\end{array}$ & $\begin{array}{r}1,544 \\
427 \\
3,600 \\
19,800\end{array}$ & \begin{tabular}{r|}
- \\
21,616 \\
4,270 \\
7,200 \\
19,800
\end{tabular} & $\begin{array}{r}18,150 \\
2,929 \\
7,150 \\
33,908\end{array}$ & $\begin{array}{l}18,150 \\
29,290 \\
14,300 \\
33,908\end{array}$ \\
\hline 4 & Gonorrhea & $\begin{array}{l}\text { 1) Ciprofloxacin } 500 \text { mg, orally } \\
\text { 2) Ofloxacin } 400 \mathrm{mg} \text {, orally } \\
\text { 3) Thiamphenicol } 3.5 \mathrm{~g} \text {, orally } \\
\text { 4) Seftriaxone } 250 \mathrm{mg} \text {, IM } \\
\text { 5) Kanamycin } 2 \mathrm{gr}, \mathrm{IM} \\
\text { 6) Spectinomycin } 2 \mathrm{gr} \text {, IM }\end{array}$ & $\begin{array}{l}\text { single dose } \\
\text { single dose } \\
\text { single dose } \\
\text { single dose } \\
\text { single dose } \\
\text { single dose }\end{array}$ & $\begin{array}{r}2,200 \\
4,573 \\
680 \\
7,573 \\
-\quad 300 \\
\end{array}$ & $\begin{array}{r}2,200 \\
4,573 \\
4,760 \\
7,573 \\
300\end{array}$ & $\begin{array}{r}10,116 \\
8,639 \\
1,779 \\
13,750 \\
8,800 \\
22,790\end{array}$ & $\begin{array}{r}10,116 \\
8,639 \\
12,453 \\
13,750 \\
8,800 \\
22,790\end{array}$ \\
\hline 5 & Chlamydia & $\begin{array}{l}\text { 1) Doxycycline } 100 \text { mg, orally } \\
\text { 2) Azithromycin } 1 \mathrm{~g} \text {, orally } \\
\text { 3) Erythromycin } 500 \text { mg, orally }\end{array}$ & $\begin{array}{l}\text { twice a day for } 7 \text { days } \\
\text { single dose } \\
4 \text { times a day for } 7 \text { days }\end{array}$ & $\begin{array}{r}243 \\
13,600 \\
443\end{array}$ & $\begin{array}{r}3,402 \\
13,600 \\
12,404\end{array}$ & $\begin{array}{r}3,048 \\
33,492 \\
3,960\end{array}$ & $\begin{array}{r}51,816 \\
33,492 \\
110,880\end{array}$ \\
\hline 6 & Syphilis & $\begin{array}{l}\text { 1) Benzathine penicillin G } 2.4 \text { m.unit IM } \\
\text { 2) Penicillin procaine } 600,000 \text { units IM } \\
\text { 3) Tetracycline } 500 \text { mg, orally } \\
\text { 4) Erithromycin } 500 \text { mg, orally } \\
\text { 5) Doxycycline } 100 \text { mg, orally }\end{array}$ & \begin{tabular}{|l|} 
single dose \\
1 times a day for 10 days \\
4 times a day for 15 days \\
4 times a day for 15 days \\
2 times a day 15 days
\end{tabular} & $\begin{array}{r}6,094 \\
398 \\
202 \\
443 \\
243\end{array}$ & $\begin{array}{r}6094 \\
3,980 \\
12,120 \\
26,580 \\
7,290\end{array}$ & $\begin{array}{rr}- & \\
- & 922 \\
3,960 \\
3,048\end{array}$ & $\begin{array}{rr}- & \\
- & \\
55,320 \\
237,600 \\
91,440\end{array}$ \\
\hline
\end{tabular}


RTI/STD Treatment Cost Implication

\begin{tabular}{|c|c|c|c|c|c|c|c|}
\hline \multirow[t]{2}{*}{ No } & \multirow[t]{2}{*}{ Disease } & \multirow[t]{2}{*}{ Drug } & \multirow[t]{2}{*}{ Dose/Person } & \multicolumn{4}{|c|}{ Range of Cost for Treatment (Rp) } \\
\hline & & & & Min.Cost/Unit & Tot Min. Cost/Reg. & Max.Cost/Unit & Tot. Max Cost/Reg. \\
\hline 7 & Chancroid & $\begin{array}{l}\text { 1) Ciprofloxacin } 500 \mathrm{mg} \text {, orally } \\
\text { 2) Ofloxacin } 400 \mathrm{mg} \text {, orally } \\
\text { 3) Azithromycin } 1 \mathrm{gr} \text {, orally } \\
\text { 4) Erythromycin } 500 \mathrm{mg} \text {, orally } \\
\text { 5) Ceftriaxone } 250 \mathrm{mg} \text {, IM } \\
\text { 6) Cotrimoxazole } 400 \mathrm{mg} \text { tablets orally }\end{array}$ & $\begin{array}{l}\text { single dose } \\
\text { single dose } \\
\text { single dose } \\
4 \text { times a day for } 7 \text { days } \\
\text { single dose } \\
2 \text { tablets BID for } 7 \text { days }\end{array}$ & $\begin{array}{r}2,200 \\
4,573 \\
13,600 \\
443 \\
7,573 \\
88\end{array}$ & \begin{tabular}{|r|}
2,200 \\
4,573 \\
13,600 \\
12,404 \\
7,573 \\
2,464
\end{tabular} & \begin{tabular}{|r|}
10,116 \\
8,639 \\
33,492 \\
3,960 \\
55,000 \\
1,726
\end{tabular} & \begin{tabular}{r|}
10,116 \\
8,639 \\
33,492 \\
110,880 \\
55,000 \\
48,328 \\
\end{tabular} \\
\hline 8 & $\begin{array}{l}\text { Herpes Simplex } \\
\text { Virus }\end{array}$ & $\begin{array}{l}\text { first clinical episode } \\
\text { 1) Acyclovir } 200 \mathrm{mg} \text {, orally } \\
\text { recurrent episode } \\
\text { 1) Acyclovir } 200 \mathrm{mg} \text {, orally }\end{array}$ & $\begin{array}{l}5 \text { times a day for } 7 \text { days } \\
5 \text { times a day for } 5 \text { days }\end{array}$ & $\begin{array}{l}1,100 \\
1,100\end{array}$ & $\begin{array}{l}38,500 \\
27,500\end{array}$ & $\begin{array}{l}5,525 \\
5,525\end{array}$ & $\begin{array}{r}193,375 \\
138,125\end{array}$ \\
\hline
\end{tabular}

Note: Unit means per tablet or capsule

Reg. (regimen) means total tablets/capsules for the length of treatment of time needed 
Appendix K

ORAL INFORMED CONSENT FORM

\section{Improved Reproductive Health and STD Services for Women Presenting to Family Planning Services in North Jakarta}

Name of Client: Study Number:

Address: Phone:

\section{Purpose of the study:}

The purpose of this study is to find out more about infections women might get in their reproductive tract. We would like your help as a participant in a study to learn more about this and be able to help women who need treatment to receive it.

\section{Procedures:}

We invite you to be examined by a doctor or midwife who will perform some tests to see if you might have an infection and need treatment. During the examination some samples of vaginal and cervical secretions will be taken, and a small amount of blood $(5 \mathrm{ml})$ will be drawn from your arm. During the examination an observer will be present to observe the health care providers actions. We will also ask you to answer some questions about your medical and reproductive health history. The answers to these questions will be kept strictly confidential. Any report from this study will not use your name.

You can freely decide if you wish to enter the study. If you do not want to participate in the study you will receive care as usual at the family planning unit. You may withdraw from the study at any time.

\section{Risks and Benefits:}

The possible risks and discomfort associated with this study include some possible discomfort during the internal examination, and when blood is drawn from your arm, and some possible embarrassment at being asked certain questions. The procedures are not considered to carry any medical risks.

If you agree to participate in this study, you will receive a comprehensive physical examination and a series of tests will be done to identify any infections that you might have in your reproductive tract. You will not have to pay for these tests and you will receive free treatment if an infection is discovered. If your partner also needs treatment, we will make a plan with you to accomplish this.

As the results of some of the laboratory tests will not be available for a little while, we would like you to contact us in two weeks' time to check whether these results show that you have an infection 
that did not get properly treated. If you wish, we can also contact you at home to let you know whether you need to come back to the clinic for follow-up. If you give us permission to contact you at home, we will not say anything about you to anyone else there.

You are welcome to ask us questions about the study at any time. If you have questions after you leave the clinic, you may contact Dr. Meiwita Iskandar, Jakarta (tel 520-0494 or 520-0094).

Signature of Investigator

Date

Subjects Statement:

The study described above has been explained to me and I agree to participate in this study. I have had a chance to ask questions. I know that I can stop participating at any time without loosing any benefits of the services I already receive in this family planning clinic.

Participants preferred plan for follow-up:

Signature of Staff Reading Informed

Date

Consent Form to Potential Participant

instrumentslconsent $\ 14 / 3 / 97$ 


\title{
PROTOKOL DIAGNOSIS DAN \\ PENATALAKSANAAN KASUS \\ INFEKSI SALURAN REPRODUKSI (ISR)/ \\ PENYAKIT MENULAR SEKSUAL (PMS)
}

\author{
"PEMERIKSAAN ISR/PMS DI UNIT KB \\ SECARA TERPADU" \\ Di RSUD Koja dan \\ Puskesmas Kecamatan Cilincing
}

The Population Council Jakarta dan HIV/AIDS Prevention Project Departemen Kesehatan RI dibiayai oleh USAID di bawah koordinasi Family Health International/AIDSCAP bekerjasama dengan

Centers for Disease Control (CDC) A.S

The Population Council-Jakarta

Asia \& Near East Operations Research and

Technical Assistance Project 


\section{PROTOKOL DIAGNOSIS DAN PENATALAKSANAAN KASUS INFEKSI SALURAN REPRODUKSI (ISR) / PENYAKIT MENULAR SEKSUAL (PMS)}

Daftar pustaka:

1. King, Holmes K., et al. Sexually Transmitted Diseases. $2^{\text {nd }}$ Ed. New York: Mc graw-Hill, Inc, 1990.

2. Daili, Sjaiful Fahmi, dkk (ed). Penatalaksanaan Penyakit Menular Seksual Berdasarkan Pendekatan Sindrom ,Fasilitas Laboratorium Sederhana, Laboratorium Khusus. Dirjen PPM \& PLP Depkes RI dan Kelompok Studi Penyakit Menular Seksual Indonesia. Jakarta 1996.

Foto-foto pada pedoman ini diambil dari:

H. Hunter Handsfield. Color Atlas and Synopsis of Sexually Transmitted Diseases. Mc Graw Hill, 1992.

\section{Catatan :}

Diagnosis untuk HIV tidak termasuk dalam studi ini, tetapi jika petugas kesehatan menilai bahwa pasien mempunyai risiko terhadap HIV, disarankan merujuk pasien menurut mekanisme yang berlaku di fasilitas tersebut. 


\section{TRIKOMONIASIS}

\begin{tabular}{|c|c|}
\hline Riwayat kesehatan & $\begin{array}{l}\text { Mungkin terdapat: } \\
\begin{array}{l}\text { 1. Cairan vagina yang abnormal : } \\
\text { - berbau } \\
\quad \text { - banyak \& berbusa } \\
\quad \text { - tampak kuning/hijau } \\
\text { 2. Gatal pada vulva } \\
\text { 3. Nyeri pada saat buang air kecil dan/atau } \\
\text { berhubungan seksual }\end{array}\end{array}$ \\
\hline Pemeriksaan fisik & $\begin{array}{l}\text { Mungkin terdapat: } \\
\text { 1. Peradangan } \\
\text { 2. Cairan berbau } \\
\text { 3. Cairan vagina tampak abu-abu/hijau/kuning } \\
\text { 4. Strawberry cervix }\end{array}$ \\
\hline Hasil laboratorium & $\begin{array}{l}\text { Tampak: } \\
\text { Motile trichomonads pada preparat basah garam faal }\end{array}$ \\
\hline $\begin{array}{l}\text { Pengobatan } \\
\text { \# Tidak diberikan kepada wanita } \\
\text { hamil. } \\
\text { \# Dilarang minum alkohol saat } \\
\text { pengobatan dengan Metronidazol } \\
\frac{\text { Catatan }}{\text { Metronidazol dapat dipakai untuk }} \\
\text { wanita hamil trimester ke - } 3\end{array}$ & $\begin{array}{l}\text { Regimen pilihan: } \\
\text { \#Metronidazol } 2 \text { gr per oral, dosis tunggal } \\
\text { Regimen alternatif: } \\
\text { \#Metronidazol } 2 \text { × } 500 \mathrm{mg}, 7 \text { hari }\end{array}$ \\
\hline $\begin{array}{l}\text { Rujukan pasangan dan } \\
\text { pemeriksaan tambahan untuk } \\
\text { pasien }\end{array}$ & $\begin{array}{l}\text { 1. Terapi bersama pasangan } \\
\text { 2. Lakukan juga tes Gonore dan Klamidia } \\
\text { 3. Dianjurkan rujukan tes serologi HIV }\end{array}$ \\
\hline
\end{tabular}


Gambar 1 : Motile Trichomonads pada preparat basah garam faal VAGINOSIS BAKTERIAL

\begin{tabular}{|c|c|}
\hline Riwayat kesehatan & $\begin{array}{l}\text { Mungkin terdapat: } \\
\text { 1. Cairan vagina yang abnormal : } \\
\text { - berbau amis } \\
\text { - tampak abu-abu/putih }\end{array}$ \\
\hline Pemeriksaan fisik & $\begin{array}{l}\text { Mungkin terdapat: } \\
\text { 1. Cairan berbau } \\
\text { 2. Cairan licin dan lengket } \\
\text { 3. Cairan tampak abu- abu/putih }\end{array}$ \\
\hline Hasil laboratorium & $\begin{array}{l}\text { Tampak: } \\
\text { 1. Clue cells pada preparat basah garam faal } \\
\text { 2. Bau }(+) \text { dengan } \mathrm{KOH}\end{array}$ \\
\hline $\begin{array}{l}\text { Pengobatan } \\
\text { \# Tidak diberikan kepada wanita } \\
\text { hamil. } \\
\text { \# Dilarang minum alkohol saat } \\
\text { pengobatan dengan Metronidazol } \\
\text { Catatan } \\
\text { Metronidazol dapat dipakai untuk } \\
\text { wanita hamil trimester ke - } 3\end{array}$ & $\begin{array}{l}\text { Regimen pilihan: } \\
\text { \#Metronidazol } 2 \text { gr per oral, dosis tunggal } \\
\text { Regimen alternatif: } \\
\text { \#Metronidazol } 2 \text { × } 500 \mathrm{mg} \text { per oral, } 7 \text { hari atau } \\
\text { Ampisilin } 4 \times 500 \mathrm{mg} \text { per oral, } 7 \text { hari }\end{array}$ \\
\hline $\begin{array}{l}\text { Rujukan pasangan dan } \\
\text { pemeriksaan tambahan untuk } \\
\text { pasien }\end{array}$ & \\
\hline
\end{tabular}


Gambar 4: Clue Cells pada preparat basah garam faal

KANDIDIASIS VULVOVAGINAL

\begin{tabular}{|c|c|}
\hline Riwayat kesehatan & $\begin{array}{l}\text { Mungkin terdapat: } \\
\text { 1. Cairan vagina yang abnormal: } \\
\quad \text { - putih kental seperti susu basi } \\
\text { 2. Gatal \& kemerahan pada vulva }\end{array}$ \\
\hline Pemeriksaan fisik & $\begin{array}{l}\text { Mungkin terdapat: } \\
\text { 1. Peradangan } \\
\text { 2. Cairan putih kental seperti susu basi }\end{array}$ \\
\hline Hasil laboratorium & $\begin{array}{l}\text { Tampak: } \\
\text { Miselium/Pseudohifa pada preparat basah } \mathrm{KOH} / \mathrm{Gram}\end{array}$ \\
\hline $\begin{array}{l}\text { Pengobatan } \\
\text { \# Tidak diberikan kepada } \\
\text { wanita hamil, menyusui, dan } \\
\text { anak-anak. }\end{array}$ & $\begin{array}{l}\text { Regimen pilihan: } \\
\text { Klotrimazol } 500 \mathrm{mg} \text { intra vagina, dosis tunggal atau } \\
\text { Mikonazol/klotrimazol } 1 \times 200 \mathrm{mg} \text { intra vagina, } 3 \mathrm{hr} \text { atau } \\
\text { Nystatin } 1 \times 100.000 \mathrm{IU} \text { intra vagina, } 14 \text { hari atau } \\
\text { \#Ketokonazole } 2 \times 200 \mathrm{mg} \text { per oral, } 5 \text { hari atau } \\
\text { \#ltraconazole } 2 \times 200 \mathrm{mg} \text { per oral, } 1 \text { hari atau } \\
\text { Flukonazol } 150 \mathrm{mg} \text { per oral, dosis tunggal. }\end{array}$ \\
\hline $\begin{array}{l}\text { Rujukan pasangan dan } \\
\text { pemeriksaan tambahan } \\
\text { untuk pasien }\end{array}$ & \\
\hline
\end{tabular}


Gambar 6: Hifa pada Pewarnaan Gram

\section{GONORE}

\begin{tabular}{|c|c|}
\hline Riwayat kesehatan & $\begin{array}{l}\text { Mungkin terdapat: } \\
\text { 1. Cairan vagina tampak kuning/putih } \\
\text { 2. Nyeri pada saat buang air kecil } \\
\text { 3. Perdarahan setelah hubungan seksual } \\
\text { 4. Nyeri perut bagian bawah }\end{array}$ \\
\hline Pemeriksaan fisik & $\begin{array}{l}\text { Mungkin terdapat: } \\
\text { 1. Cairan vagina bertambah banyak } \\
\text { 2. Serviks merah } \\
\text { 3. Ektopi serviks } \\
\text { 4. Serviks rapuh } \\
\text { 5. Cairan mukopus keruh } \\
\text { 6. Rasa nyeri saat serviks digerakkan } \\
\text { 7. Rasa nyeri pada palpasi uterus dan/atau adneksa. }\end{array}$ \\
\hline Hasil laboratorium & $\begin{array}{l}\text { Mungkin terdapat }>30 \text { lekosit/PMN } \\
\text { Tampak: } \\
\text { Diplococcus Gram Negative Intra Sel } \\
\text { Kultur Gonore }(+)\end{array}$ \\
\hline $\begin{array}{l}\text { Pengobatan } \\
\text { \# Tidak diberikan kepada } \\
\text { wanita hamil, menyusui, dan } \\
\text { anak-anak }\end{array}$ & $\begin{array}{l}\text { Regimen pilihan: } \\
\text { \#Siprofloksasin } 500 \mathrm{mg} \text { per oral, dosis tunggal atau } \\
\text { \#Ofloksasin } 400 \mathrm{mg} \text { per oral, dosis tunggal atau } \\
\text { \#Tiamfenikol 3,5 gr per oral, dosis tunggal atau } \\
\text { Seftriakson } 250 \mathrm{mg} \text { IM, dosis tungggal atau } \\
\text { Kanamisin } 2 \mathrm{gr} \mathrm{IM} \text {, dosis tunggal atau } \\
\text { Spektinomisin } 2 \mathrm{gr} \mathrm{IM} \text {, dosis tunggal }\end{array}$ \\
\hline $\begin{array}{l}\text { Rujukan pasangan dan } \\
\text { pemeriksaan tambahan } \\
\text { untuk pasien }\end{array}$ & $\begin{array}{l}\text { 1. Pasangan harus diberitahu, diperiksa dan diobati } \\
\text { 2. Lakukan juga tes Klamidia } \\
\text { 3. Dianjurkan rujukan tes serologi HIV }\end{array}$ \\
\hline
\end{tabular}


Gambar 8 : Uretritis Gonore

\section{KLAMIDIA GENITAL}

\begin{tabular}{|l|l||}
\hline Riwayat kesehatan & Umumnya asimtomatik, mungkin terdapat : \\
& $\begin{array}{l}\text { 1. Cairan vagina kekuningan dan encer } \\
\text { 2. Nyeri pada saat buang air kecil }\end{array}$ \\
& $\begin{array}{l}\text { 3. Perdarahan setelah hubungan seksual. } \\
\text { 4. Nyeri perut bagian bawah. }\end{array}$ \\
\hline Pemeriksaan fisik & $\begin{array}{l}\text { Mungkin terdapat: } \\
\text { 1. Cairan vagina bertambah banyak }\end{array}$ \\
& $\begin{array}{l}\text { 2. Serviks merah } \\
\text { 3. Ektopi serviks }\end{array}$ \\
& $\begin{array}{l}\text { 4. Serviks rapuh } \\
\text { 5. Cairan mukopus keruh }\end{array}$ \\
\hline 6. Rasa nyeri saat serviks digerakkan \\
7. Rasa nyeri pada palpasi uterus dan/atau adneksa.
\end{tabular}




\section{Gambar 10 : Servisitis mukopurulen Klamidia}

\section{SERVISITIS MUKOPURULEN}

\begin{tabular}{|c|c|}
\hline Riwayat kesehatan & $\begin{array}{l}\text { Mungkin terdapat: } \\
\text { 1. Cairan vagina kekuningan dan encer } \\
\text { 2. Nyeri pada saat buang air kecil } \\
\text { 3. Perdarahan setelah hubungan seksual } \\
\text { 4. Nyeri perut bagian bawah }\end{array}$ \\
\hline Pemeriksaan fisik & $\begin{array}{l}\text { Mungkin terdapat: } \\
\text { 1. Cairan vagina bertambah banyak } \\
\text { 2. Serviks merah } \\
\text { 3. Ektopi serviks } \\
\text { 4. Serviks rapuh } \\
\text { 5. Cairan mukopus keruh } \\
\text { 6. Rasa nyeri saat serviks digerakkan } \\
\text { 7. Rasa nyeri pada palpasi uterus dan/atau adneksa }\end{array}$ \\
\hline Hasil laboratorium & $\begin{array}{l}\text { Mungkin terdapat: } \\
>30 \text { lekosit/PMN, ingat diagnosis empiris }\end{array}$ \\
\hline Pengobatan & $\begin{array}{l}\text { Regimen pilihan: } \\
\text { Harus termasuk regimen yang efektif terhadap Gonore } \\
\text { dan Klamidia }\end{array}$ \\
\hline $\begin{array}{l}\text { Rujukan pasangan dan } \\
\text { pemeriksaan tambahan } \\
\text { untuk pasien }\end{array}$ & $\begin{array}{l}\text { 1. Pasangan harus diberitahu, diperiksa dan diobati } \\
\text { dengan regimen } \\
\text { 2. Lakukan juga tes Gonore dan Klamidia } \\
\text { 3. Dianjurkan rujukan tes serologi HIV }\end{array}$ \\
\hline
\end{tabular}


Gambar 12 : Servisitis Mukopurolen Non Gonore SIFILIS

\begin{tabular}{|c|c|}
\hline Riwayat kesehatan & $\begin{array}{l}\text { Umumnya asimtomatik. Mungkin terdapat: } \\
\text { 1. Ulkus di genitalia } \\
\text { 2. Kemerahan di seluruh kulit }\end{array}$ \\
\hline Pemeriksaan fisik & $\begin{array}{l}\text { Mungkin terdapat: } \\
\text { 1. Ulkus tunggal yang tidak sakit } \\
\text { 2. Diameter ulkus } 5 \text { - } 15 \mathrm{~mm} \\
\text { 3. Tepi ulkus meninggi dan berbatas jelas } \\
\text { 4. Dasar ulkus: halus dan bersih } \\
\text { 5. Perabaan ulkus: keras } \\
\text { 6. Kelenjar limfe: keras, tidak sakit } \\
\text { 7. Setelah ulkus sembuh timbul kemerahan yang } \\
\text { simetris pada tubuh, telapak tangan dan telapak kaki }\end{array}$ \\
\hline Hasil laboratorium & $\begin{array}{l}\text { Harus tampak: } \\
\text { VDRL atau RPR (+) dengan konfirmasi TPHA, yang } \\
\text { memerlukan waktu untuk bereaksi setelah 3-4 bulan } \\
\text { permulaan timbul ulkus }\end{array}$ \\
\hline $\begin{array}{l}\text { Pengobatan } \\
\text { \# Tidak diberikan kepada } \\
\text { wanita hamil, menyusui, dan } \\
\text { anak-anak }\end{array}$ & $\begin{array}{l}\text { Regimen pilihan } \\
\text { Benzatin Penisilin G 2,4 juta IU, IM, dosis tunggal atau } \\
\text { Penisilin Prokain } 600.000 \text { unit IU, IM, } 10 \text { hari } \\
\text { Bila alergi Penisilin, dapat diberikan: } \\
\text { \#Tetrasiklin } 4 \text { × } 500 \text { mg per oral, } 15 \text { hari atau } \\
\text { Eritromisin } 4 \text { ×500 mg per oral, } 15 \text { hari atau } \\
\text { \#Doksisiklin } 2 \text { × } 100 \mathrm{mg} \text { per oral, } 15 \text { hari }\end{array}$ \\
\hline $\begin{array}{l}\text { Rujukan pasangan dan } \\
\text { pemeriksaan tambahan } \\
\text { untuk pasien }\end{array}$ & $\begin{array}{l}\text { 1. Sangat penting untuk memberitahu, memeriksa, dan } \\
\text { mengobati pasangannya bersama-sama. (Sifilis } \\
\text { adalah penyakit sistemik yang serius) } \\
\text { 2. Lakukan juga tes Gonore dan Klamidia untuk pasien } \\
\text { 3. Dianjurkan rujukan tes serologi HIV }\end{array}$ \\
\hline
\end{tabular}


Gambar 14 : Ulkus Sifilis

\section{ULKUS MOLE/CHANCROID}

\begin{tabular}{|c|c|}
\hline Riwayat kesehatan & $\begin{array}{l}\text { 1. Ulkus di genitalia } \\
\text { 2. Pembengkakan yang sakit di daerah selangkangan / } \\
\text { lipat paha }\end{array}$ \\
\hline Pemeriksaan fisik & $\begin{array}{l}\text { 1. Ulkus yang multipel yang sakit } \\
\text { 2. Diameter ulkus } 2 \text { - } 20 \mathrm{~mm} \\
\text { 3. Tepi ulkus kasar dan tidak teratur } \\
\text { 4. Dasar ulkus: kotor dan purulen. } \\
\text { 5. Perabaan ulkus: lunak } \\
\text { 6. Mungkin terdapat kelenjar limfe: bubo unilateral dan } \\
\text { sakit }\end{array}$ \\
\hline Hasil laboratorium & $\begin{array}{l}\text { Konfirmasi laboratorium spesifik tidak terdapat pada } \\
\text { penelitian ini. Diagnosis berdasarkan riwayat dan gejala } \\
\text { klinis }\end{array}$ \\
\hline $\begin{array}{l}\text { Pengobatan } \\
\text { \# Tidak diberikan kepada } \\
\text { wanita hamil, menyusui, dan } \\
\text { anak-anak }\end{array}$ & $\begin{array}{l}\text { Regimen pilihan: } \\
\text { \#Siprofloksasin } 500 \mathrm{mg} \text { per oral, dosis tunggal atau } \\
\text { \#Ofloksasin } 400 \mathrm{mg} \text { per oral, dosis tunggal atau } \\
\text { Azitromisin } 1 \mathrm{gr} \text { per oral, dosis tunggal atau } \\
\text { Eritromisin } 4 \times 500 \mathrm{mg} \text { per oral, } 7 \text { hari atau } \\
\text { Seftriakson } 250 \mathrm{mg} \text { IU IM, dosis tunggal atau } \\
\text { Trimetoprim-Sulfametoksasol } 80 \mathrm{mg}-400 \mathrm{mg} \text {, } \\
2 \times 2 \text { tablet per oral, } 7 \text { hari }\end{array}$ \\
\hline $\begin{array}{l}\text { Rujukan pasangan dan } \\
\text { pemeriksaan tambahan } \\
\text { untuk pasien }\end{array}$ & $\begin{array}{l}\text { 1. Perlu memberitahu, memeriksa, dan mengobati } \\
\text { pasangannya bersama-sama } \\
\text { 2. Lakukan juga tes Gonore dan Klamidia untuk pasien } \\
\text { 3. Dianjurkan rujukan tes serologi HIV }\end{array}$ \\
\hline
\end{tabular}


Gambar 16: Ulkus Mole/Chancroid

HERPES GENITAL

\begin{tabular}{|c|c|}
\hline Riwayat kesehatan & $\begin{array}{l}\text { Mungkin terdapat: } \\
\text { 1. Luka di genitalia yang pada permulaan sangat sakit. } \\
\text { 2. Nyeri pada saat buang air kecil } \\
\text { 3. Malaise (rasa tidak enak badan) dan mialgia/rasa } \\
\text { sakit pada otot } \\
\text { 4. Terdapat rekurensi }\end{array}$ \\
\hline Pemeriksaan fisik & $\begin{array}{l}\text { Mungkin terdapat: } \\
\text { 1. Vesikel-vesikel berisi air, yang } \\
\text { 2. Ulserasi, dan } \\
\text { 3. Berdiameter } 1-5 \mathrm{~mm}\end{array}$ \\
\hline Hasil laboratorium & Diagnosis empiris \\
\hline Pengobatan & $\begin{array}{l}\frac{\text { Episode pertama }}{\text { Asiklovir } 5 \times 200 \mathrm{mg} \text { per oral, } 7 \text { hari }} \\
\text { Bila gejala sistemik berat } \\
\text { Asiklovir } 5 \mathrm{mg} / \mathrm{kg} \text { BB intravena tiap } 8 \text { jam, } 7 \text { hari } \\
\text { Episode rekurensi } \\
\text { Bila gejala berat dan lama } \\
\text { Asiklovir } 5 \times 200 \mathrm{mg} \text { per oral, } 5 \text { hari }\end{array}$ \\
\hline $\begin{array}{l}\text { Rujukan pasangan dan } \\
\text { pemeriksaan tambahan } \\
\text { untuk pasien }\end{array}$ & $\begin{array}{l}\text { 1. Perlu penyuluhan dan konseling pasangan } \\
\text { 2. Lakukan juga tes Gonore dan Klamidia untuk pasien } \\
\text { 3. Dianjurkan rujukan tes serologi HIV }\end{array}$ \\
\hline
\end{tabular}


Gambar 20 : Erosi tipis multipel pada wanita yang disebabkan oleh Herpes Genital

\section{KONDILOMA AKUMINATA}

\begin{tabular}{||l|l||}
\hline Riwayat kesehatan & $\begin{array}{l}\text { Mungkin terdapat: } \\
\text { Kutil di genitalia yang tidak sakit }\end{array}$ \\
\hline Pemeriksaan fisik & Lesi genitalia yang menyerupai veruka/kutil \\
\hline Hasil laboratorium & Diagnosis empiris \\
\hline $\begin{array}{l}\text { Pengobatan } \\
\text { \# Tidak diberikan kepada } \\
\text { wanita hamil, menyusui }\end{array}$ & $\begin{array}{l}\text { Eradikasi: belum ada } \\
\text { Menghilangkan kutil eksternal dapat dilakukan dengan: } \\
\text { \#Tinktura Podofilin } 10-25 \% \text { atau } \\
\text { Asam trikloro-asetat } 40-50 \% \text { topikal atau } \\
\text { Asam salisilat } 20-40 \%\end{array}$ \\
\hline $\begin{array}{l}\text { Rujukan pasangan dan } \\
\text { pemeriksaan tambahan } \\
\text { untuk pasien }\end{array}$ & $\begin{array}{l}\text { 1. Perlu penyuluhan dan konseling pasangan } \\
\text { 2. Lakukan juga tes Klamidia } \\
\text { 3. Dianjurkan tes serologi HIV }\end{array}$ \\
\hline \hline
\end{tabular}


Gambar 18 : Kondiloma Akuminata yang disebabkan oleh Human Papililoma Virus (HPV

\section{TRIKOMONIASIS}

Gambar 2 : Cairan vagina yang berbusa pada trikomoniasis 
Gambar 3 : Serviks yang kemerahan pada trikomoniasis (Strawberry Cervix)

\section{VAGINOSIS BAKTERIAL}

Gambar 5 : Cairan dari vagina yang licin dan lengket pada Vaginosis Bakterial 


\section{KANDIDIASIS}

Gambar 7 : Cairan dari vagina yang bergumpal seperti susu Kandidiasis

Vulvoginal 


\section{GONORE}

Gambar 8 : Uretritis gonore

Gambar 9 : Cairan purulen uretritis Gonore pada pria 


\section{KLAMIDIA}

Gambar 11 : Servisitis Klamidia 


\section{SERVISITIS MUKOPURULEN}

Gambar 13 : Servisitis Mukopurulen pada pemakai IUD 


\section{SIFILIS}

Gambar 14 : Ulkus Sifilis 
Gambar 15 : Sifilis sekunder, kemerahan yang simetris pada tubuh, telapak tangan dan telapak kaki

\section{ULKUS MOLE / CHANCROID}

Gambar 17 : Ulkus di labia pada Chancroid 


\section{KONDILOMA AKUMINATA}

Gambar 19 : Kutil pada genitalia eksterna pada wanita yang disebabkan oleh Human Papilloma Virus ( HPV) 


\section{RTI/STD Case Study Game}

Purpose: To conduct a secondary training program for HCP's that demonstrate the need for improved etiological assessment of RTI/STD syndromes. This style of training reduces the lecture format and emphasizes an interactive educational session that uses positive reinforcement for the learners.

Target audience: Midwives that have received the introductory RTI/STD core training, but don't have a history of making etiological judgements and prescriptions.

Instructions: $\quad$ RTI/STD clinical case scenarios will be individually printed on a deck of index cards. A facilitator with RTI/STD clinical expertise will shuffle the deck of cards, and allow a volunteering participant to select a card that is held face down. The facilitator reads the scenario then guides the participants response to the correct answer. If the volunteering participant does not have the correct answer, the facilitator may offer the question to another volunteer participant. Participants who respond with the correct answer, will be awarded a token for each correct answer. The participant with the most correct answers at the end of the "game" will win a prize, such as a decorative pewter bowl for the HCP's office to display condoms for clients in.

Learning objectives: Upon completion of this training activity, the student participant will be able to correctly:

- $\quad$ Describe an etiological diagnosis for eight different clinical case presentations;

- $\quad$ List the appropriate pharmaceutical selections for four separate RTI/STD;

- $\quad$ Recognize the need to refer a pregnant client with a suspected syphilis infection to a medical doctor for treatment both for herself and any sexual partner(s);

- $\quad$ List the RTI/STD's that require concurrent partner treatment;

- $\quad$ Recognize the probable exam signs that lead to an etiological diagnosis from a photographs of classical RTI/STDs;

- Include a discussion and offer of condoms in all STD client education sessions;

- $\quad$ Recognize HIV education and testing as an adjunct of STD case management.

\section{Materials:}

- $\quad 31$ clinic case study cards

- 50 correct answer tokens (one scenario may have more than one question)

- $\quad$ Prizes for participants. Consider a first place for the most correct answers, and addtional awards for morale, i.e., most enthusiastic, 2nd place, etc. 


\section{Case study/question:}

1. A 20 year old woman who contracepts with injections presents to the FP clinic with a chief complaint of vaginal itching, and a thick chunky white discharge. On exam you find her vulva to be swollen and red. Her speculum exam reveals a curdy white discharge. Her vaginal microscopy shows pseudo hyphae.

What is the diagnosis?

Answer: $\quad$ Candidiasis.

Bonus question: What is the treatment?

Answer: $\quad$ An antifungal medicine such as miconazole or clotrimasole. If she is not pregnant and has no history of liver disease, Fluconazole can also be used.

2. A 40 year old woman who contracepts with an IUD, complains of a white discharge that has a bad odor. She denies vaginal itching. She complains that the discharge is so heavy it constantly makes her underwear wet. On exam you notice a smooth white discharge. There is no sign of tissue irritation. When you combine the discharge with $\mathrm{KOH}$, you notice a strong odor.

What is the probable diagnosis?

Answer: $\quad$ suspect Bacterial Vaginosis

What should you see on her vaginal microscopy report?

Answer: Clue cells

Bonus question: What medicine should you use to treat this infection?

Answer: If she is not pregnant or allergic, use Metronidazole.

3. A 32 year old woman who contracepts with injections, complains of vaginal discharge and itching. She tells you that it stains her underwear a green/yellow color. On exam, her vulva is normal without ulcers, warts, or significant inflammation. Her speculum exam reveals a frothy grey discharge. There are signs of cervical and vaginal erythema.

What should you expect to see on the normal saline wet mount?

Answer: $\quad$ Motile Trichomonads. 
Bonus question: What medicine should you use to treat this infection?

Answer: $\quad$ If she is not pregnant or allergic, use Metronidazole.

4. A monogamous 27 year old woman who contracepts with pills is not sure if her husband has sex with other women or not. She complains of bleeding after intercourse. Her husband is a sailor and is frequently gone from home for long periods of time. Her external exam reveals a normal genitalia, without signs of inflammation, ulcers or warts. Her speculum exam shows a sore red cervix that has thick yellow discharge oozing out of her os. When you gently insert a sterile swab into the endocervix, her cervix bleeds easily.

What should you do?

Answer: $\quad$ 1. Consider a diagnosis of Mucopurulent cervicitis;

2. Get endocervical specimens for gonorrhea, and chlamydia;

3. Provide treatment for gonorrhea and chlamydia;

4. Make a treatment plan with her for treatment of her sexual partner(s).

5. A 38 year old woman who is 2 months pregnant, presents with a red rash on her chest, abdomen, palms, and soles of her feet. She doesn't feel sick. 4 weeks ago she had a sore on her labia that was as big as a 25 Rupiah coin. It wasn't painful and disappeared without any problems. Her husband is a truck driver. She tells you that she is afraid he might have given her something. Her pelvic exam is normal without any signs of discharge, ulcers or cervicitis.

What should you do?

Answer: $\quad$ 1. Tell the woman that it is possible that she has an infection that could hurt her pregnancy if it is not carefully diagnosed and treated. Tell her that it is important that you have her evaluated by a doctor today.

2. Obtain a blood specimen for syphilis screening (RPR), and also endocervical specimens to test for gonorrhea and chlamydia.

3. Find a doctor in your clinic or make a same day referral to a doctor to evaluate this client. Tell the doctor that you suspect "syphilis" as the cause for this rash, and request same day treatment for the client. 
4. Make a treatment plan for her sexual partner(s).

5. Provide education after she has sent the doctor to be certain she understands the importance of the treatment recommendations, and to schedule follow-up evaluations.

6. A 29 year old woman who contracepts with implants complains of a painful sore on her labia and pain in her groin. Her exam shows a purulent ulcer about $20 \mathrm{~mm}$ in diameter with rough irregular borders. The sore seems very tender. Her left groin has an erythematous swelling about 1 by $2 \mathrm{~cm}$ in diameter.

What is your first thought about what infection this could be?

Answer: $\quad$ Chancroid.

Name at least 2 other STD's that can cause genital ulcers to occur:

Answer: $\quad$ Syphilis, herpes, LGV.

7. An 18 year old woman complains of small blisters on her vulva that come and go. She has had these blisters 2 other times this year. They are only painful when she urinates, but the first time they occurred, they were very painful. On her external genital exam, you notice some firm and tender bilateral inguinal lymphadenopathy when you palpate the inguinal area with a gloved hand. Her vulva has 5 small ulcers that are moist and red.

What is a possible cause for these genital ulcers?

Answer: $\quad$ Herpes Simplex Virus II. (Genital herpes)

Can this infection be cured with medication?

Answer: Since herpes is a virus, it can not be eliminated with a medication. If the outbreaks are frequent and problematic for the client, she can take an antiviral drug called "Acyclovir" which will decrease the intensity and duration of the outbreaks.

8. A 24 year old woman complains of vaginal discomfort and discharge. She reports that her partner has "bumps" on his penis. Her exam reveals small clusters of rough raised skin growths on her perineum.

What possible infection has caused these growths?

Answer: Human Papilloma Virus (genital warts, or, condylomata accuminata). 
9. List as many medications as possible, that are commonly used to treat sexually transmitted diseases that are not safe to take in the first trimester of pregnancy:

Answer: $\quad$ Metronidazole

Ciprofloxacin

Fluconazole

Doxycycline.

10. What are two very important things to determine before prescribing any medication to a woman?

Answer: $\quad$ 1. Is there a possibility of pregnancy?

2. Are there any medical allergies?

11. Is it necessary to also treat the sexual partner of a client you just diagnosed and treated for:

Bacterial Vaginosis?

12. Is it necessary to also treat the sexual partner of a client you just diagnosed and treated for:

Candidiasis?

13. Is it necessary to also treat the sexual partner of a client you just diagnosed and treated for:

Trichomoniasis?

14. Is it necessary to also treat the sexual partner of a client you just diagnosed and treated for:

Mucopurulent cervicitis? 
15. Is it necessary to also treat the sexual partner of a client you just diagnosed and treated for:

Gonorrhea?

16. Is it necessary to also treat the sexual partner of a client you just diagnosed and treated for:

Chlamydia?

17. Is it necessary to also treat the sexual partner of a client you just diagnosed and treated for: Syphilis?

18. Photo ID (\#2)- Trichomoniasis

19. Photo ID (\#5)- Bacterial Vaginosis

20. Photo ID (\#7)- Candidiasis

21. Photo ID (\#8)-Gonococcal female urethritis

22. Photo ID (\#11)- Mucopurulent cervicitis before and after treatment

23. Photo ID (\#14)- Primary syphilis chancre - male

24. Photo ID (\#15)- Secondary syphilis rash

25. Photo ID (\#17)- Chancroid ulcer- female

26. Photo ID (\#18)- Human Papilloma Virus-internal 
27. Photo ID (\#19)- Human Papilloma Virus- external

28. Photo ID (\#20)- Ulcers from Herpes Simplex Virus II

29. What additional supplies should always be discussed and offered to dispense with every STD treatment for future disease prevention?

Answer: Condoms.

30. Although not a part of this study, what additional blood test might you discuss and refer clients at risk for STDs to obtain? 


\section{Appendix N}

\section{Health Facility Assessment}




\section{Health Facility Assessment}

Facility Name :

Address :

Date of survey :

\section{Physical Layout}

1. Are clients examined in the same room they give their history in?

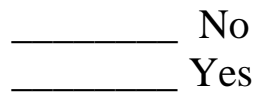

2. Is visual privacy maintained in the room clients give their initial history in?

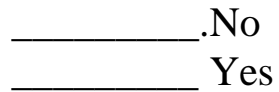

3. Is auditory privacy maintained in the room clients give their initial history in?

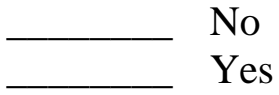

4. Is visual privacy maintained in the examination room?

$$
\text { No }
$$$$
\text { Yes }
$$

5. Is auditory privacy maintained in the examination room?

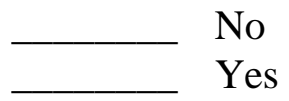

6. Are there RTI/STD educational materials available in either the interview or exam area?

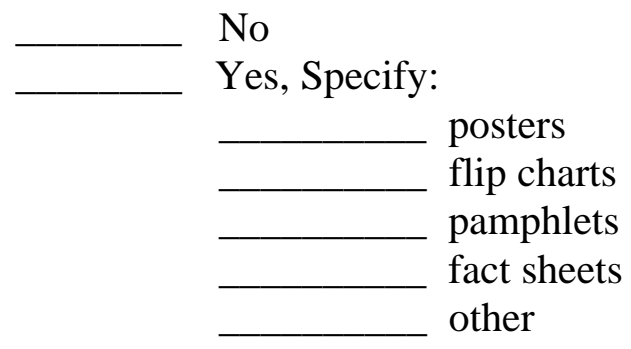

Phone :

Fax :

\section{Infection Control}

7. Is the exam area clean? (fresh linen, floor swept, no garbage on floor, etc.)

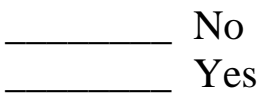

8. Is the exam table free of visibly contaminated material \&/or dirt?

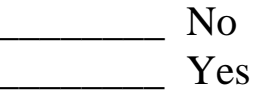

9. Is there a new covering (paper or linen) on the exam table that is changed after each patient lays on the table?

$$
\begin{aligned}
& \text { No } \\
& \text { Yes }
\end{aligned}
$$

10.Is there running water and a sink in the exam room?

No

Yes

11.Is there soap for hand washing in the exam room?

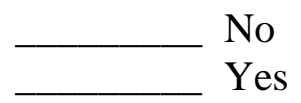

12.Are there towels for drying hands after washing them in the exam room?

No

Yes, Describe:

paper that is discarded cloth that is reused 
13. Describe the step by step process for cleaning and disinfecting vaginal speculums after they are used

14.What type of syringes and needles are used in the clinic?

$$
\begin{aligned}
& \text { disposable } \\
& \text { reusable }
\end{aligned}
$$

15.After a needle has been used to give an injection, or draw blood, does the staff re-cap the needle?

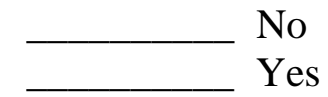

16. Where does the staff place the dirty needle after it has been used?

\section{Equipment Inventory}

17.Indicate the presence $(+)$ or absence $(0)$ of the following resources. Make notes on the working condition of these items if they are not in good repair.

\begin{tabular}{|l|l|l|}
\hline ITEM & $+/ 0$ & Condition \\
\hline $\begin{array}{l}\text { Autoclave for } \\
\text { speculums }\end{array}$ & & \\
\hline $\begin{array}{l}\text { Exam table with } \\
\text { stirrups }\end{array}$ & & \\
\hline Exam light & & \\
\hline Speculum & & Type: \\
\hline Trash cans & & \\
\hline Light microscope & & \\
\hline Incubator & & \\
\hline Refrigerator & & \\
\hline
\end{tabular}

\section{Record Keeping and Reporting}

Note: Attach an example of a client record form and of other report forms used.

18.Is a separate record kept for each client?

$$
\begin{aligned}
& \text { No } \\
& \text { Yes }
\end{aligned}
$$

19.Are client locators (address, phone, village) recorded in sufficient detail on the record to allow for follow-up?

$$
\begin{aligned}
& \text { No } \\
& \text { Yes }
\end{aligned}
$$

20.In what condition is the record system maintained?

Well ordered
Partially obscured, still
usable
Disordered, not usable

21.Are records stored in a locked, secure cabinet?

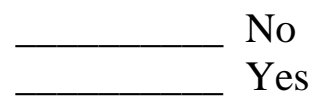

22.If a communicable disease is diagnosed, is it recorded or reported anywhere other than the individual medical record?

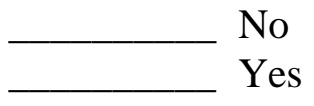

23. Does the clinic maintain epidemiological records to track the rate of STD's? No Yes, if "yes" attach a copy of the form 


\section{List of Training Participants}

"Improved Reproductive Health and STD Services for

Women Presenting to Family Planning Services in North Jakarta"

\begin{tabular}{|c|c|c|}
\hline No & Name & Address \\
\hline 1. & dr. Umar Wahid (Director) & Koja Hospital \\
\hline 2. & dr. Basuki Mulyono, DSOG (Head of ObGyn Clinic) & Koja Hospital \\
\hline 3. & dr. Bambang Çantayuda, DSOG & ObGyn Clinic, Koja Hospital \\
\hline 4. & dr. Mangisi Tambunan, DSOG & ObGyn Clinic, Koja Hospital \\
\hline 5. & dr. Sundari & ObGyn Clinic, Koja Hospital \\
\hline 6. & dr. Gurmukh Sing & ObGyn Clinic, Koja Hospital \\
\hline 7. & Prikatun (midwife) & ObGyn Clinic, Koja Hospital \\
\hline 8. & Nurjanah S (Nurse) & ObGyn Clinic, Koja Hospital \\
\hline 9. & Hayati (Nurse) & ObGyn Clinic, Koja Hospital \\
\hline 10. & dr. Melina Henratna, DSPK (Head of Laboratory Unit) & Koja Hospital \\
\hline 11. & dr. Tjan Sian Hwa, DSPK (Vice Head of Laboratory Unit) & Koja Hospital \\
\hline 12. & Sumarni (Lab Technicians) & Koja Hospital \\
\hline 13. & Ranita (Lab Technicians) & Koja Hospital \\
\hline 14. & dr. Sri wahyudiyati (Head of Puskesmas Cilincing) & Puskesmas Cilincing \\
\hline 15. & Teji Sulastri (midwife) & MCH/FP Clinic, Puskesmas Cilincing \\
\hline 16. & Limanis (midwife) & MCH/FP Clinic, Puskesmas Cilincing \\
\hline 17. & Rusmiyati (midwife) & MCH/FP Clinic, Puskesmas Cilincing \\
\hline 18. & Sri Nurhidayati (Lab Technicians) & Puskesmas Cilincing \\
\hline 19. & Dyan Shofa Ma'addin (Lab Technicians) & Puskesmas Cilincing \\
\hline $\begin{array}{l}\mathrm{MCH} \\
\mathrm{FP}\end{array}$ & $\begin{array}{l}=\text { Mother \& Child Health } \\
=\text { Family Planning }\end{array}$ & \\
\hline
\end{tabular}

